\title{
Nondestructive Methods and Special Test Instrumentation Supporting NASA Composite Overwrapped Pressure Vessel Assessments
}

\author{
AIAA-2007-2324 \\ Regor Saulsberry ${ }^{1}$ and Nathanael Greene ${ }^{2}$ \\ NASA Johnson Space Center White Sands Test Facility, Las Cruces, New Mexico, 88012 \\ Ken Cameron ${ }^{3}$ and Eric Madaras ${ }^{4}$ \\ NASA Langley Research Center, Hampton, Virginia 23681-2199 \\ Lorie Grimes-Ledesma ${ }^{5}$ \\ Jet Propulsion Laboratory, Pasadena, California, 91109 \\ John Thesken ${ }^{6}$ \\ Ohio Aerospace Institute-NASA Glenn Research Center, Cleveland, Ohio, 44135 \\ Leigh Phoenix $^{7}$ \\ Cornell University, Ithaca, New York, 14853 \\ Pappu Murthy ${ }^{8}$ and Duane Revilock ${ }^{9}$ \\ NASA Glenn Research Center, Cleveland, Ohio, 44135
}

\begin{abstract}
Many aging composite overwrapped pressure vessels (COPVs), being used by the National Aeronautics and Space Administration (NASA) are currently under evaluation to better quantify their reliability and clarify their likelihood of failure due to stress rupture and age-dependent issues. As a result, some test and analysis programs have been successfully accomplished and other related programs are still in progress at the NASA Johnson Space Center (JSC) White Sands Test Facility (WSTF) and other NASA centers, with assistance from the commercial sector. To support this effort, a group of Nondestructive Evaluation (NDE) experts was assembled to provide NDE competence for pretest evaluation of test articles and for application of NDE technology to real-time testing. Techniques were required to provide assurance that the test article had adequate structural integrity and manufacturing consistency to be considered acceptable for testing and these techniques were successfully applied. Destructive testing is also being accomplished to better understand the physical and chemical property changes associated with progression toward "stress rupture" (SR) failure, and it is being associated with NDE response, so it can potentially be used to help with life prediction. Destructive work also includes the evaluation of residual stresses during dissection of the overwrap, laboratory evaluation of specimens extracted from the overwrap to evaluate physical property changes, and quantitative microscopy to inform the theoretical micromechanics.
\end{abstract}

\footnotetext{
${ }^{1}$ Project Manager, NESC Independent Technical Assessment NDE Lead, Laboratories Office, P.O. Box 20/201LD.

2 Project Manager, Laboratories Office, P.O. Box 20/201LD.

${ }^{3}$ NESC COPV Independent Technical Assessment Leader, NASA Langley Research Center, Hampton, Virginia.

${ }^{4}$ Ph.D., NDE Test Office, NASA Langley Research Center, Hampton, Virginia.

${ }^{5}$ Ph.D., NESC COPV Team Leader, 4800 Oak Grove Drive.

${ }^{6}$ Ph.D., 21000 Brookpark Road.

${ }^{7}$ Professor, Cornell University, Ithaca, New York.

${ }^{8}$ Deputy Structural Fellow, NESC, NASA Glenn Research Center, Cleveland, Ohio.

${ }^{9}$ Project Manager, Structures and Acoustics Division, NASA Glenn Research Center, Cleveland, Ohio.
} 


\section{Introduction}

NASA is engaged with recertification and life extension of the many aging Kevlar ${ }^{\mathbb{B}^{*}}$ composite overwrapped 1 pressure vessels (COPVs). The COPVs have varying criticality, usage histories, damage and repair histories, time at pressure, and number of pressure cycles.

When NASA reviewed the COPVs, a concern was raised with respect to "stress rupture" (SR) life predictions. Similarly, concerns arose regarding the graphite (carbon) epoxy COPVs also used in newer systems. A Nondestructive Evaluation (NDE) Super Problem Resolution Team (SPRT) was formed to provide NDE competence for the necessary technical assessment. The NDE SPRT evaluated the data available and established observations and recommendations; however, immediate application of NDE to COPVs was found limited by the "state of the art" and specific experience base. Additionally, assisted by observations of the SPRT, the NASA NDE Working Group (NNWG) recognized the need for development of NDE specifically applicable to COPVs, some of which is actively underway.

As a resolution to the life prediction issue, a COPV test project was initiated at NASA Johnson Space Center White Sands Test Facility (WSTF) to better understand where these vessels stood in their available life. Additionally, carbon COPV SR test programs have been ongoing at WSTF for several years, and recent investigations have been supported by the SPRT. Pretest NDE was needed and applied to screen the COPVs prior to testing, and NDE technology was also needed and applied during testing to gather critical test data. Since validated processes were not always available, "best practices" were applied. This effort is producing very valuable results.

\section{Assessment of NDE Applicable to COPVS}

NDE techniques were reviewed to identify those applicable to the COPVs of concern. Traditional and mature techniques had been used successfully to find isolated or discrete mechanical damage (e.g., impact damage) in COPVs $;{ }^{1}$ however, methods that may help characterize global degradation or damage resulting in creep and/or SR were not as well documented. An in-depth research program would be necessary to determine the COPV material properties undergoing degradation leading to SR. A technology assessment of NDE for SR degradation in COPVs was accomplished and published in November 2004 by a COPV NDE SPRT subcontractor, the Department of Defense (DOD) Nondestructive Testing Information Analysis Center (NTIAC); and it represents a good compilation of technology that is applicable and leads to further work in this area. ${ }^{2}$ The SPRT recognized that a comprehensive research and development program was needed to further identify potential NDE methods and evaluate their potential to monitor SR in COPVs.

\section{Methods for Characterizing Global Damage}

As of this study, no NDE technique is currently known to be directly applicable to prediction of SR and other life-dependent COPV issues. For life issues, we still need to better identify the only partially defined physical attributes or phenomena producing failure to allow appropriate NDE techniques to be down-selected from the list of potential candidate methods. These down-selected methods will then need to be further developed and applied.

Since essentially all current and future NASA spacecraft utilize COPVs subject to SR, this creates a major concern that needs to be addressed. In response to this, the NDE SPRT identified and ranked possible candidate NDE methods that may potentially be used to assess the COPV material properties that are undergoing degradation leading to SR, and information was collected to delineate future research needs. In addition, the NTIAC technology assessment of NDE for SR degradation in COPVs represents a useful compilation of current technology that may be applicable in the future, but requires further work as described in the formal report. A study is currently being undertaken by the NASA NDE Working Group (NNWG) to help understand the degradation process leading to SR, so as to target and develop NDE that may be useful in detection. It is noted that the NNWG SR NDE research effort does not have adequate funding to fully resolve this issue, and other synergistic funding and complementary efforts are being sought to fill this important need for future NASA space programs.

\section{Methods for Locating Isolated Damage}

Although detection of delaminations in COPVs has been successfully accomplished by various methods, detection of small fibers that have previously broken, independently of matrix damage, is far more difficult, and success is limited. Discontinuities in the extremely small fibers (typically only a few micrometers) are very difficult

\footnotetext{
${ }^{*} \operatorname{Kevlar}^{\circledR}$ is a registered trademark of E. I. Du Pont de Nemours and Co., Wilmington, DE.
} 
to detect with direct imaging techniques. New developments such as high resolution x-ray computed tomography (XCT) hold some promise for laboratory-level analysis. Additionally, the acoustic emissions method allows detection of the origin and monitoring of active defect growth in COPVs under load. Generally, significant acoustic emissions only occur when new peak pressures are reached, and the vessels are generally acoustically silent at pressure variations below the last peak pressure. However, even with this limitation, it is effective in identifying new impact damage or areas where fiber has been strained to the point of damage or breakage. Also as discuss later in this paper, Shearography has also been found effective in identifying delaminations, impact damage, and localized variations in stress fields in COPVs.

One if the largest issues was also noted to be the general lack of a correlation between the specific NDE response and specific loss in structural integrity of the vessel. This is another area the NNWG has started looking at. An initial project to establish a correlation between calibrated inpacts, NDE response, and specific reduction in burst strength of certain carbon bottles is in progress.

\section{Brief NNWG "Stress Rupture" NDE Project Overview}

The NNWG Stress Rupture NDE started in late 2005 and is currently continuing. The objective of the NNWG project is to advance the state-of-the-art by developing NDE techniques that are capable of assessing SR degradation in COPVs in either a health-monitoring mode or a traditional remove-and-inspect mode. NDE techniques resulting from this effort will be a challenge to field and it will likely take several years.

The general approach is to determine the feasibility of a selected number of candidate NDE techniques for detecting degradation leading to SR in COPVs in either a health-monitoring mode or a traditional remove-andinspect mode. This is done by submitting specimens of various SR age to many different type of NDE and evaluating for response that can be correlated. In parallel, destructive analysis (DA) is used to better understand SR failure signatures so as to better target NDE techniques.

The study is using Kevlar as the model COPV SR system for initial study, due to the substantial knowledge base in literature and numerous test specimens. An extensive number of Kevlar test articles with varying amount of actual age and time at stress are available for NDE evaluations. Additional, accelerated aging is being accomplished and the NDE response compared to the old Kevlar specimens. After knowledge is gained from the Kevlar study, it will be applied to COPVs made from carbon new and emerging fibers.

Kevlar composite specimens were developed by overwrapping aluminum-lined cylinders and aged to simulated long term stress rupture degradation. The accelerated aging efforts were accomplished using two different approaches: 1) by elevated stress levels, and 2) separately by stepped increases in temperature ASTM D $6992^{3}$ to provide sets of test specimens (cylinders and coupons made from cylinders) for evaluation by NDE and destructive analysis. These methods provide test specimens with creep degradation without the complexities that result from oxidation, moisture, and ultraviolet light. During the aging, In addition to temperature and pressure transducers, Fiber Bragg grating (FBG) strain sensors and Acoustic Emission (AE) sensors were use in an effort to correlate their respective response to the stress rupture age progression and help develop data for later health monitoring applications. The FBG were predominantly surface-bonded, although a few were embedded to compare surface strain near the liner. Due to their extensive experience with ASTM D 6992, the Texas Research Institute accomplished the aging of the specimens in consultation with researchers at Cornell University, and NASA is accomplishing most of the NDE.

Aging has gone as anticipated and interesting relationships are being observed in the data FBG, AE, and temperature data. This data will be assemble and reported following data analysis. Each of the cylinder specimen sets will now be evaluated by each NDE technique and also by destructive assay. The most likely candidates for health monitoring are thought to be acoustic emission, eddy current sensors to evaluate composite and liner thinning through changes in stand-off, Bragg gratings, and other conventional strain sensing techniques. Following this, all NDE and DA results are to be analyzed and the most promising NDE methods selected. Various fleet leader specimens (virgin, aged, and failed) will then be evaluated with down-selected NDE and DA to determine capability of NDE and DA methods on complex specimens with "real" age.

\section{NDE for WSTF Experimental Carbon Bottle Burst Testing}

The NDE SPRT supported the commercially available ${ }^{\dagger}$ Carbon COPV Bottle Burst Testing at WSTF in 2004 and the project provided an excellent example of successful applications of pretest NDE and optical FBGs. The objectives were to screen for detectable impact damage or manufacturing defects, assess any notable tank-to-tank

\footnotetext{
${ }^{\dagger}$ Manufactured by Luxfer ${ }^{\circledR}$ Inc., Riverside, CA.
} 
manufacturing variance, and assess the potential use of multiple FBG strain sensors for COPV ground test monitoring and/or flight COPV health monitoring purposes. Pretest NDE included ultrasonic testing (UT), eddy current testing (ET), flash thermography, and shearography. Following pretest NDE, 18 FBG sensors were bonded to the COPVs and monitored during the testing.

\section{A. Pretest NDE}

NDE SPRT members at the Aerospace Corporation (El Segundo, California) accomplished the UT and ET. For UT, the COPVs were filled with water and immersed. The cylindrical region of each COPV was subjected to pulseecho testing at $25-\mathrm{MHz}$ using a commercial system. Reflected radio frequency wave trains were digitized and stored for each point on a 0.05 -in. axial by 2 -degree circumferential grid. These data were analyzed in a number of ways to reveal potential delaminations between the overwrap layers, unbonds between the overwrap and liner, and potential wind anomalies.

For ET, a commercial $2.5-\mathrm{MHz}$ anisotropic probe was held in dry contact with the cylindrical surface of the COPV. Data were accumulated on a 0.05 -in. axial by 2-degree circumferential grid. Scans were then performed for two orientations of the probe: with the induced current 1) perpendicular and 2) parallel to the hoop fiber direction. The results reflected variations in the overwrap (fiber conductivity, fiber density, wind anomalies, etc.).

For example, there was one prominent indication (in bottle No. 1894) evident in both the UT and ET results. The material was at least one ply thinner on one side of the indication and at least one ply thicker on the other side; therefore, it appeared that a ply had slipped. There was nothing to indicate that a ply was twisted (no local high spot). This was not thought to have a significant effect on the burst data, and proved not to since it had the secondhighest burst pressure of the lot.

Flash thermography was performed at NASA Marshall Space Flight Center (MSFC) using a thermal wave imaging data acquisition system running EchoTherm ${ }^{\mathbb{*}}$ software and an Indigo Merlin infrared camera. The bottles were prepared for the thermographic test by painting with water-soluble flat black paint and applying temporary 0.125 -in. square lead tape markers placed on 60-degree centers. The thermographic evaluation was relatively quick, taking approximately $1 \mathrm{~h}$ per bottle, including setup. Thermography provided a screening for handling damage (delaminations) and process variations (such as porosity or misplaced fibers/tows) that may be present in the vessels. Enhanced thermography images were made by subtracting the pre-trigger image from the images acquired after flash heating. Many small regions of porosity, voids, or low consolidation were noted. These regions show up as small white "hot" patches in the thermograms. The regions were noted to be scattered and numerous, but not thought to be significant enough to affect the structural integrity of the vessels.

Shearography was also performed at MSFC using a Laser Technology, Inc. (LTI) (Norristown, Pennsylvania) SC-5100 system (Figure 1). The bottles were prepared for testing by coating them with water-washable penetrant developer. The bottles were pressurized to less than 5 psig during the shearography test. This evaluation was nearly as quick as the thermography, with surface preparation for each vessel taking less than $0.5 \mathrm{~h}$ each and the actual test taking no more than $1 \mathrm{~h}$ for each vessel. Shearography provided a measure of the expected strain field generated during pressurization, but at a very low proof level. Variations in the strain field will show in the out-of-plane surface deformation that shearography measures. The test locates regions of the vessel that have lower stiffness properties as a result of handling damage, manufacturing/process variations, or aging. No indications were noted in raw data or wrapped or unwrapped phase maps. The NDE testing helped ensure that the data collected during burst testing were not biased by poor bottle quality.

\section{B. Fiber Bragg Grating Strain Sensors}

The NDE SPRT used FBG sensors to monitor the stress strain relation in the carbon fiber/matrix during the testing at WSTF with consultation from MSFC staff. Twelve FBG sensors were laid out and attached to the bottle surface as described below.

\section{Sensor Layout and Installation}

Figure 2 shows the layout orientation of the sensor strings on the bottle. Four sensor strings (three sensors in each string, two strings to a channel) were adhered to the bottle surface with the fiber along the bottle axis, and two sensor strings were aligned with the fiber along the hoop direction.

\footnotetext{
$\$$ EchoTherm $^{\circledR}$ is a registered trademark of Thermal Wave Imaging, Inc., Ferndale, MI.

$\S$ Merlin $^{\circledR}$ is a registered trademark of Indigo Systems Corporation, Santa Barbara, CA.
} 


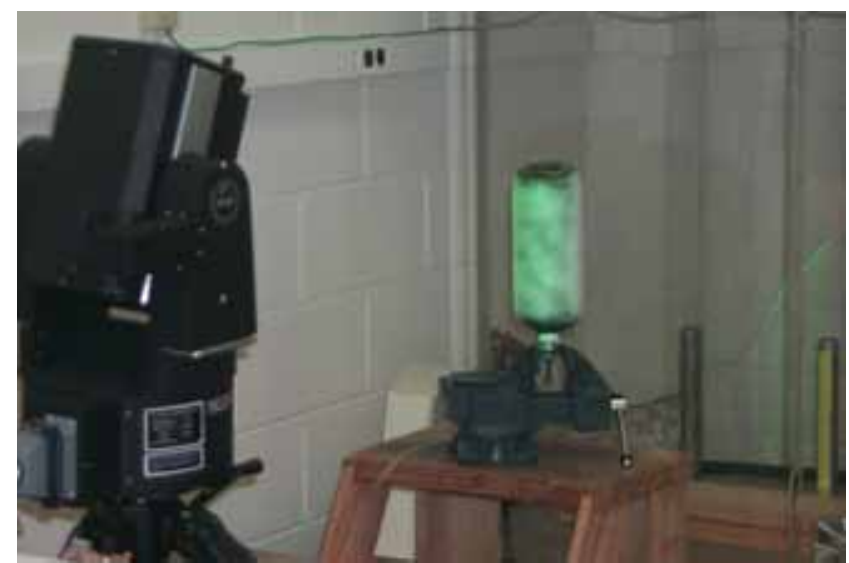

Figure 1. Shearography setup.

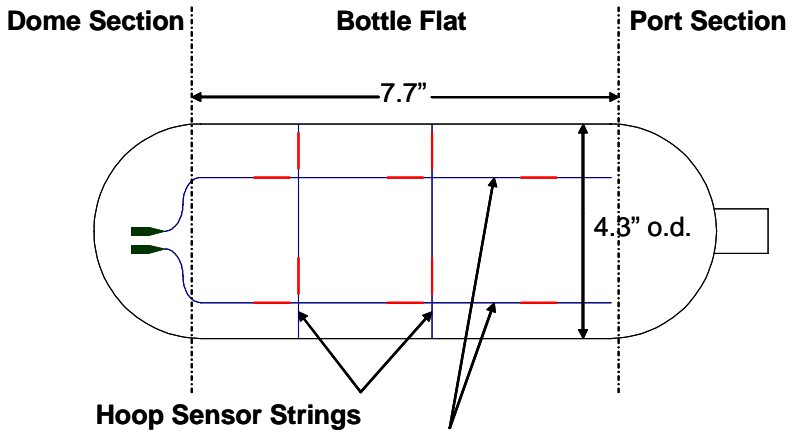

Axial Sensor Strings

Figure 2. FBG sensor layout.

When looking down at the bottle from the pressure port, the origin is designated to be at the transition from curved surface to the bottle flat directly below the first digit of the serial number on the bottle pressure port (see Figure 2), the axial sensors are centered in the flat along the y direction (along the bottle axis) with $2.5 \mathrm{in}$. between sensors, and are placed every 90 degrees in the $\phi$ (hoop) direction. The hoop sensors were placed as close as possible to six of the axial sensors.

\section{Sensor Interrogator Setup}

The sensor interrogation unit consisted of a tunable laser module, beam coupling optics, wavelength reference, light detectors, and a personal computer with a high-speed data acquisition card. An optical diagram of the interrogation unit is shown in Figure 3. Light emitted from the tunable laser was split equally into four paths: three sensor channels and one reference channel. In each sensor channel the light was split equally into each of two sensor strings. The sensor reflections passed back through the $2 \times 2$ coupler to the detector. In the reference channel, light passed through a gas reference cell in which it was absorbed at a series of well-known wavelengths. As the laser swept through its wavelength range, the channel waveforms were collected by an external computer using a high-speed analogto-digital (A/D) data acquisition card that monitored the voltages output by the detector amplifier modules. Each channel supported six sensor wavelengths, three each on two strings. A spare $\mathrm{A} / \mathrm{D}$ channel was used to collect the pressure transducer voltage so that the FBG sensor strain values could be directly plotted

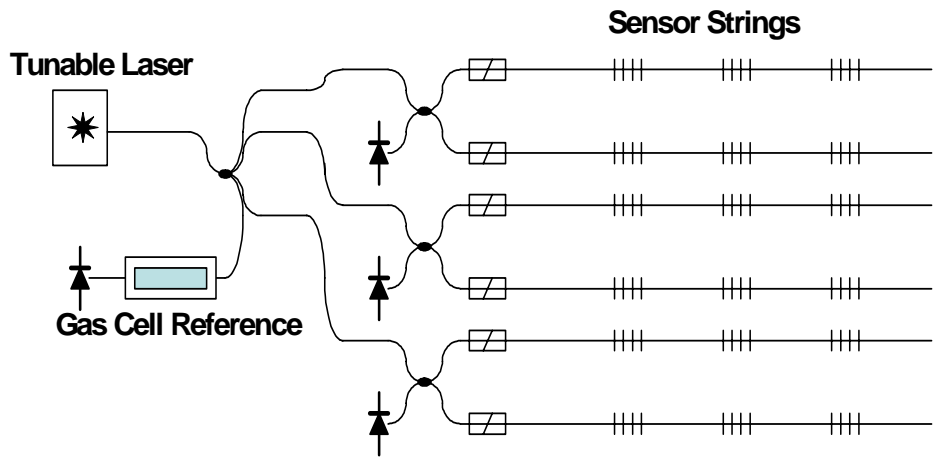

Figure 3. Sensor interrogation unit. with bottle pressure.

\section{Experimental Procedure and Results}

For each of the ten commercial Carbon bottles that were tested, the pressure was ramped up at $50 \mathrm{psi} / \mathrm{s}$ to roughly $2000 \mathrm{psi}$, held constant for roughly $3 \mathrm{~min}$, allowed to drop to $0 \mathrm{psi}$ and held for another $3 \mathrm{~min}$. Then the pressure was ramped at $50 \mathrm{psi} / \mathrm{s}$ to $2000 \mathrm{psi}$ and held for one min, then ramped up at the same rate until the bottle burst. The baseline strain readings were taken at time $=0 \mathrm{~s}$.

After the bottles were burst and removed from the test chamber, the burst locations were recorded. The burst locations for each bottle are depicted in Figure 4 and listed in Table 1. All of the burst locations were within 1 in. of the center of the bottle in the axial direction, and were well distributed in the hoop direction. 


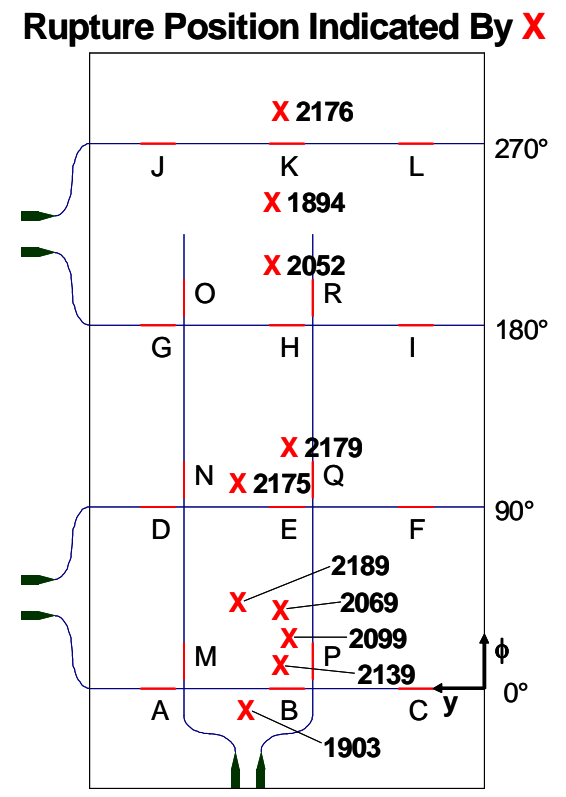

Figure 4. Bottle burst location depicted on the same plot as sensor location.
Table 1. Hoop and Axial Coordinates of the Burst Location $^{\text {a }}$

\begin{tabular}{|c|c|c|}
\hline Bottle Number & $\begin{array}{c}\phi \\
\text { Degrees } \\
\pm 10\end{array}$ & $\begin{array}{c}\mathrm{y} \\
\text { Inches } \\
\pm 0.25\end{array}$ \\
\hline 2189 & 45 & 4.75 \\
\hline 2052 & 210 & 4.25 \\
\hline 2099 & 20 & 3.75 \\
\hline 2139 & 10 & 4.00 \\
\hline 1903 & 350 & 4.50 \\
\hline 2175 & 100 & 4.75 \\
\hline 2179 & 120 & 3.75 \\
\hline 2069 & 40 & 4.00 \\
\hline 2176 & 285 & 4.00 \\
\hline 1894 & 240 & 4.25 \\
\hline \multicolumn{2}{|c|}{$\begin{array}{l}\text { Bottle numbers are listed in the order they } \\
\text { were burst }\end{array}$} \\
\hline
\end{tabular}

The graphs in Figures 5 through 9 depict the data corresponding to the 50-percent pressure cycle and burst cycle. The plots display the ramp up to $2000 \mathrm{psi}$, the 3-min hold, the ramp back down to $0 \mathrm{psi}$, and the following 3 -min hold. The plots are of the sensor strains as a function of time. These plots are useful when looking for creep during the 50-percent load cycle: creep is indicated if the sensor strains do not return to their starting position. An example of this effect is depicted in Figures 5 and 6: the strain curves during the 50-percent load cycle for the hoop sensors for a previously cycled bottle, No. 2179, and a pristine bottle, No. 2139. The hoop strains all return to within 15 microstrains of their starting strain for the previously exercised bottle, but remain as much as 600 microstrains above their starting strain for the pristine bottle, indicating residual fiber stress.

For an elastic material, assuming that the bottle stress is proportional to bottle pressure, the strain-versuspressure plots should be linear, and should not show any appreciable gap between the rising and falling pressure curves. Most of the well-conditioned bottles exhibit elastic behavior during the 50-percent pressure cycle, as shown in Figure 7. However, a similar plot for a pristine bottle exhibits a far larger degree of hysteresis (Figure 8), indicative of material stretching in the hoop direction during the load cycle. There is also a difference in onset of non-elastic behavior during the burst testing between the pristine and well-conditioned bottles. Although the burst pressures for bottle Nos. 2179 and 2139 were different by only 220 psi (4430 psi versus 4210 psi, respectively),

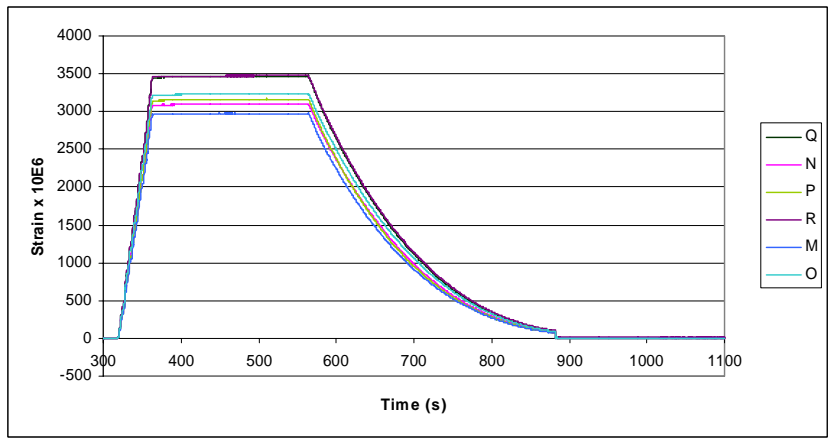

Figure 5. Strain as a function of time during the 50-percent load cycle for the channel 3 sensors (all in the hoop direction) for bottle No. 2179.

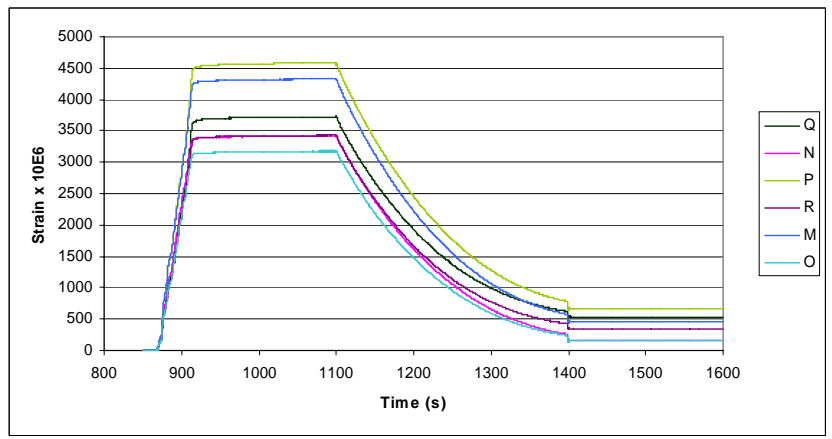

Figure 6. Strain as a function of time during the 50-percent load cycle for the channel 3 sensors (all in the hoop direction) for bottle No. 2139. 


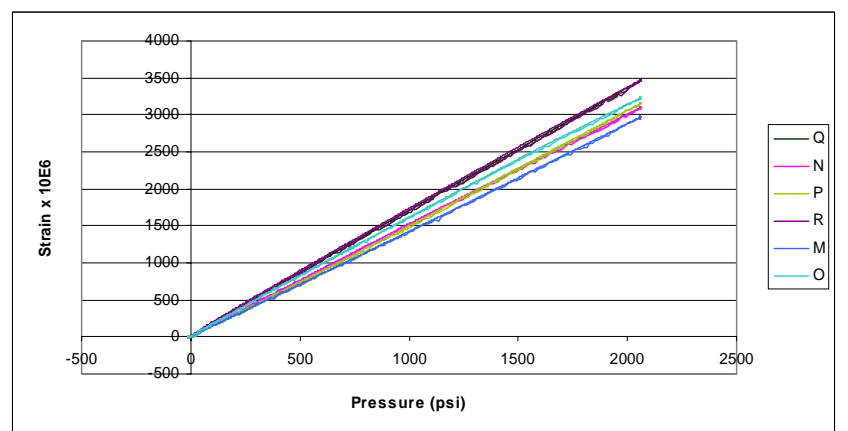

Figure 7. Strain as a function of pressure during the 50-percent load cycle for the channel 3 sensors (all in the hoop direction) for bottle No. 2179.

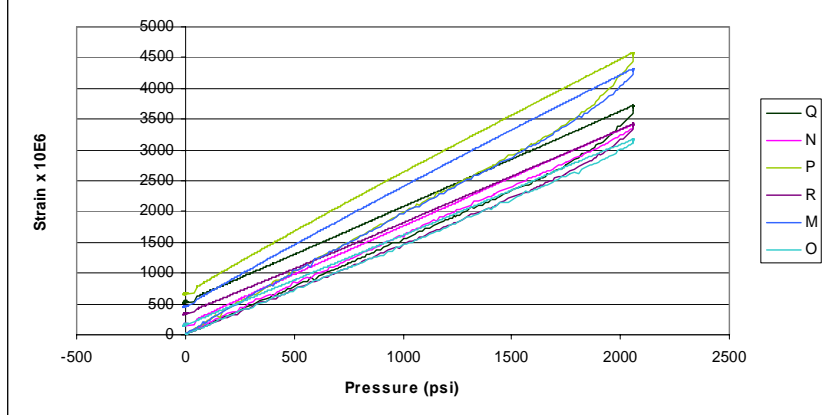

Figure 8. Strain as a function of pressure during the 50-percent load cycle for the channel 3 sensors (all in the hoop direction) for bottle No. 2139.

Figure 9 shows that a large increase in slope of the strain curve occurs at approximately 3700 psi for the wellconditioned bottle (left), but close to 2300 psi for the pristine bottle (right). This increase in slope is likely a first indication of fiber and liner realignment of load sharing characteristics. This occurs at different pressures depending on the previous stress state of the bottle. Figure 9 also shows the first attempt to model the bottles and compare it with the actual measurement. This was done using $\operatorname{ANSYS}^{\circledR * *}$ failure analysis software, without taking plastic behavior of the aluminum liner into account; hence it did not predict the liner's behavior at the point of rapid strain transfer to the fiber.

A second model, constructed using the GENOA Progressive Failure Analysis (PFA) ${ }^{\dagger \dagger}$ software, applied nonlinear elastic/plastic behavior for the liner material and micromechanics modeling of the fiber/matrix composite layers based on the manufacturing wind patterns. This particular model was only performed using data for a pristine vessel. The GENOA model indicates the onset of plastic behavior and the subsequent shift of stress to the composite layers. A plot of the stress at the surface in the hoop direction near the equator of the vessel is shown in Figure 10. The lower curve represents the stress in the composite, while the upper curve is the computed stress in the fibers themselves. The plot supports the assessment of the knee occurring near the same point as measured by the Bragg sensor.

\section{General FBG Experimental Conclusions}

Since the testing was performed on the ten articles, interesting trends and repeatable measurements were made showing in the strain fields during initial pressurization to $2000 \mathrm{psi}$ and then from ambient to burst pressurization up to burst. Clear differences were seen in the behavior of virgin versus previously pressurized vessels that could be correlated with a structural analysis of the tanks. Additionally, the FBG results were instrumental in determining the true stress ratio. This resulted in substantial upward revisions to the actual stress ratios that were present in the
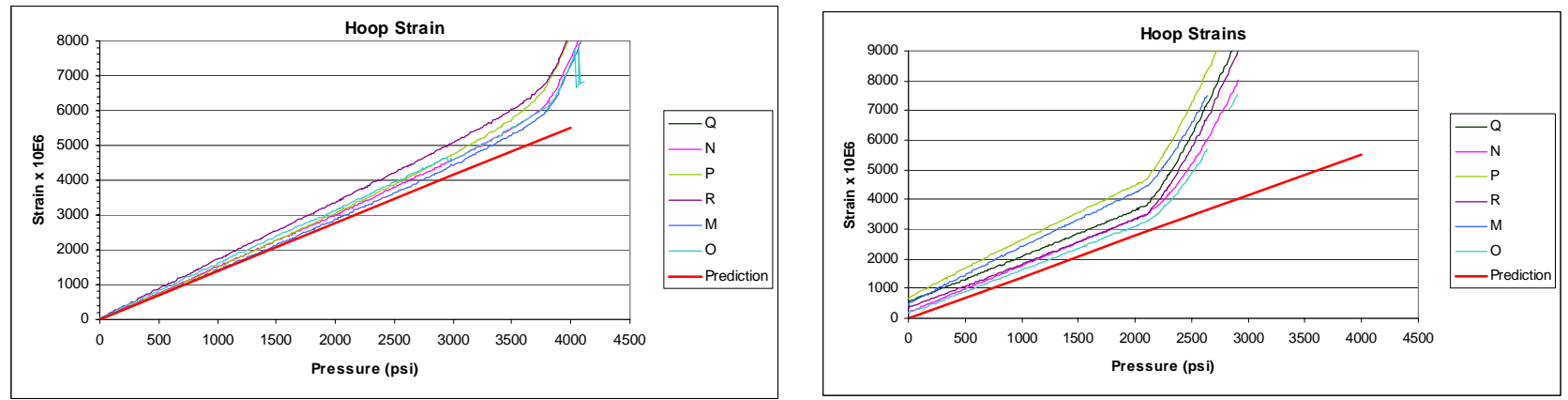

Figure 9. Strain as a function of pressure during the burst cycle for the channel 3 sensors (all in the hoop direction) with predictions made with ANSYS software.

\footnotetext{
${ }^{* *}$ ANSYS $^{\circledR}$ is a registered trademark of Swanson Analysis Systems, Inc., Houston, PA.

${ }^{\dagger}$ GENOA-PFA is licensed by Alpha STAR Corp., Long Beach, CA.
} 


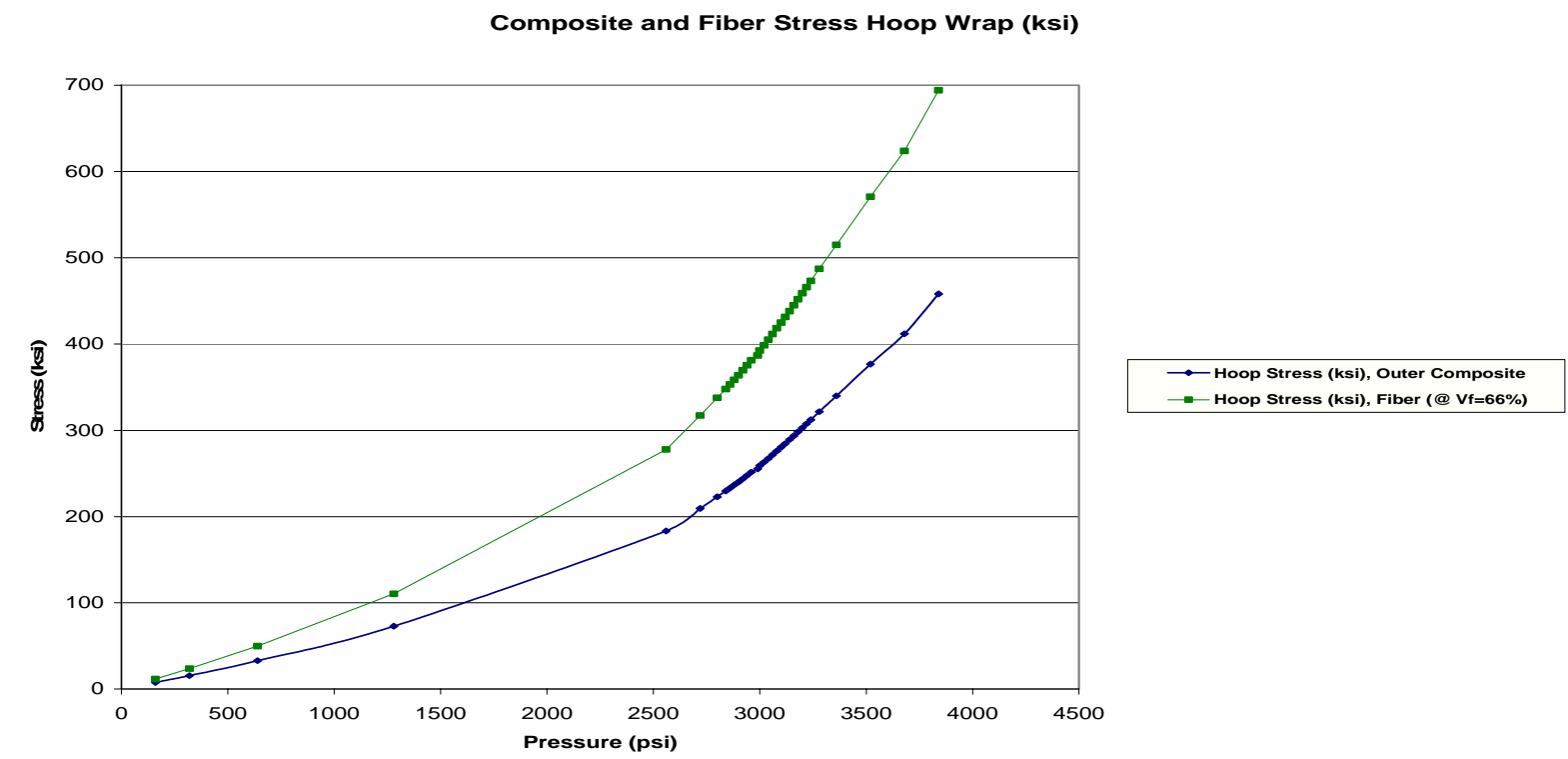

Figure 10. Strain plots using the Genoa software to predict structural failure.

WSTF SR testing. One of the vessels was first thought to have ruptured at a problematic 52-percent stress ratio and the FBG system provided the data necessary to correct the stress ratio to 58 percent. Many of the FBGs also indicated valuable information on fiber load redistribution and matrix micro cracking. This, like acoustic emissions data, helps give the location of active areas of load redistribution and needs more study to better utilize the capability. The method also shows promise for longer-term monitoring of other bottles during testing at WSTF and for potential flight application.

\section{NDE Supporting Current WSTF Kevlar COPV Testing}

A test program is in progress at WSTF with the objective of providing data that can be used to better predict the reliability of certain Kevlar COPVs types that have been in use for many years, and hopefully extend their useful life. Volumetric/strain testing and associated laboratory analysis are being accomplished to understand composite/liner interaction, the "through-wall" stress gradient, and evaluate other strain and volume changes as the as COPVs are pressure cycled and then finally burst. Age and environmental related material degradation are also being evaluated. Stress rupture testing may also be accomplished to evaluate the life prediction model. To effectively accomplish this testing, both pretest NDE to verify the structural integrity of the test articles and realtime NDE are being used during testing to develop critical data.

Table 2 indicates the typical NDE and test instrumentation being applied, with a brief indication of what is being measured. Pretest NDE and other NDE used to gather test data are discussed in more detail in the following sections (such as eddy current used to determine composite thickness change with pressurization).

\section{A. Overview of COPV FBG Strain Measurement}

The basic FBG system and sensor interrogation unit is the same as discussed previously under NDE for the earlier WSTF Experimental Carbon Bottle Burst Testing; however, additional strain sensors are utilized. The FBG sensor attachment area on the Kevlar COPV was cleaned and the surface conditioned. The sensor strings were routed to the dome section of the bottle, where they were taped in place and terminated to the fiber optic connector block using double-sided adhesive foam tape. The sensors were all placed on the bottom hemisphere, under the rationale that the bottle was symmetrical about the equator, the sensors would be more out of the way on the bottom side, and the fiber cables could be more easily mounted to a connector block near the bottom pressure port for patching and routing.

Most of the sensors were aligned in the direction of the tow that makes up the wrap, since this should be the direction of the critical strain that would determine when the wrap will fail; but a few sensors were also oriented perpendicular to the tow orientation. The FBG were routed to avoid the location of several acoustic emission sensors, and none of the fibers were allowed to pass over the bottle equator, since two "belly band" wire 
Table 2. Typical WSTF COPV Test NDE and Instrumentation.

\begin{tabular}{|l|l|}
\hline \multicolumn{1}{|c|}{ Method } & \multicolumn{1}{c|}{ Measurement } \\
\hline Visual inspection (pretest) & External inspection of overwrap. Indication of gross damage \\
\hline Flash thermography (pretest) & Heat signature decay. Sub-surface ply delamination \\
\hline Borescope inspection (pretest) & Internal inspection of liner. Indication of damage or buckling \\
\hline IR heat soak thermography (pretest) & Heat signature decay. Sub-surface ply delamination \\
\hline Shearography (pretest) & $\begin{array}{l}\text { Differential strain resulting from anything that would cause it } \\
\text { (e.g., impacts, delaminations, broken fiber) }\end{array}$ \\
\hline Fiduciary marking (pre/posttest) & Measurement of distance between marks \\
\hline Pressure, temperature (test) & Time, pressure, and temperature \\
\hline $\begin{array}{l}\text { Cabled girth linear variable displacement } \\
\text { transducer (LVDT) (test) }\end{array}$ & Circumferential displacement measured at 0, 45, and 80 degrees \\
\hline Boss LVDT (test) & Axial displacement \\
\hline Conventional Strain gauge (test) & Change in length. Fiber strain \\
\hline Fiber Bragg grating (test) & Change in length. High resolution \\
\hline Acoustic emission (test) & Acoustic noise. Fiber breakage or delamination \\
\hline $\begin{array}{l}\text { Volume displacement } \\
\text { (load cell and supply weight) }\end{array}$ & $\begin{array}{l}\text { Vessel test fluid mass. Strain and fiber creep (weighed from } \\
\text { supply and expulsion volumes) }\end{array}$ \\
\hline Full field digital image correlation & Vessel strain \\
\hline Eddy current probes & Composite thickness change \\
\hline Raman Spectroscopy - portable & Residual stress and stress changes while pressurizing \\
\hline
\end{tabular}

displacement sensors were installed there to measure the bottle diameter as a function of pressure. After the FBG sensors were installed, foil strain gauges were installed adjacent to them to allow comparison of data. It was found that the method of attachment was much more critical for application of surface mount FBG and in general the data was not as accurate or repeatable as the conventional strain gauges.

\section{B. Eddy Current Composite Thickness Measurement}

During pressurization, a thinning of the Kevlar composite of the COPVs was predicted. Eddy current techniques provide a means to measure this change in composite thickness, and have been implemented for the pressurization and burst tests at WSTF. Additionally, it was determined that liner thickness variations could also be evaluated by using both the horizontal and vertical component of the signal. NASA Langley Research Center (LaRC), in conjunction with WSTF, has instrumented a COPV eddy current composite thickness gauging measurement system. A brief description of the inspection system and anticipated results are discussed in the following paragraphs.

Eddy current techniques are primarily designed to operate based upon the electromagnetic induction of current into a conducting object due to the applied alternating magnetic field of a test coil. The induced current acts to oppose changes in the applied field, and results in a change in impedance of the test coil. Eddy current instruments are designed to measure these changes in the test coil impedance, which are then correlated with physical properties such as the conductivity of the material under test and lift-off distance (test coil to conductor spacing). For COPV composite thickness inspections, eddy current lift-off measurements can be performed to measure the probe-to-liner spacing. With the probe bonded to the Kevlar surface, this effectively measures the thickness of the Kevlar composite.

Figure 11 displays the system supporting the WSTF COPV studies. A commercial Zetec MIZ-27 ${ }^{\circledR \sharp}$ SI eddy current instrument is used to simultaneously drive four custom-wound eddy current coils on the Kevlar COPV and

$\mathrm{MIZ}^{\circledR}$ is a registered trademark of Zetec, Inc., Issaquah, WA. 
eight on the larger gaseous helium tanks. The coils, shown in the right-hand side of Figure 11, are each enclosed in a housing 1 -in. in diameter and 0.75 -in. tall. Each coil has been placed on an insulating surface (Delrin ${ }^{\circledR \S}$ sheet) over a stainless steel conductor. In this laboratory environment, the simple geometry mimics the Kevlar composite over a COPV with a metal. A laptop computer is used to acquire and archive the data in real-time during testing. In the figure, the normalized impedance of the four coils is displayed in the four dots in the center of the MIZ-27 screen. The signals have been nulled, or balanced, at the respective composite thicknesses seen by each probe and rotated such that a change in lift-off results in a vertical deflection of the eddy current signal. The probe response is digitized and stored on the laptop computer, while the vertical components of the signals are displayed in a strip chart on the computer screen. A separate analog input channel is reserved to acquire timing information from the pressurization tests.

In order to determine the voltage change caused by a given change in composite thickness, calibration of the probes and equipment is needed. This is performed using nonconductive shim material to measure the change in probe output for a known thickness change. The calibration range should encompass the range-of-thickness change anticipated during the test. In Figure 12, the computer display for the removal of a $0.001-i n$. plastic shim over the 0.25 -in. insulator block is

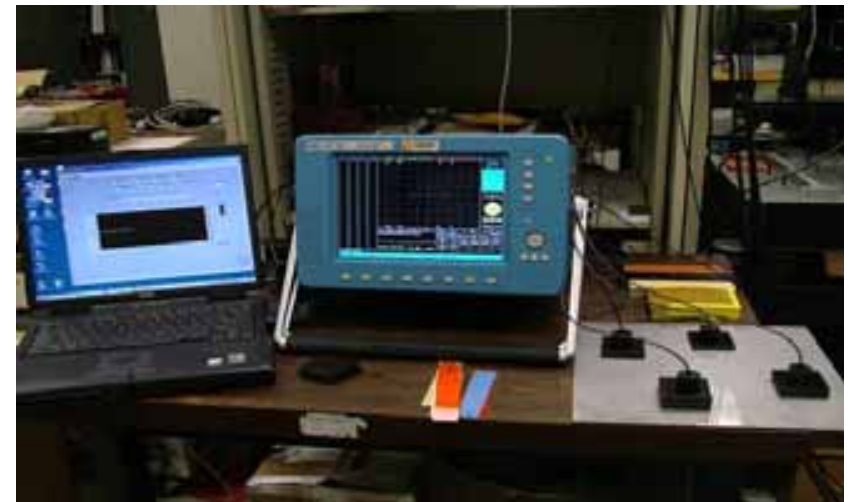

Figure 11. Eddy current inspection system for COPV composite thickness measurement

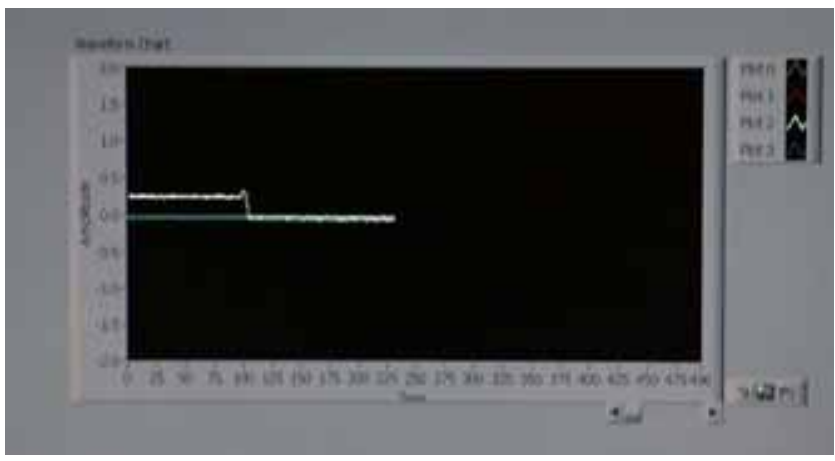

Figure 12. Screenshot of data in Plot 2 shows voltage change associated with change in thickness from 0.251 to 0.250 in. as a 1-mil shim is removed from probe 2 at $T \sim 100$. All other channels remained at nominal coating thicknesses.

shown. For these tests, a $15-\mathrm{kHz}$ drive signal was supplied to the test coils. A unit drop in the voltage measured when the shim was removed was clearly well above the background variation of the system. The sensitivity of the measurement is dependent upon the nominal composite thickness and is typically inversely proportional to probe-toconductor spacing. Table 3 shows the voltage change corresponding to a 0.001 -in. change in composite thickness at nominal composite thickness values of $0.25,0.375,0.5$, and 0.75 in.

Table 3. Eddy Current System Response for Various Nominal Lift-Off Values.

\begin{tabular}{|c|c|c|c|c|c|}
\hline $\begin{array}{c}\text { Nominal Composite } \\
\text { Thickness }\end{array}$ & 0.25 in. & 0.375 in. & 0.5 in. & 0.625 in. & 0.75 in. \\
\hline$\Delta \mathrm{V} / \mathrm{mil}$ & $0.35 \mathrm{~V} / \mathrm{mil}$ & $0.18 \mathrm{~V} / \mathrm{mil}$ & $0.12 \mathrm{~V} / \mathrm{mil}$ & $0.065 \mathrm{~V} / \mathrm{mil}$ & $.04 \mathrm{~V} / \mathrm{mil}$ \\
\hline
\end{tabular}

The noise floor of the system has been measured at about $0.02 \mathrm{~V}$, providing an absolute sensitivity of near $0.5 \mathrm{mil}$ for the 0.75 -in. composite thickness, and greater sensitivities at smaller composite thicknesses. In reality, the measurable composite thickness change is likely to be limited by external system noise and instrumentation drift. In the open laboratory, sensor outputs were seen to drift by approximately $0.1 \mathrm{~V}$ over a 1 -h time period, due in part to temperature variations. An equivalent value for sensors bonded onto a COPV configured for pressurization testing is not currently available.

After laboratory validation at the NASA-Langley Research Center, the eddy current system was shipped to WSTF for installation on a COPV vessel. Figure 13 shows an example COPV with the eddy current sensors attached. One of the sensors is clearly visible just above the equatorial belly band.

$\S_{\S}$ Delrin $^{\circledR}$ is a registered trademark of E. I. Dupont de Nemours, Wilmington, DE. 


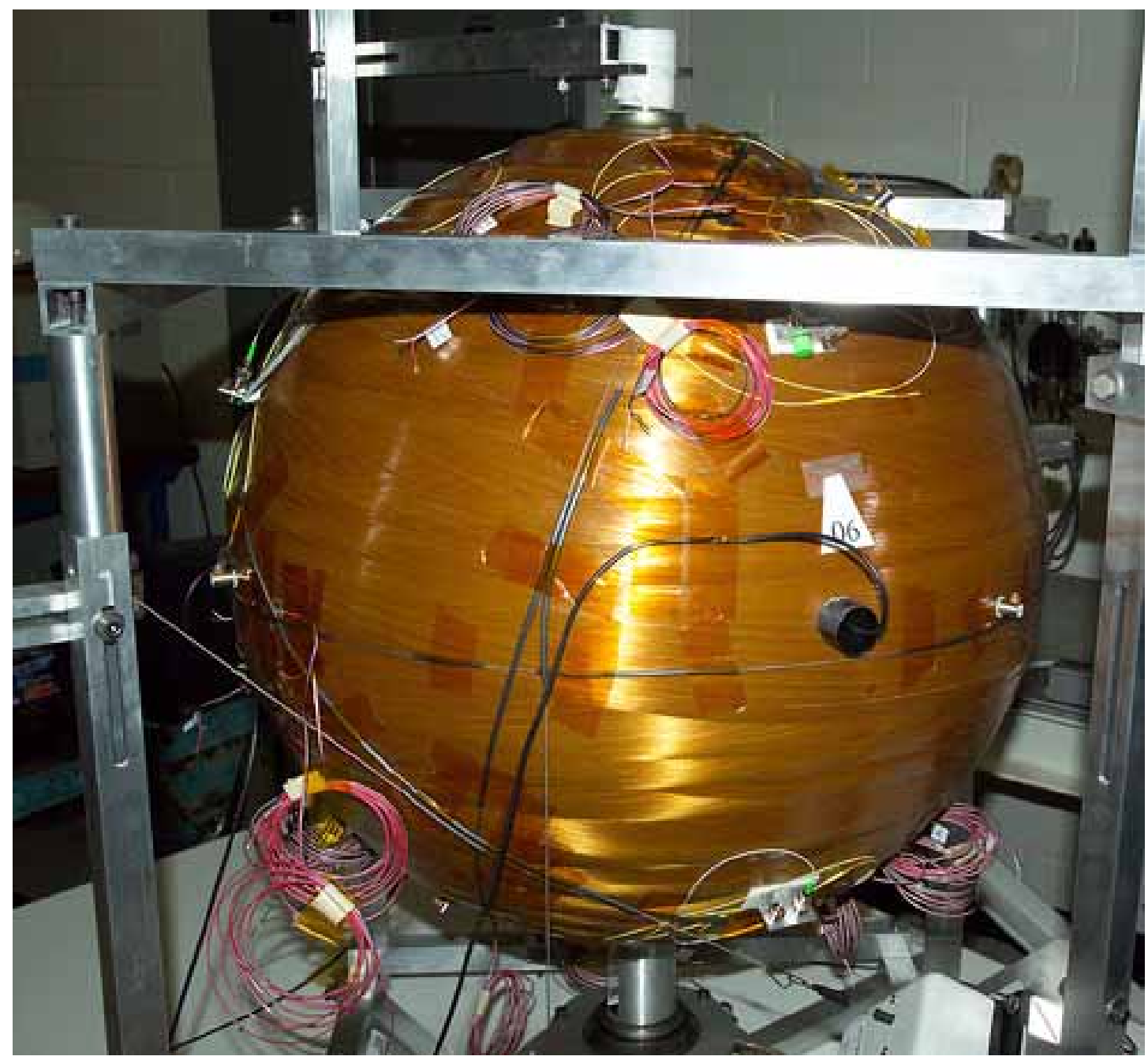

Figure 13. Eddy current sensors installed on COPV.

Following laboratory calibration, COPVs were installed on at the pressurization facility. Various pressurization cycles were applied while the composite overwrap thickness was measured with the eddy current sensors. Figures 14 and 15 display resulting composite and liner thickness change in a sample final ramp to burst. A decrease in the composite and liner thickness is measured on all channels as the pressure increases. An x-ray correlation was accomplished on the first vessel to help validate the eddy current thickness measurements and found the eddy current measurements to be accurate to the resolution of the x-ray technique. Although data from up to eight eddy current sensors per COPV was sometimes a bit time consuming to reduce and analyze, it has been instrumental and has indicated how the composite and liner strain together through yield and all the way to burst.

\section{Digital Image Correlation}

Digital image correlation (DIC) was accomplished using ARAMIS software. This technology uses the principles of 3D image correlation photogrammetry that gives full-field displacement and strain measurements. The basic principles of 3D image correlation photogrammetry have been known for about 15 years. ${ }^{4}$ The particular 3D image correlation system being utilized, ARAMIS, has been commercially available for about 10 years.

The system requires spraying random high-contrast dot patterns onto a sample; this pattern is then tracked in ARAMIS by thousands of unique correlation areas known as facets. The center of each facet is a measurement point that can be thought of as a 3D extensometer. Arrays of them form in-plane strain rosettes. The facet centers are tracked in each successive pair of images, with accuracy up to one-hundredth of a pixel. ${ }^{5}$ 


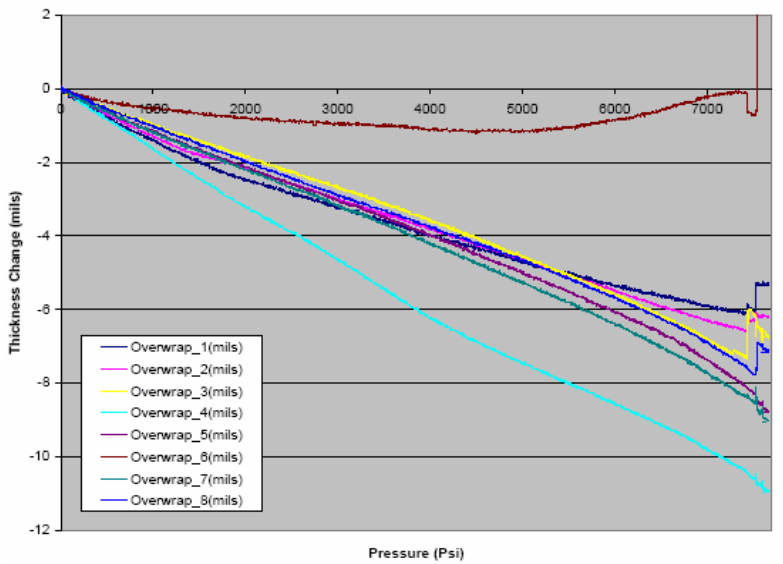

Figure 14. Example Composite thickness reduction with pressure.
Liner Thickness Vs. Pressure

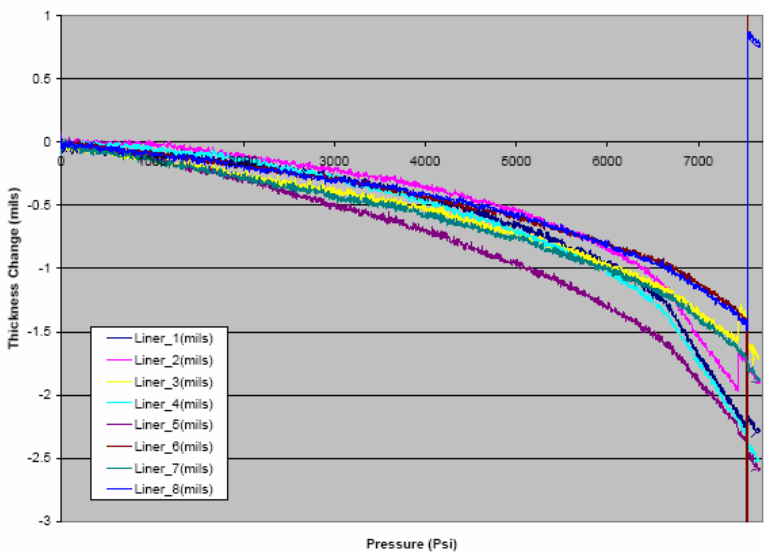

Figure 15. Example Liner thickness reduction with pressure.

For the typical WSTF COPV installation (Figure 16), digital high-speed Phantom ${ }^{\circledR * * *}$ v7.0 cameras were used at a resolution of 512 x 512 pixels, giving a recording speed ranging from 100 to 3000 frames per second (fps). Lower speeds were used for some tests due to the negative heating affect that supplemental lighting had on other COPV surface mounted instrumentation. The Phantom cameras act as a stereo pair to create a volume of area in which the ARAMIS software can take measurements. The volume varies with the calibration method and field of view. This camera setup consisted of 35-mm lenses with the cameras at a typical angle of 15.7 degrees, giving a measuring volume of $1060 \mathrm{~mm} / 875 \mathrm{~mm} / 875 \mathrm{~mm}$. To calibrate for this volume, the camera resolution was set at $800 \mathrm{x} 1200$ pixels, and a $1200 \mathrm{~mm}$ NIST-traceable calibration cross was rotated and moved in specified locations to calibrate the sensor. After successful computation, the calibration deviation was below 0.04 and the angle variance was larger than the 15 degrees required for a successful calibration. The cameras used inter-range instrumentation group (IRIG) time for synchronization, which provided accuracy within 1 microsecond between images. The pattern sprayed on the vessel consisted of a white background with 0.25 -in. black dots sprayed on the surface viewed, as noted in Figure 16. The system was particularly useful in indicating overall principal strain fields that developed higher in the COPV pressurization range as indicated in Figure 17 and indicating surface fiber failure near burst. The system also provided excellent strain data in areas where conventional strain gauges were not installed and correlated well to these, as indicated in Figure 18, except where cables or other instrumentation interfered.

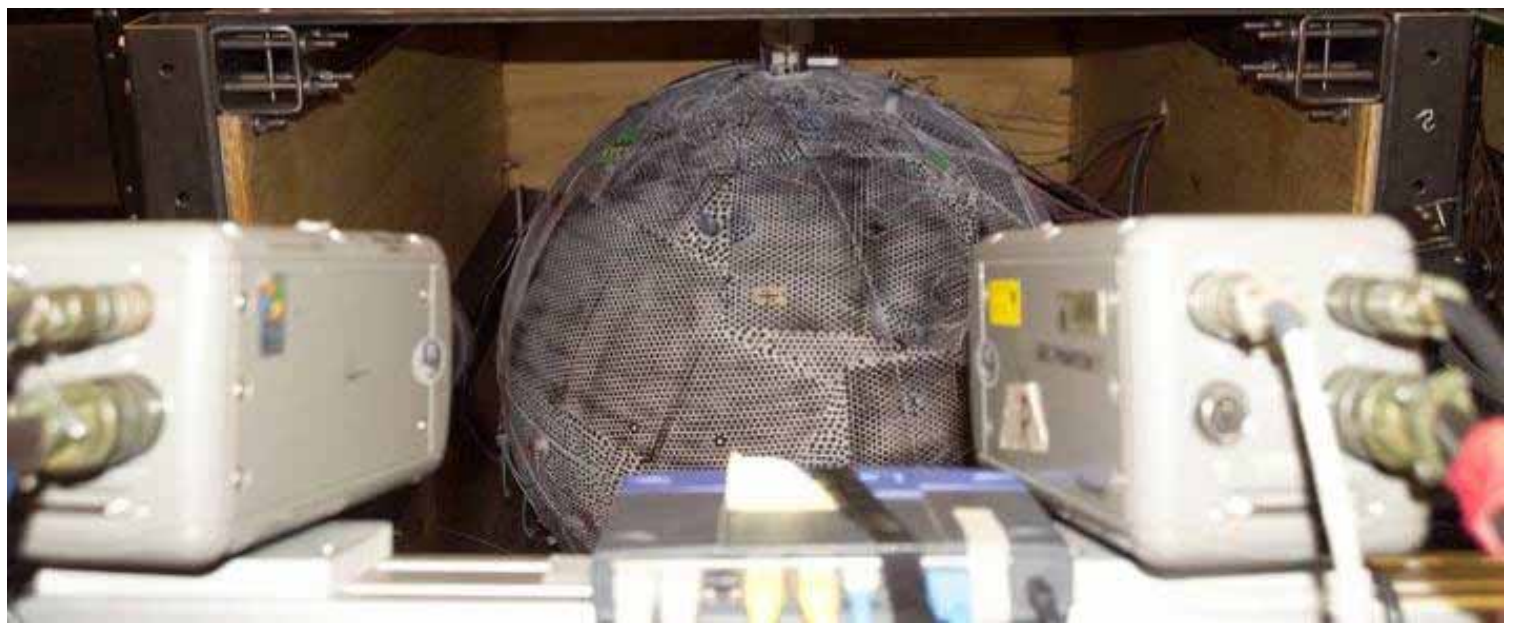

Figure 16. Digital image correlation camera view of COPV (Black dots sprayed over area of interest).

\footnotetext{
${ }^{* * *}$ Phantom ${ }^{\circledR}$ is a registered trademark of Vision Research, Inc., Wayne, NJ.
} 


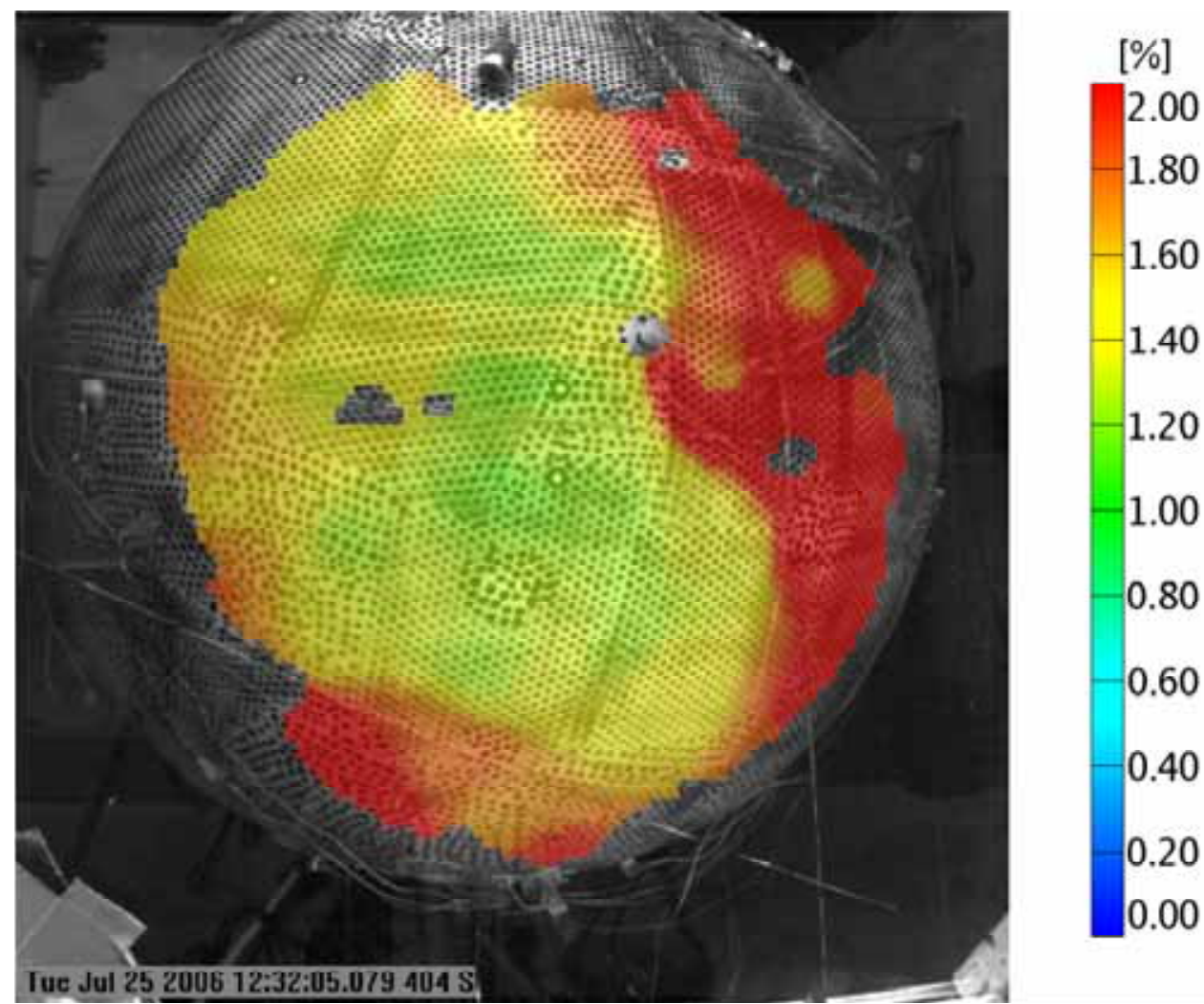

Figure 17. Digital image correlation Full Field Principal Strain .

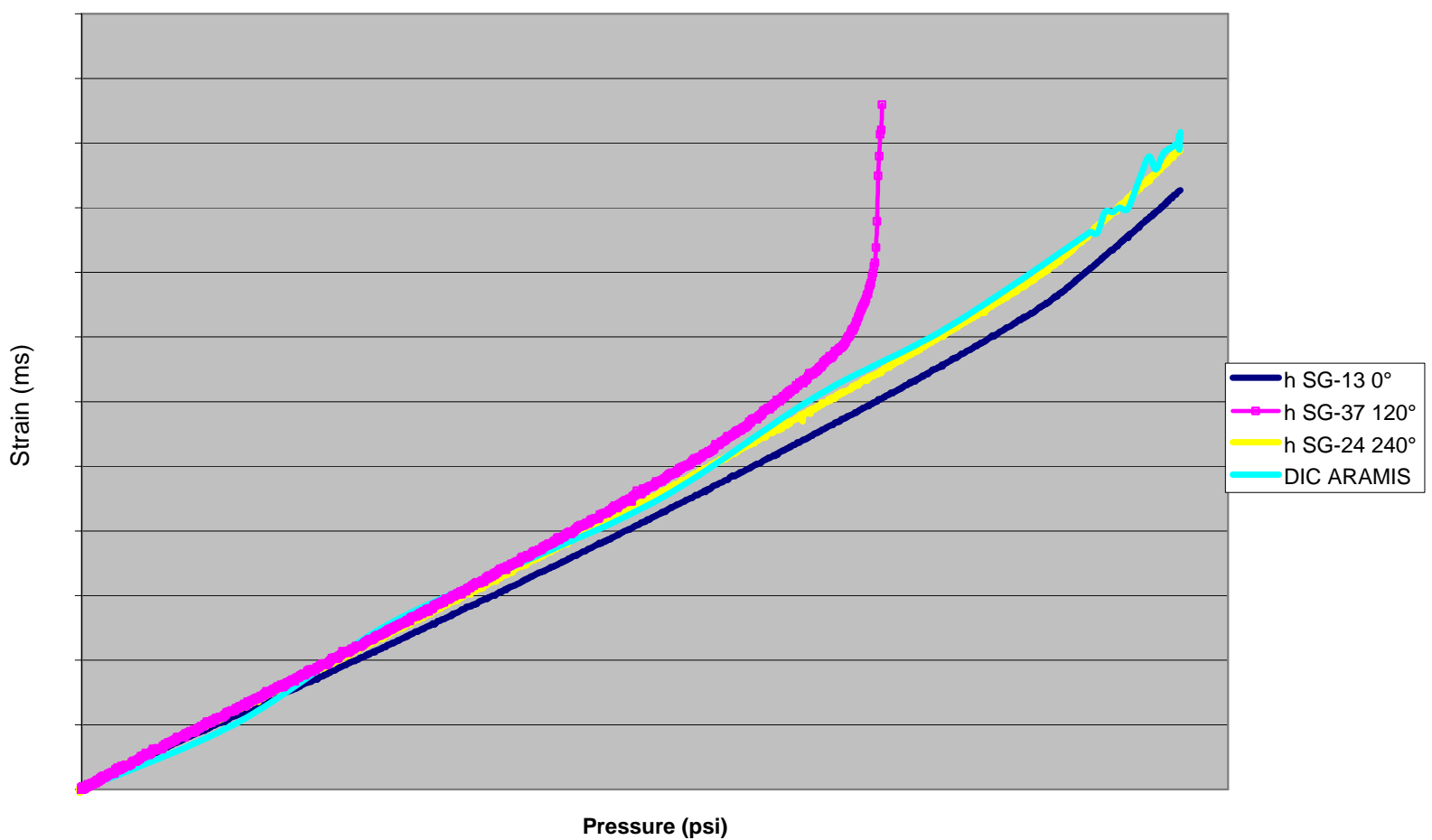

Figure 18. Digital image data correlation to conventional strain gauges 


\section{40-in. COPV Pretest NDE Shearography}

To help verify the integrity of a large 40 -in. COPV prior to test, shearography was utilized as shown in Figure 19. This testing was accomplished under the guidance of John Newman ${ }^{\dagger \dagger}$ and with equipment supplied by NASA Kennedy Space Center. This approach, in combination with heat soak thermography, was deemed to give an excellent pretest health check of the 40 -in. COPV. A general discussion of the system follows. Subsequent testing of 24 additional spherical Kevlar and spherical and cylindrical carbon COPVs was then accomplished in September 2006 and provide excellent results.

The shearography camera uses a Michelson-type interferometer with two essential modifications. First, one mirror is precisely tilted to induce an offset, or sheared image, of the test part with respect to a second image of the part. Second, the sheared amount is a vector with an angle and a displacement amount. The shear vector, among other factors, determines the sensitivity of the interferometer to surface displacement derivatives.

The two laser speckle images of the test part, offset by the shear vector, interfere at every paired point over the surface in the field of view. The single frequency laser light from the two sheared images of the part is focused onto the camera array of photosensitive pixels. Light from pairs of points in each sheared image interfere. Each video frame, comprised of the complex addition of these two sheared images, can be subtracted from a stored reference image. The absolute difference yields a fringe pattern observed on the monitor. The second mirror in the Michelson interferometer may be phase-stepped using a piezoelectric device and the images combined to create a phase map (Figure 20). Further processing using any number of unwrapping algorithms may be used to generate fringe-free images of local surface deformation derivates.

In practice, each step in creating a shearogram is performed automatically using image-processing macros constructed by combining each processing function in a sequence. Shearography system operators perform a test with a single keystroke.

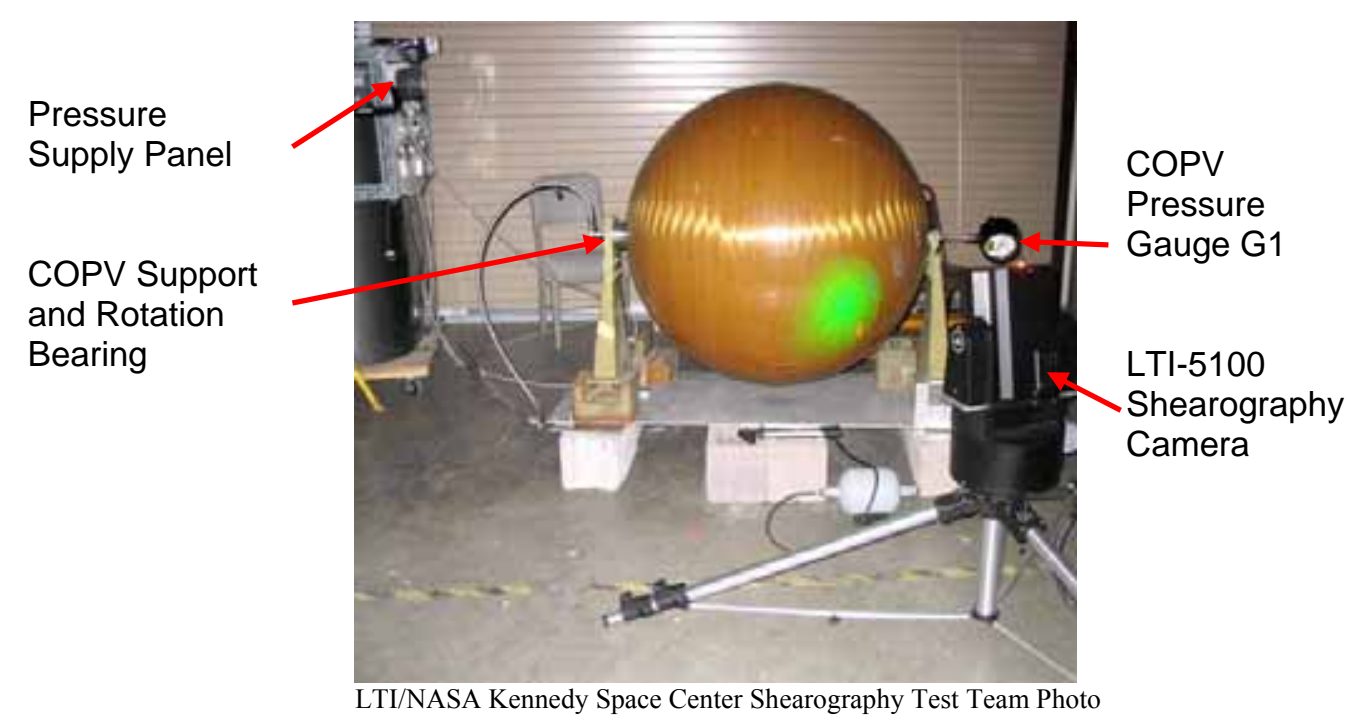

Figure 19. LTI SC-5100 system being applied to Kevlar COPV.

tit John Newman is the president and founder of Laser Technology, Inc. in Norristown, PA, and author of the background information on shearography. He has worked in the field of holography, shearography, and laser NDT methods since 1970. Mr. Newman founded LTI in 1977 and led the development of the first electronic shearography system in the mid 1980s. Mr. Newman initiated the ASNT Laser Methods Committee and is the current Chairman. 


\section{E. Quantitative Shearography Measurements}

Precision calibration of the shearogram image scale (pixels/in.) and the shear vector allows further processing of shearography data to determine defect indication dimensions, area, and the deformation of the material. The digital measurement of the deformation derivative may be integrated to show the shape of the target surface deformation as well as the magnitude of the deformation at any location, as in Figure 20. Shearography can be used to measure the deformation response of a structure to an applied load and as a means for deriving material properties.

An example of composite shearography images of a Kevlar test tank is shown in Figure 21. The pressure was cycled between 70 and 90 psi to create a delta strain for each image. The sensitivity is noted by very slight strain indicated in the overwrap pattern and from tank features such as the girth weld area. Minor delaminations are also indicated in the upper right where wrap patterns cross. However, no impact damage was noted as seen on the impact standard image shown on the lower right. Shearography of a carbon test COPV is also shown in Figure 22. In this figure, damage from calibrated impacts are clearly imaged and the sensitivity of the system is indicated by the less substantial and unexpected un-programmed damage noted on the lower left.
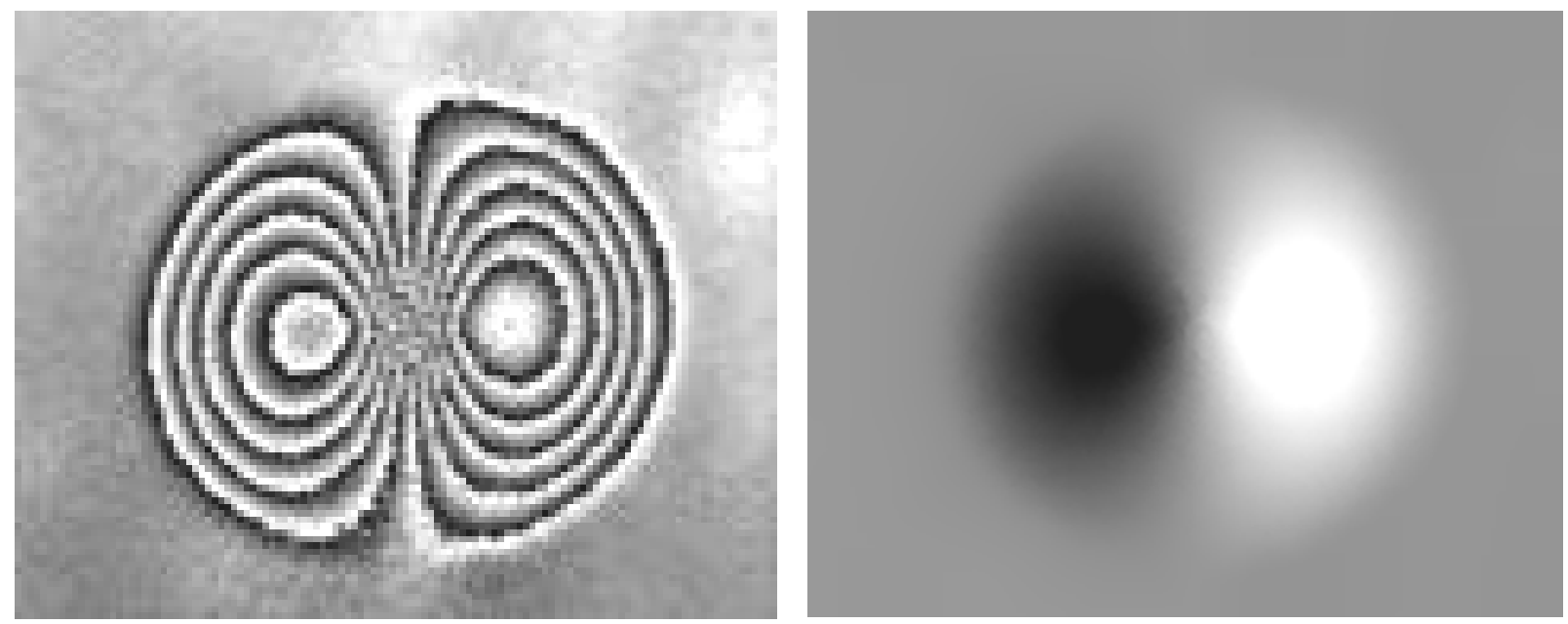

Figure 20. A phase map shearogram with horizontal shear vector yields a fringe pattern showing the first derivative of the out-of-plane deformation, $\partial w / \partial x$. Using an unwrapping agorithm, the image at right shows the positive (white) and negative (black) slope change. The metal plate with a 4.0-inch diameter flatbottomed hole was deformed by $7.0 \mu \mathrm{m}$.

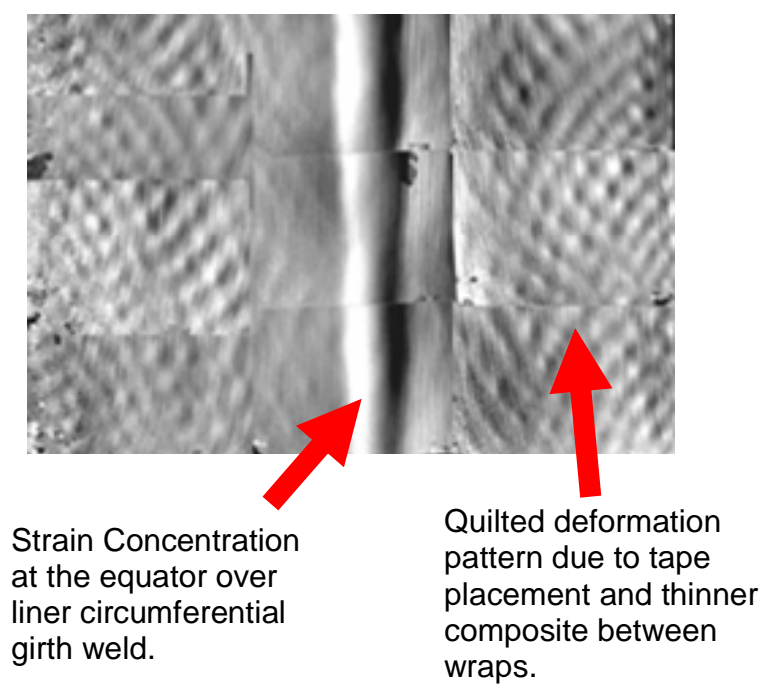

\section{Minor tape delamination} Near end boss.

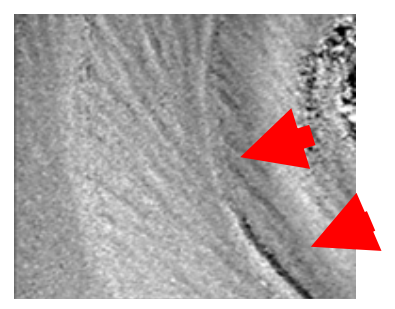

\section{COPV Test Standard}

Impact damage on a COPV at WSTF. Damaged areas are 1.3 in. diam. compared to the 0.25 in. visual dent on the surface.

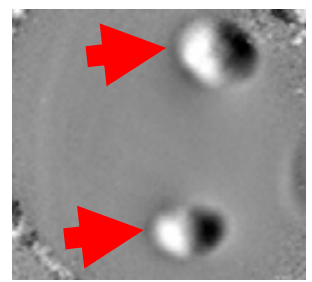

Figure 21. Example Shearography image of Kevlar COPV as compared to a damage standard. 

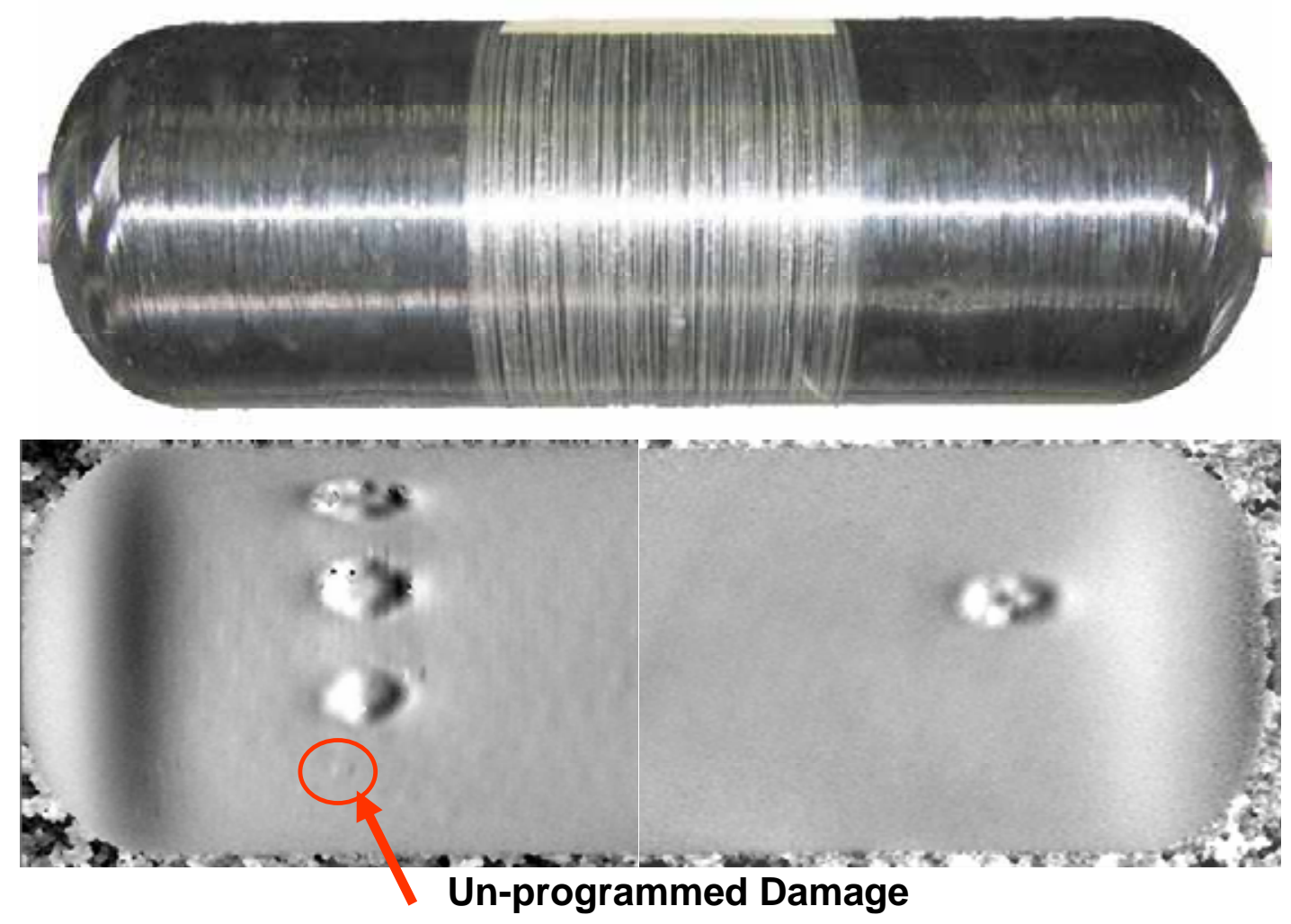

Figure 22. Shearography Inspection of Impact Damaged Carbon COPV

\section{F. Thermography Experimental Setup}

NASA LaRC developed the WSTF IR thermography system that was used for single-sided data acquisition on the 40-in. Kevlar COPV, shown in Figure 23. The IR imager is a commercial radiometer with a cooled $256 \mathrm{H} \mathrm{x} 320 \mathrm{~V}$-element InSb (indium - antimonide) focal plane array detector. The radiometer's noise equivalent temperature difference (NE $\Delta \mathrm{T}$ ), cited by the manufacturer, is $0.025{ }^{\circ} \mathrm{C}$ when operating the detector in the 3 to $5 \mu \mathrm{m}$ wavelength range. The radiometer produces images at both $30 \mathrm{fps}$ output (video frame rate, in an RS170 format compatible with standard video equipment) and 60 fps output in a 12-bit, RS422 digital format. External optics, consisting of a wide-angle lens using germanium optical elements, were used to increase the system field-of-view by a factor of approximately two. The expanded field-of-view of this lens is 41 degrees horizontally and 31 degrees vertically.

Heating of the inspection surface is produced by focusing two $500-\mathrm{W}$ quartz lamps on the inspection area, using parabolic reflectors. The heating time for the COPV was $90 \mathrm{~s}$, and temperature data were acquired during the cooldown for 10 min (a reduced frame rate of 5 fps was achieved by sub-sampling). Because of the large thermal mass of these specimens, the surface temperature rise during heating was less than $10^{\circ} \mathrm{C}$. Although the surface of the specimen was somewhat reflective, it was not necessary to apply any emissivity enhancing coating since data were only acquired during the cool-down.

\section{Experimental Results}

Only one minor indication, possibly a small near-surface ply disband or resin lean area, was noted real-time during data collection (Figure 24). However, additional heat soak thermography and ultrasound were done of the area and it was deemed not to be a concern. 


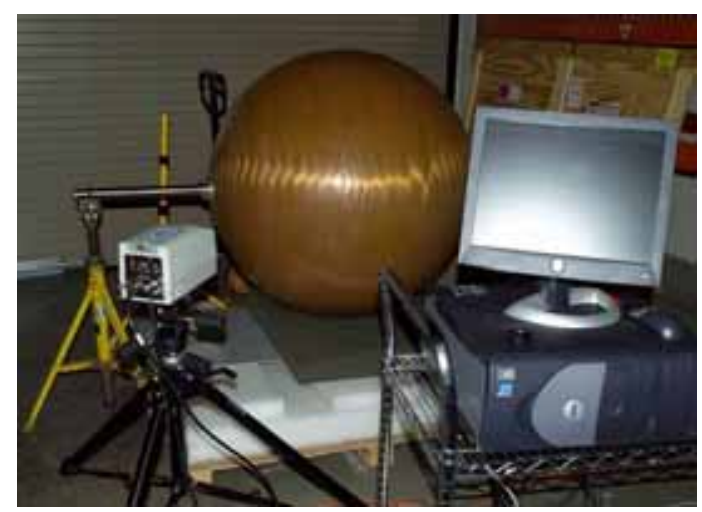

Figure 23. Heat soak thermography application to Kevlar COPV.

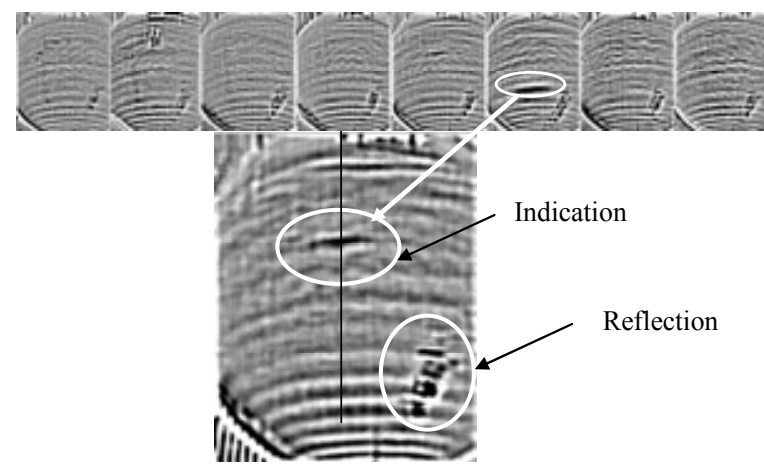

Figure 24. Example Kevlar COPV heat soak thermography images.

\section{Acoustic Emissions Overview}

Technical support for the AE test support was provided by the NASA Langley Research center. AE sensors were installed typically in 5 locations on smaller COPVs and 12 positions on larger COPVs. Three were installed on the upper boss, three others on the lower boss and six were installed around the equator. Using this configuration, sensors were used to triangulate the source locations for the acoustic activity. Sample data is shown super imposed on the 2D symbolic view of a spherical COPV shown in Figure 25. Lighter indications depict activity locations on the lower side. An example of the total number of acoustic events plotted during a pressurization and hold is indicated in Figure 26. In this case it is significant to note that acoustic activity continued during the pressure hold from 1500 to 2000 seconds. At lower pressure holds, this acoustic activity did not continue. This may be indicating that damage is profligating and the overwrap may be slowly failing. As more data is added to the COPV AE database, this type of data may be very valuable for COPV in situ health monitoring. During the WSTF COPV testing, a timeline of all COPV failure events was assembled and AE data was reviewed in detail and was extremely useful for correlation to DIC and other measurement techniques to substantiate and map locations of fiber breakage and fully characterize COPV performance.

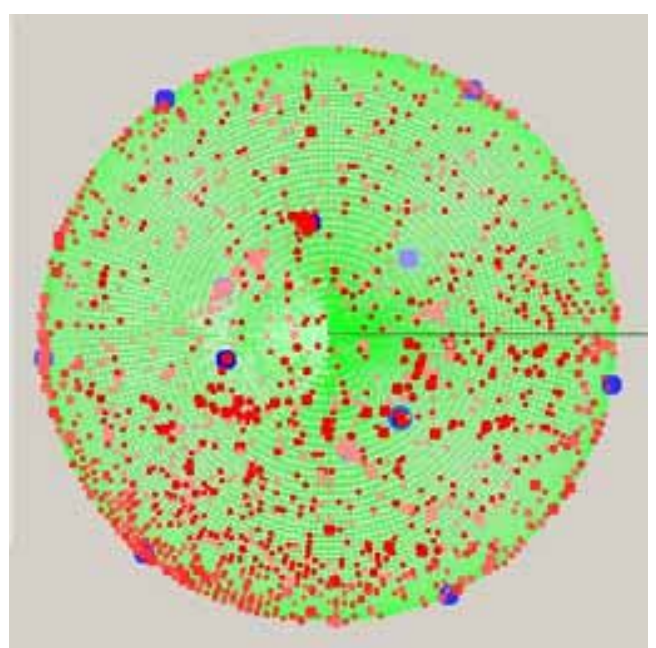

Figure 25. Example Unfiltered AE COPV Data - All Events
Events Count vs. Time and Pressure vs. Time

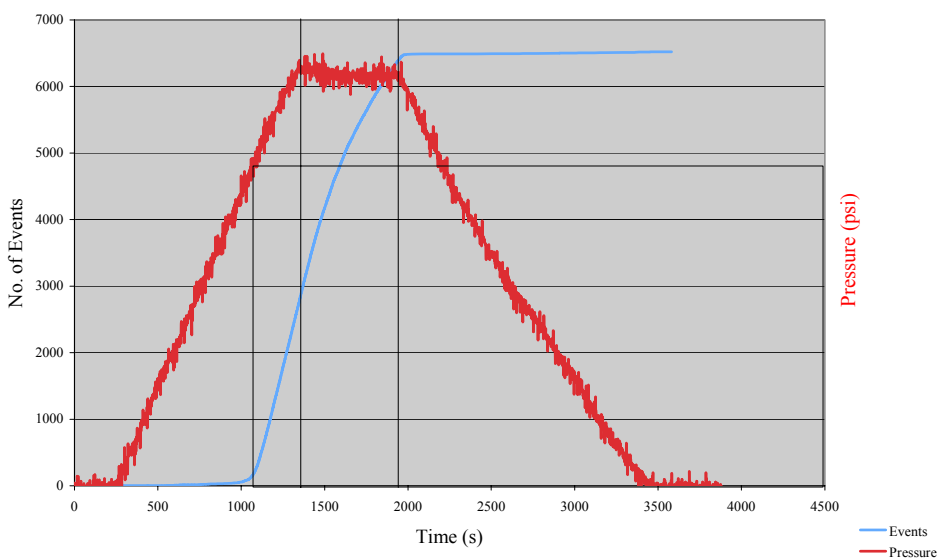

Figure 26. Example AE Events vs. Time during a pressurization and hold 


\section{Conclusions}

The NASA COPV assessments started by the NESC in 2004 led to the evaluation of NDE applicable to COPVs and the follow-on work is still in progress. Reasonably mature NDE methods were identified for application to detect impact and other localized damage. However, NDE response has not been quantitatively related to a specific reduction of structural integrity. Additionally, no NDE methods were found available for evaluation of global material property changes that could be related to progression toward stress rupture or that could aid in life predictions. Therefore, detailed recommendations for a stress rupture NDE program were provided by the NESC NDE SPRT, but the new NDE will likely take years to field. The NNWG is currently proceeding with the recommendations to the extent that funding is available, but more work needs to be done in this area.

The applications of several NDE methods to pretest screening of Kevlar and other carbon COPVs undergoing testing at WSTF have demonstrated their effectiveness. Additionally, NDE techniques applied real-time during COPV testing is providing excellent test data and helping to provide critical rationale to continue flying aging vessels. Due to the magnitude of these efforts, these applications are provided as an overview only and the paper serve as a pathfinder for other who may want to collaborate on COPV NDE.

\section{References}

1. Johnson, E. C. and J. P. Nokes. "NDE Techniques Assessment for Gr/EP Composite Overwrapped Pressure Vessels." Proceedings of the Ninth International Symposium on Nondestructive Characterization of Materials, Sydney, Australia, June 28-July 2, 1999.

2. Nondestructive Evaluation for Stress-rupture Degradation in Composite Overwrapped Pressure Vessels. Prepared by the Nondestructive Testing Information Analysis Center, a DOD Information Analysis Center. Sponsored by the Defense Technical Information Center (DTIC). Prepared for the NASA Engineering and Safety Center, Contract SPO700-97-D-4003, Delivery Order No. 0033, TAT No. NT-04-0005/0038, November 2004.

3. ASTM 6992, Standard Test Method for Accelerated Tensile Creep and Creep-Rupture Of Geosynthetic Materials Based on Time-Temperature Superposition Using the Stepped Isothermal Method, American Society for Testing of Materials, West Conshohocken, PA, 2003. Method applied by J. S. Thornton, Texas Research Institute, TRI/Austin, Inc., 9063 Bee Caves Road, Austin, Texas 78733, U.S.A.

4. Kahn-Jetter, Z. L. and T. C. Chu. "Three-dimensional Displacement Measurements Using Digital Image Correlation and Photogrammetric Analysis," Experimental Mechanics, Vol. 30:1, pp. 10-16, March 1990.

6. Schmidt, T., J. Tyson, D. M. Revilock, Jr., and M. Melis. "Full-field dynamic deformation and strain measurements using high-speed cameras." SPIE 26th ICHSPP, September 2004. 


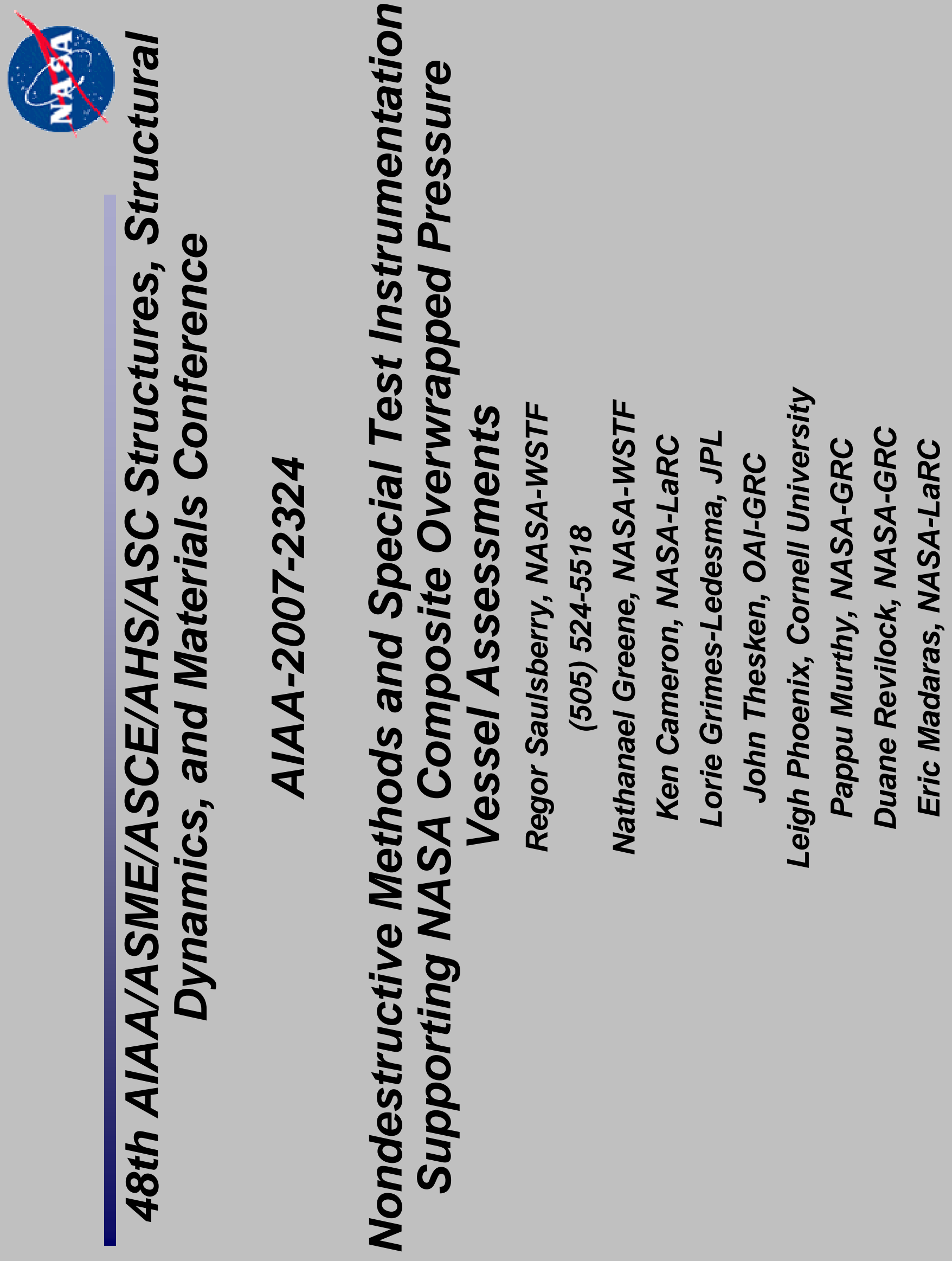




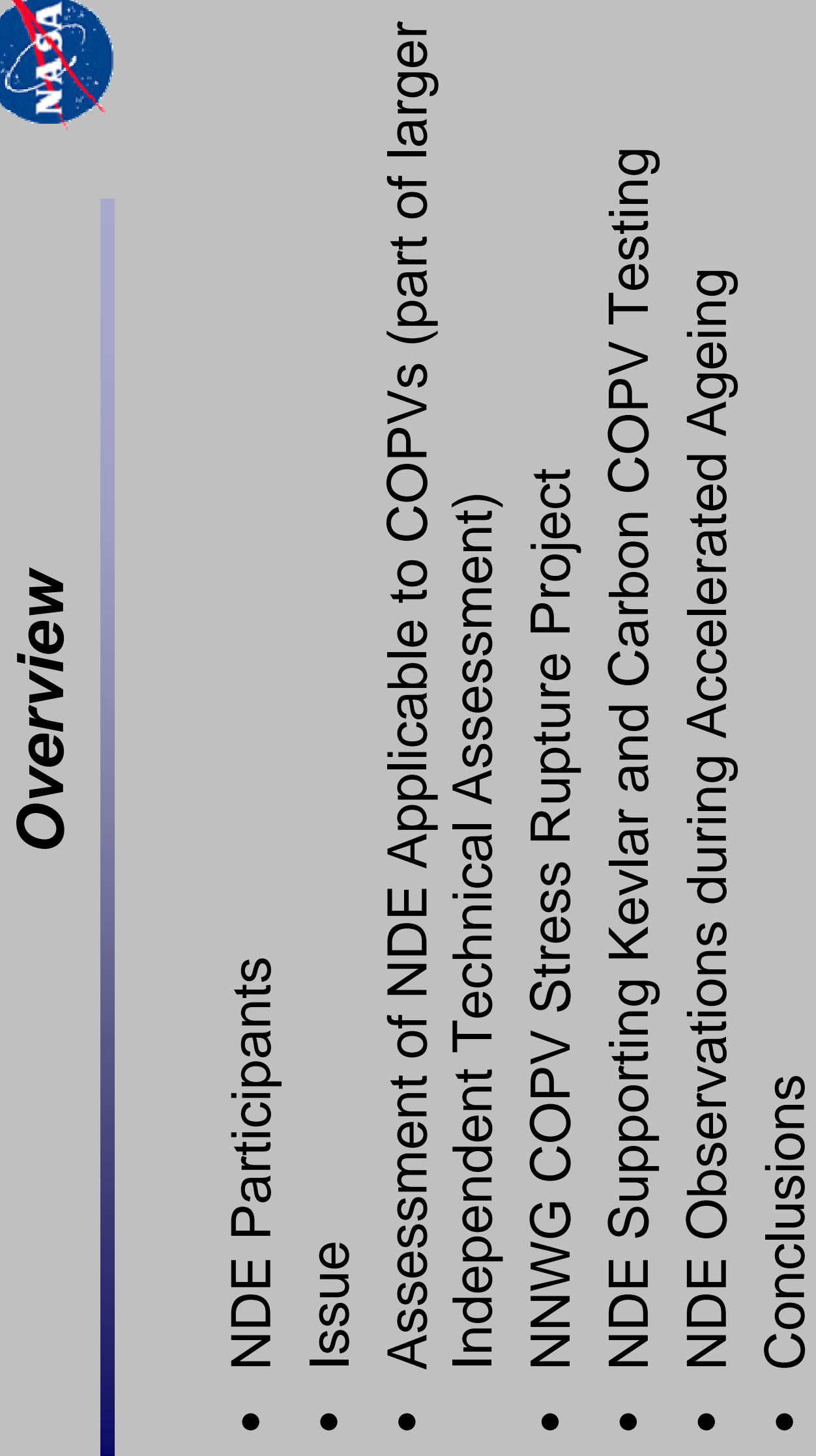


대닝

อิ드

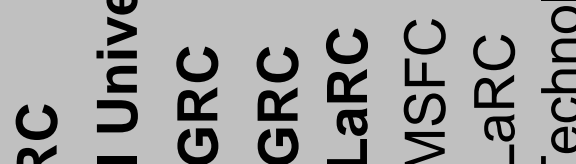

零 
$+$

1)

(1)

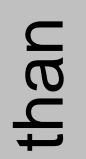

$\stackrel{5}{\circ}$

㢲

0

d

$\frac{\mathscr{T}}{\underline{0}}$

(1)

U

음

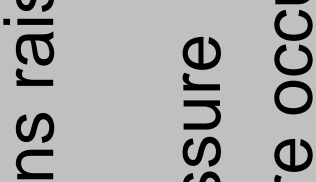

(1)

产 की

U

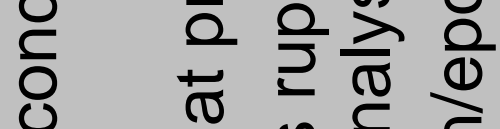

U ब

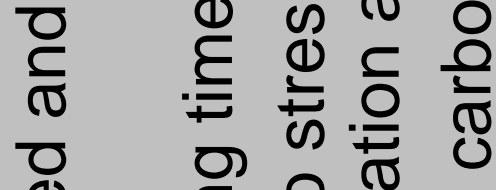

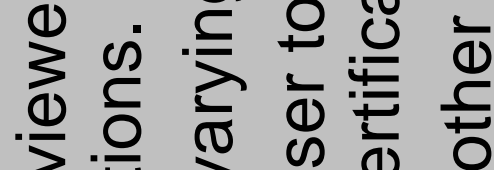

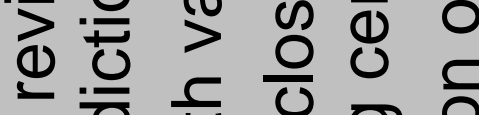

ต ब

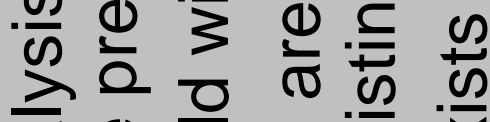

तิ ब

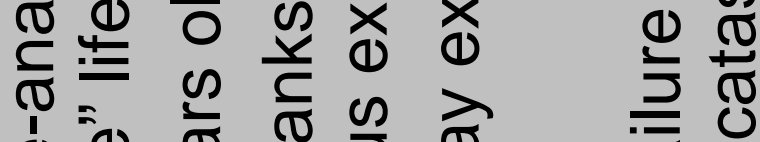

m

d ప ప స

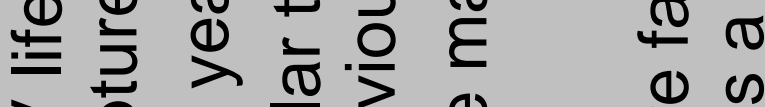

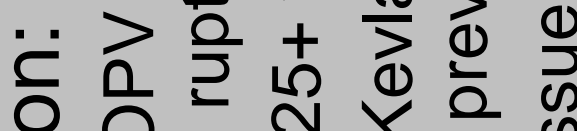

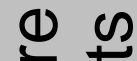

至

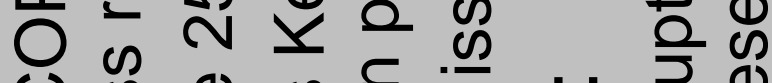

U

(⿻)

য়

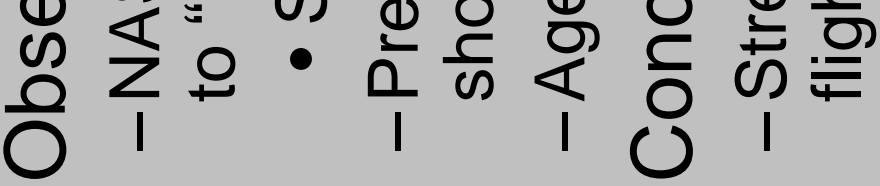


1

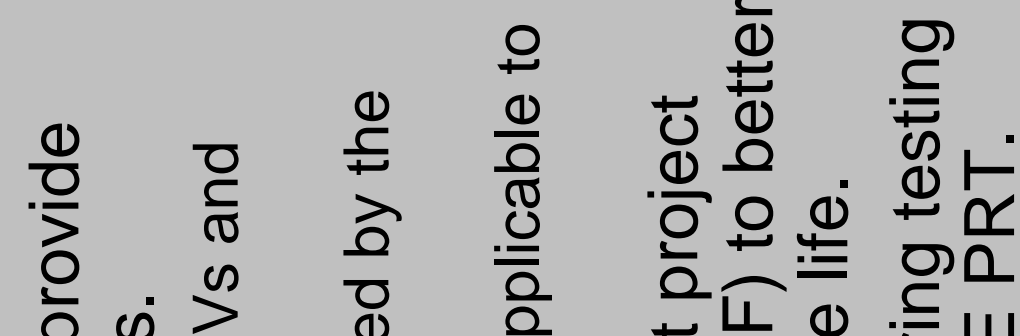

(a)

3

$0 \stackrel{0}{0} \stackrel{0}{ \pm}$

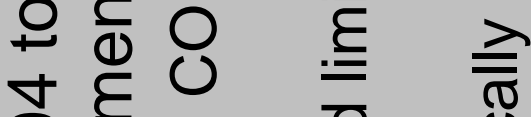

ᄋ ज

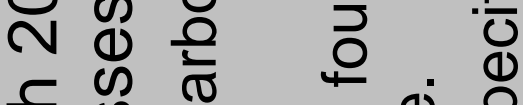

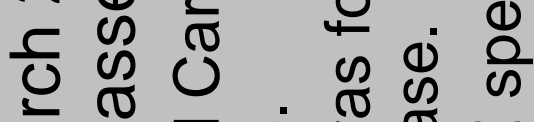

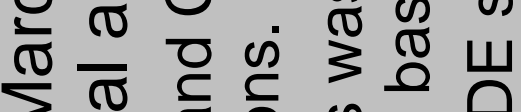

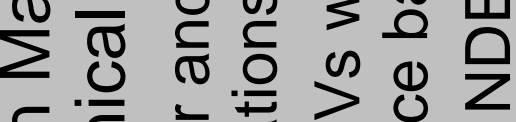

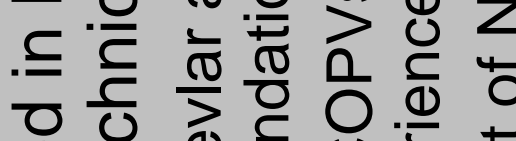

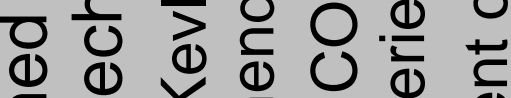

$\varepsilon+1$ (1) 0 वे दै

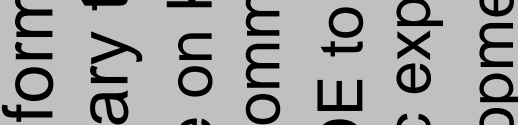

E ज

क⿱ $)$ (1)

๒

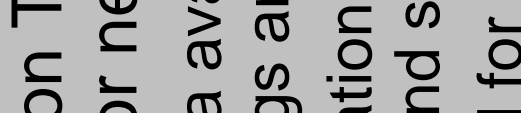

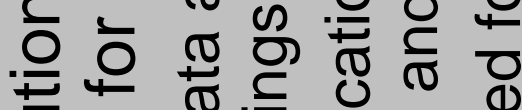

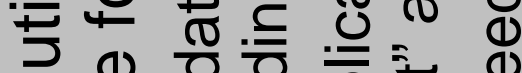

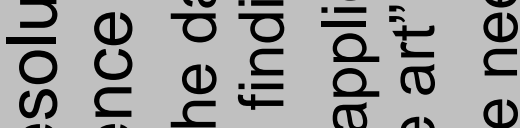

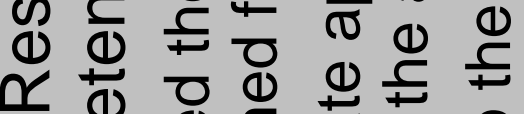

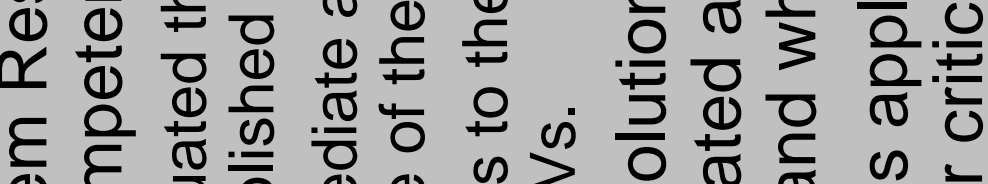

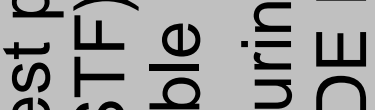

$\pm \geqslant \frac{0}{2} \frac{5}{2}$

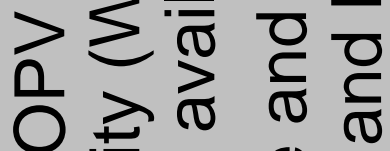

U $\overline{\overline{0}}: \frac{1}{4}$ (1)

ช

$\frac{1}{\omega}+\frac{0}{\infty} \sum$

ज車 $0>$

( )

$\frac{1}{0} \stackrel{0}{0} 00$

एह थ U U

U) $\frac{\pi}{4}$ (1) $\frac{\pi}{4}$

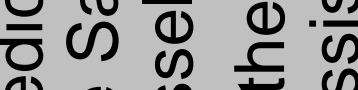

(1) $) \rightleftharpoons \omega$

니 (1) ฮ

(1) $\sum$ (1) U)

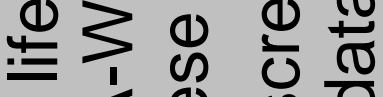

(1) 1 (1) क 0

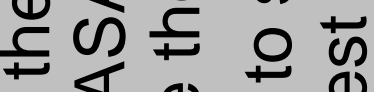

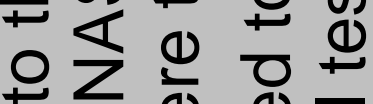

+2 (1) (1)

造

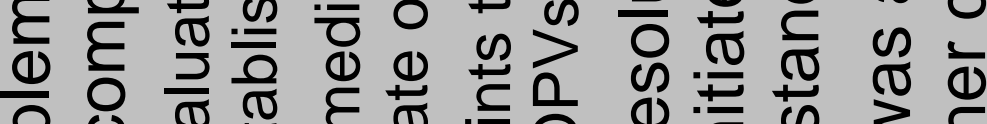

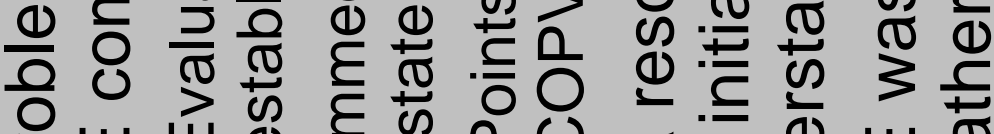

내 Ш

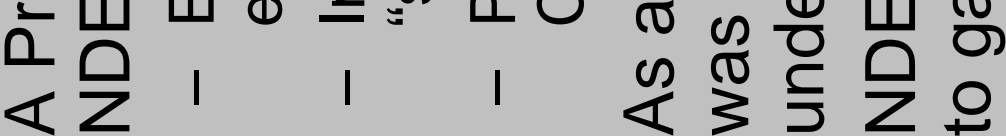


1

10

ชิ ๘

(1)

(

$\stackrel{\text { ㄹ }}{\mp}$

$>\quad \frac{1}{0}$

를 을

들

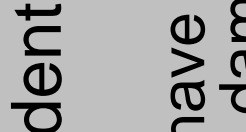

으 드든

ㅇ ต

○ 음

(1) 을

¿ $\frac{1}{(1)}$

$>\quad \underline{\Xi}$

(1). ()

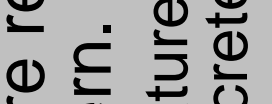

ญ 凹

ต

Uิ $\frac{1}{\sigma} \frac{0}{0}$

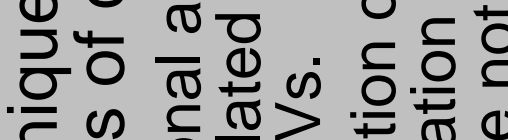

을 응<smiles>[Li]</smiles>

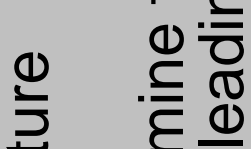

을 ह든

즌 군

응

으롫

(1) ज

Nㅡ능

(1)응

ชิ $\frac{\bar{\sigma}}{\sigma}$

สำ

뚼 을

○

은 중

ฉํํำ

ธู ป

ส্ู

(1)

U.

뜽ㅇㅇ

으는

(1)

으응

뜨도

드.

윽

สิ으 \它

हᄐ

๘๘

뜨

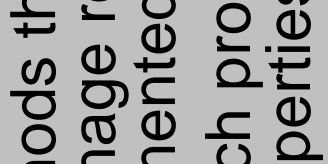

ह

들 능

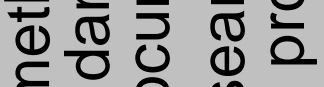

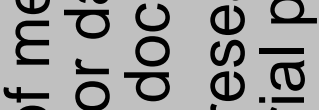

ส্

ర)

돈돈

을

0

13

(1)

ษ

山U 


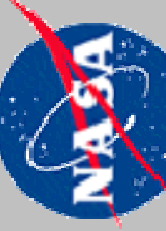

(a)

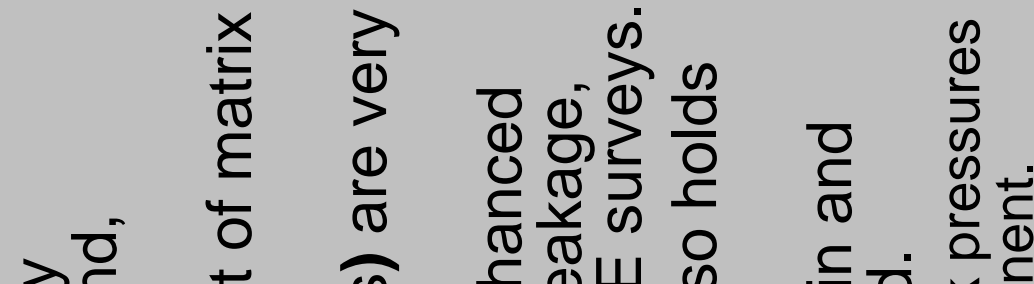

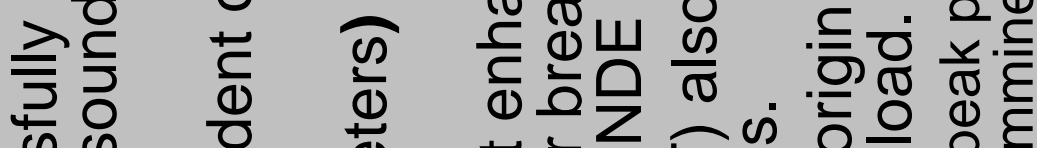

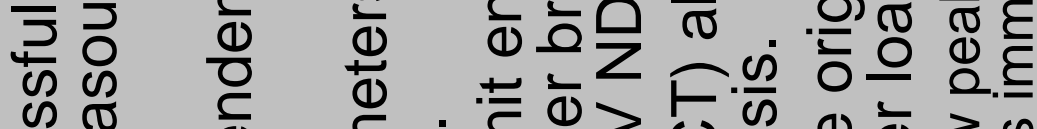

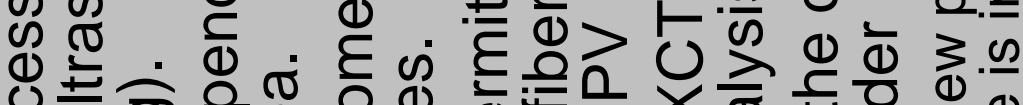

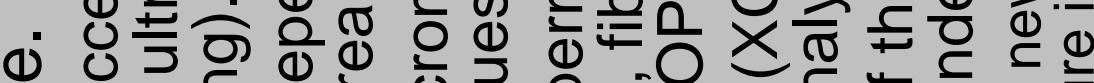

อ)

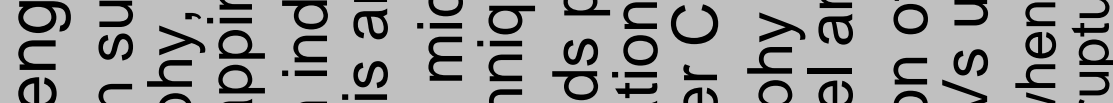

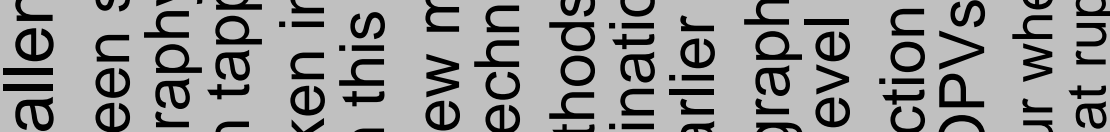

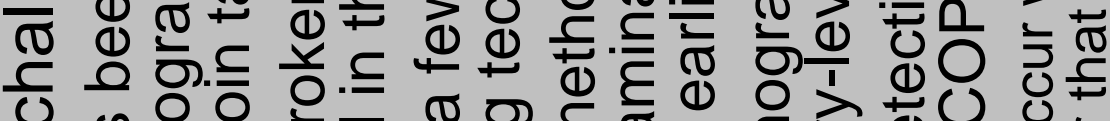

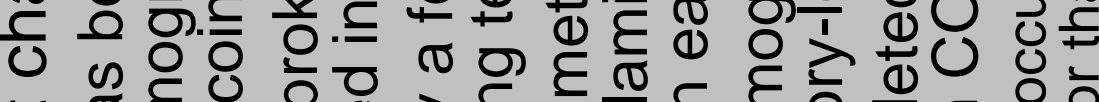

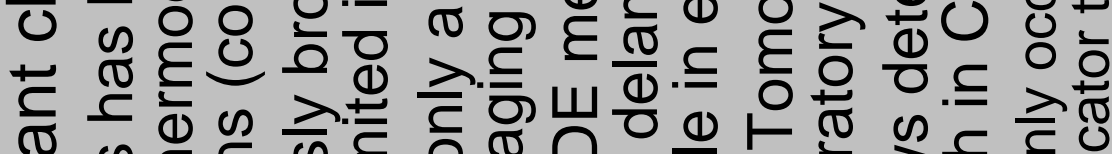

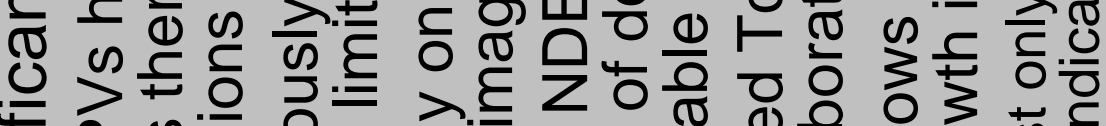

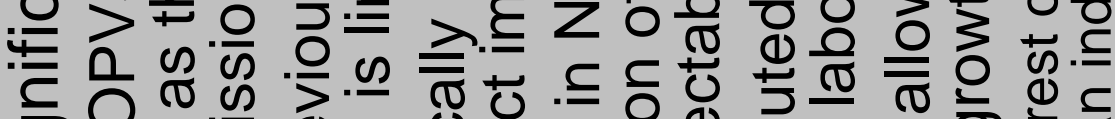

은

ज U U व

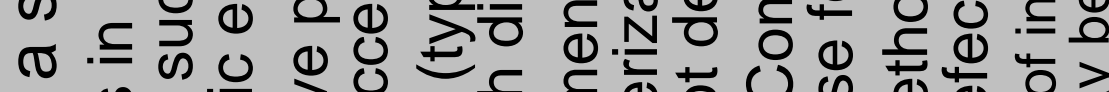

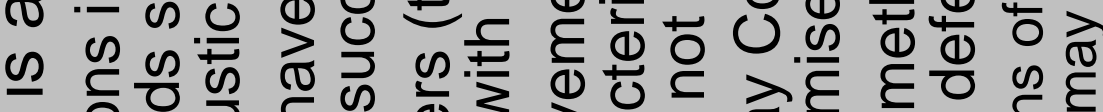

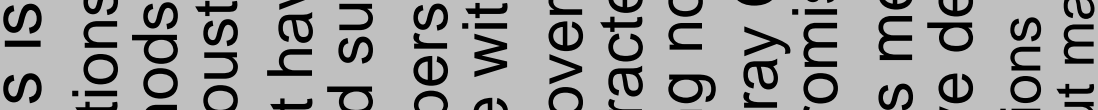

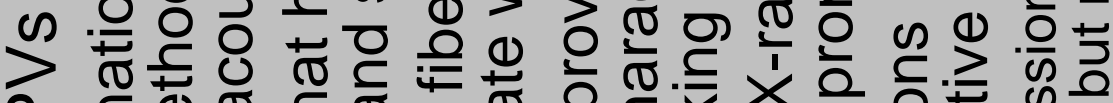

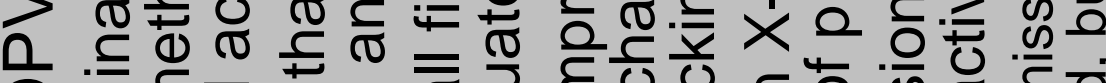
О ह हठ

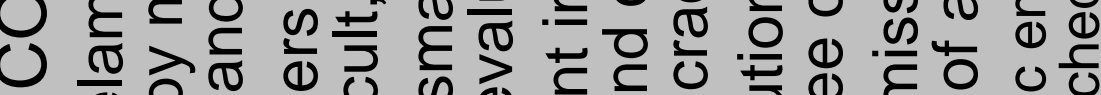
ป (1)

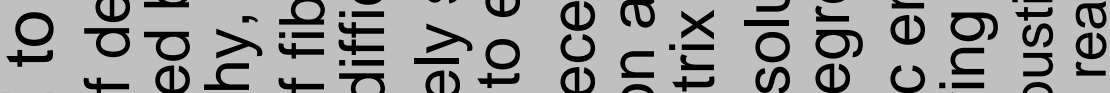
山

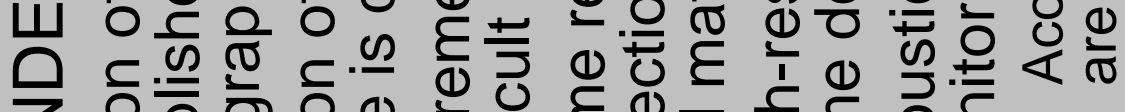

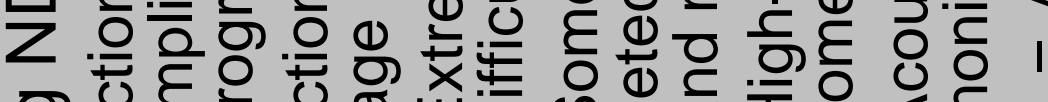

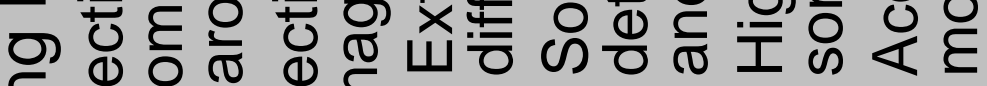

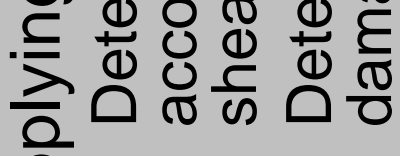




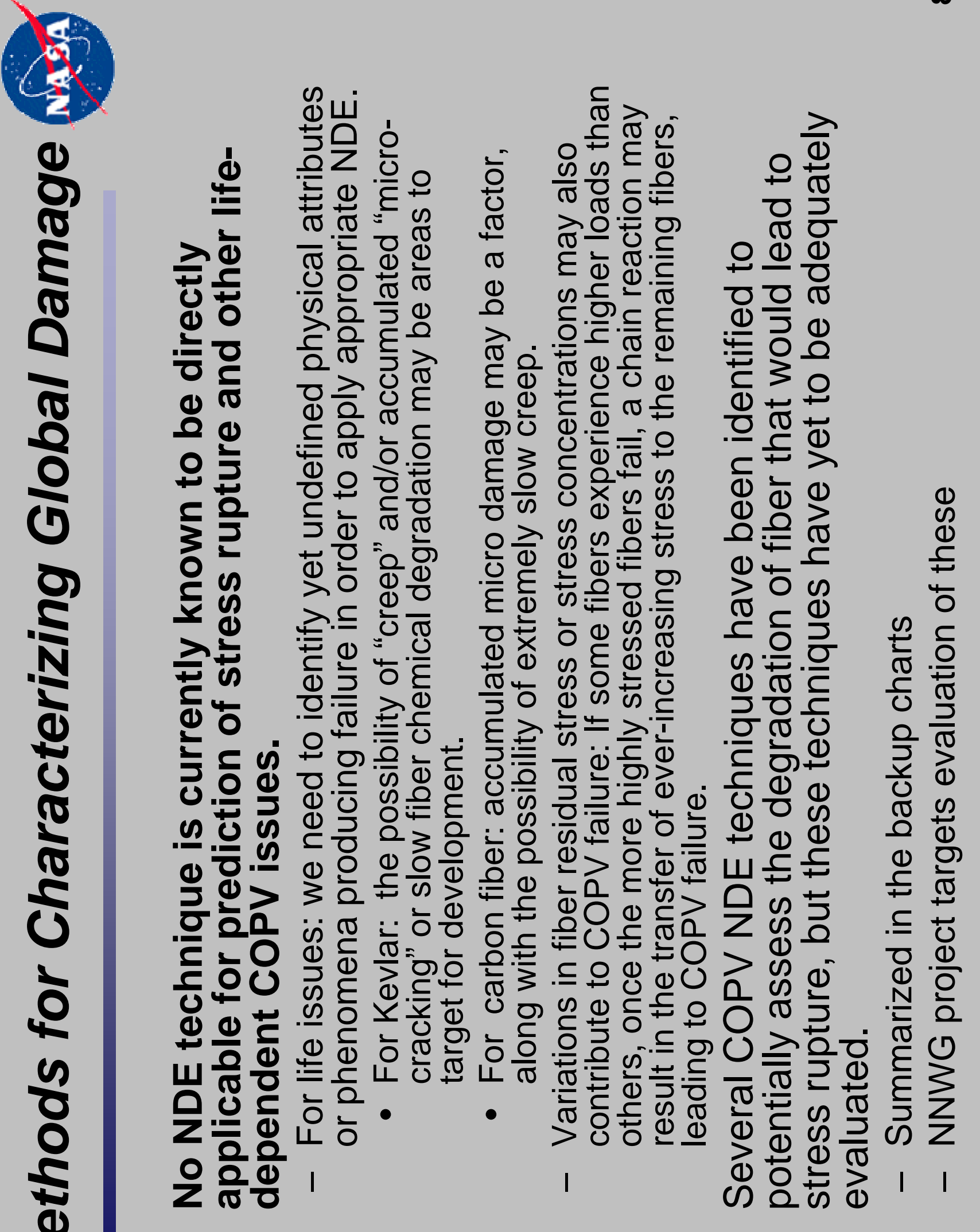




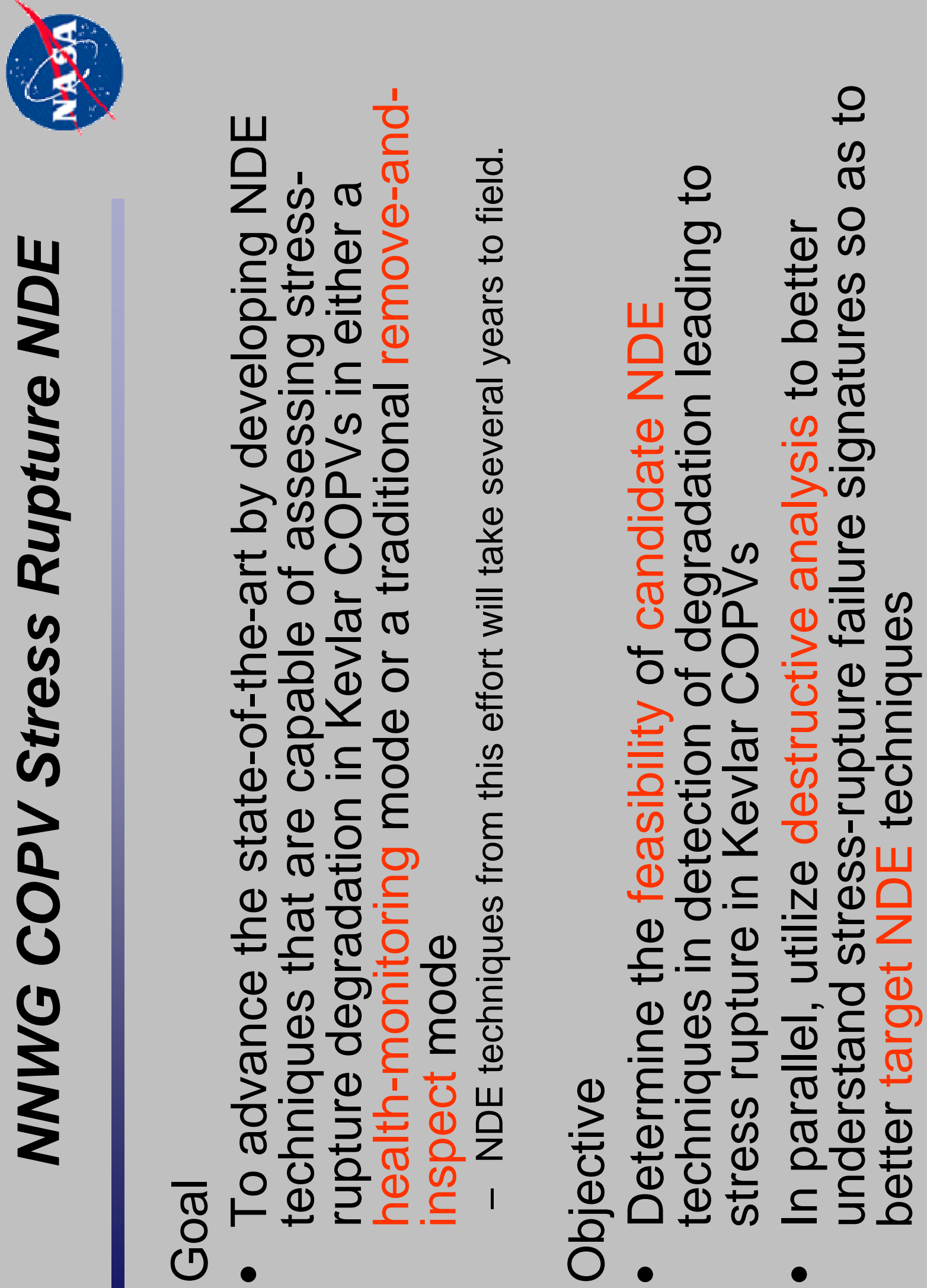


ह

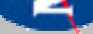

2

下

苑

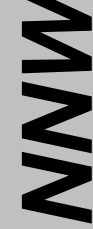

○

U

$\bar{\sigma}$

$\because$

吾

트를 줄

川 0 얼

๘ั山

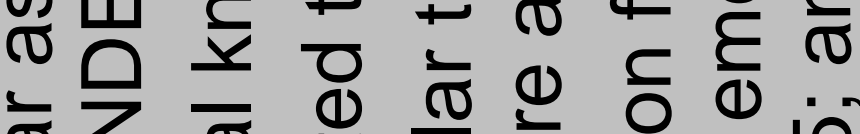

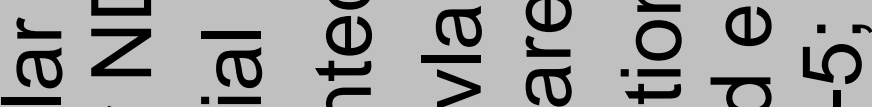

>

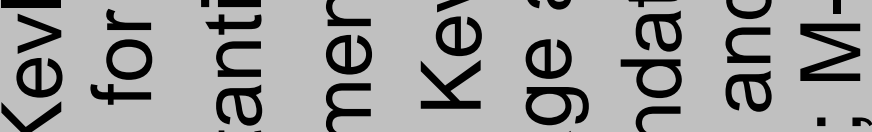

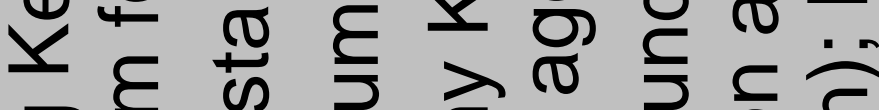

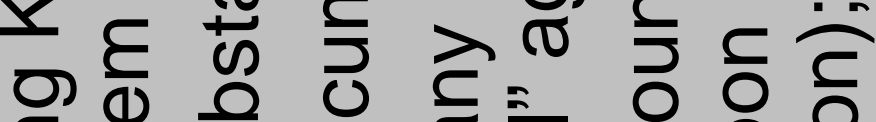

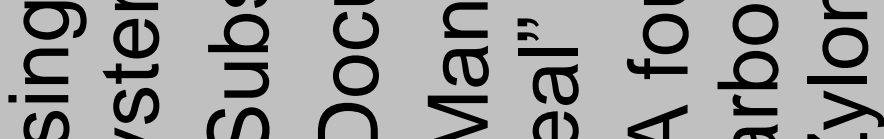

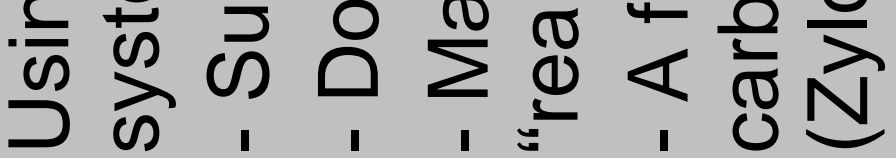

n

仓ั

ज $\frac{\sigma}{x} 0$

(4)

\pm 0 б

$\overline{\widetilde{\sigma}} \pm \frac{0}{\square}$

잉

(1)

जิ 虫

$\div$ (1)

ส

> $=$

य) $\bar{\Sigma}$

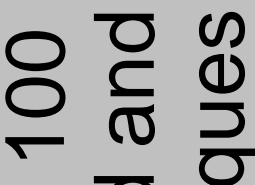

능 엉 을

드은

을 원

宁

긍들

을

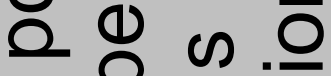

늘

巴)

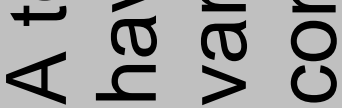




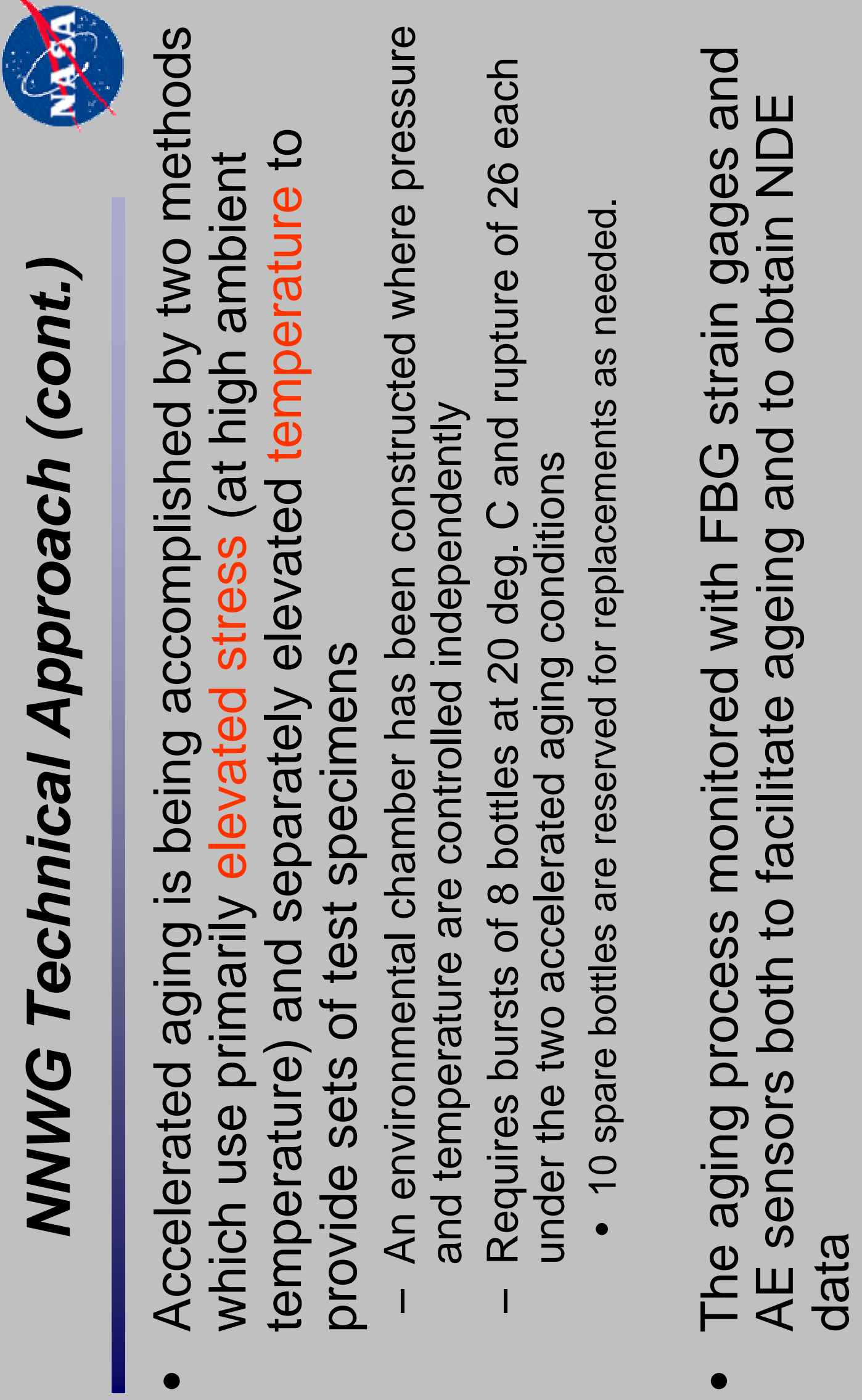




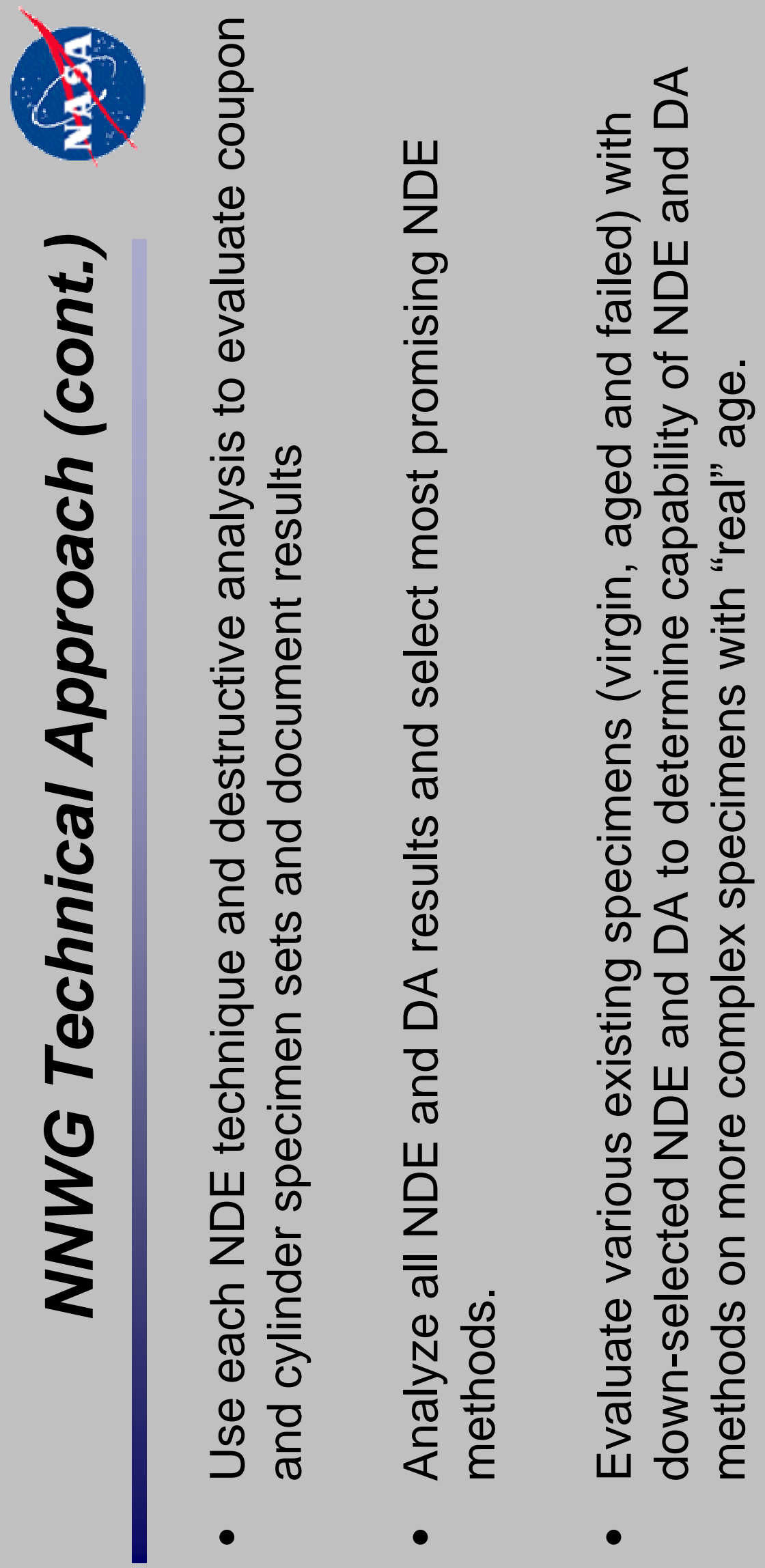




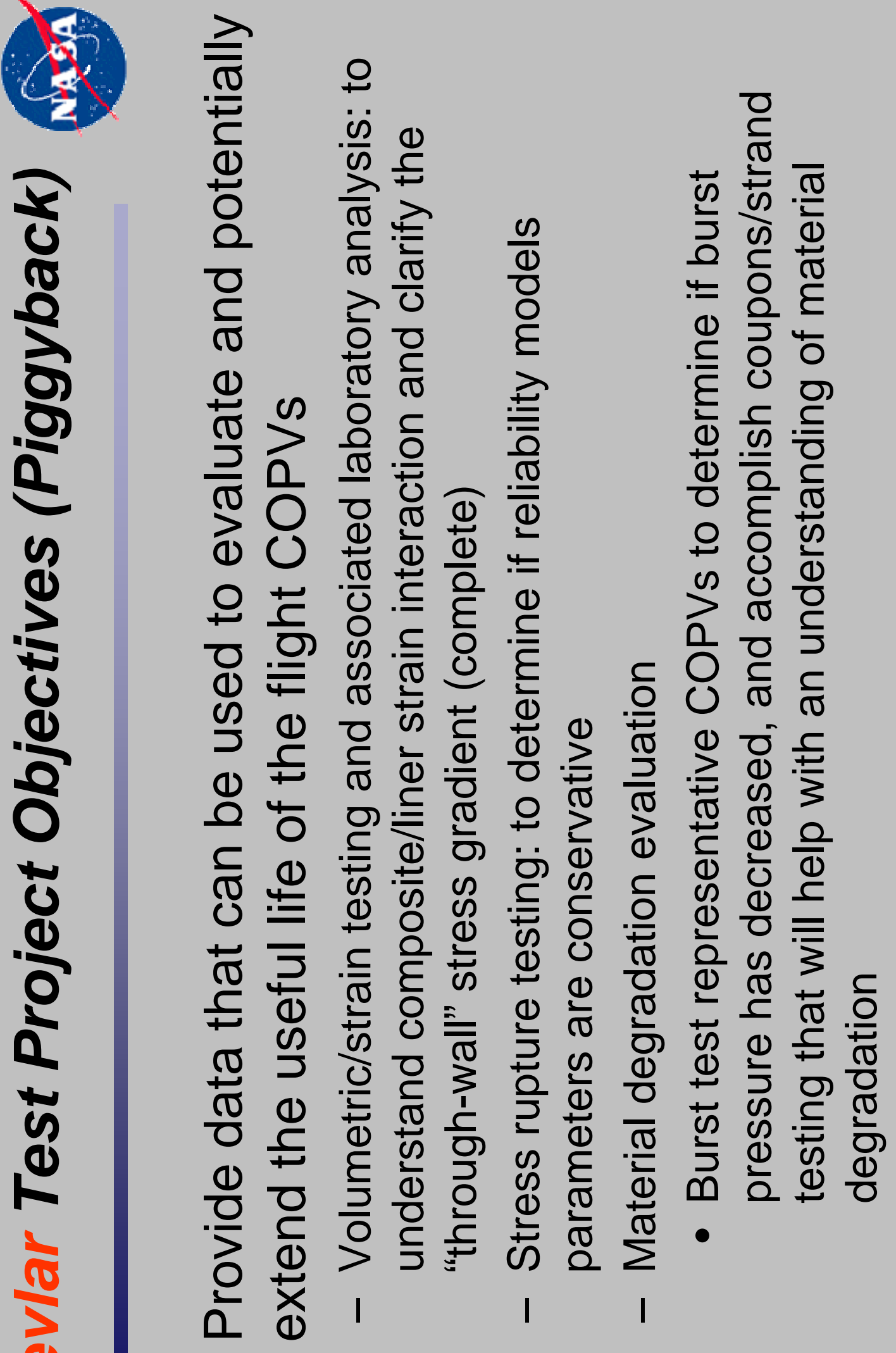




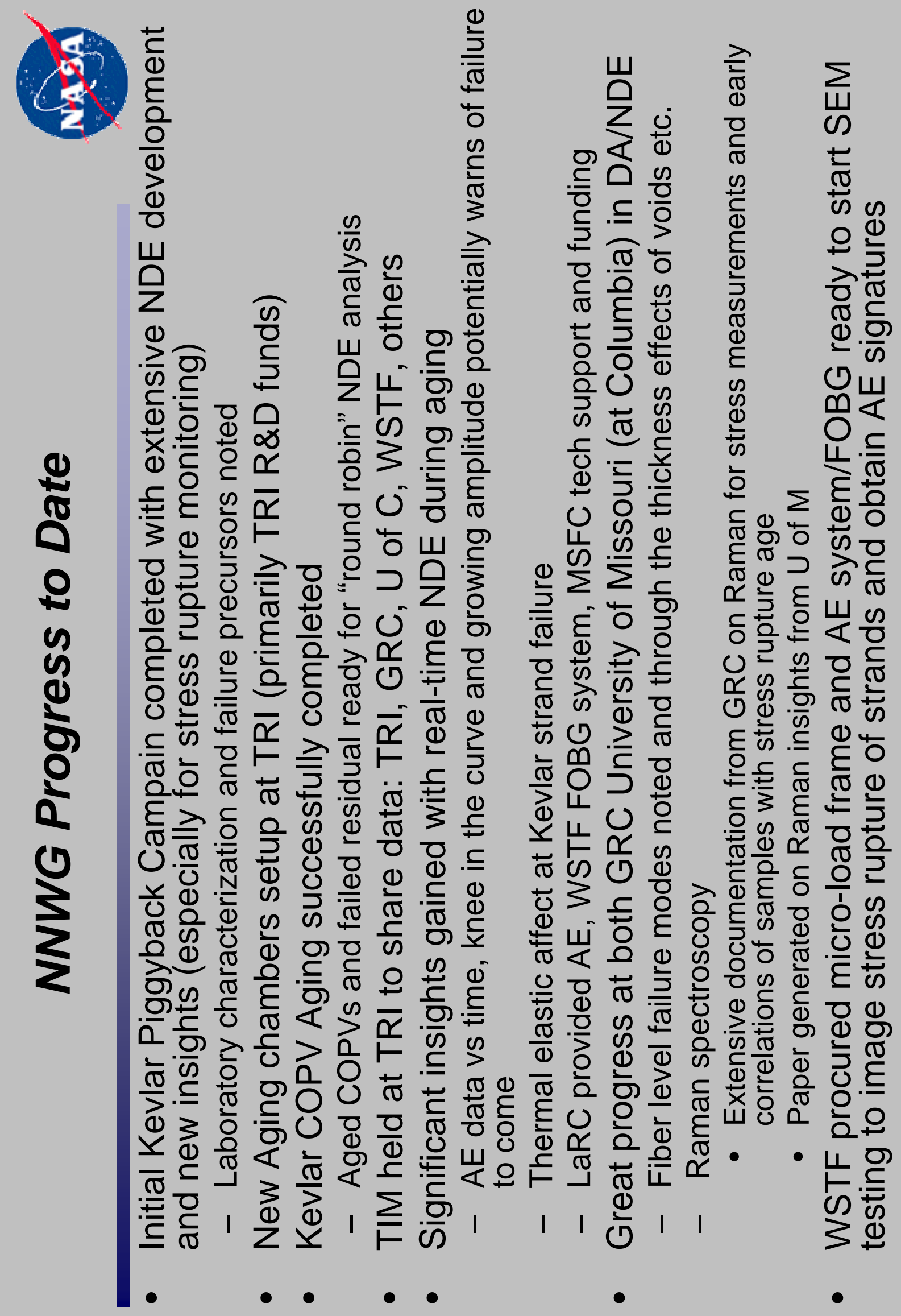




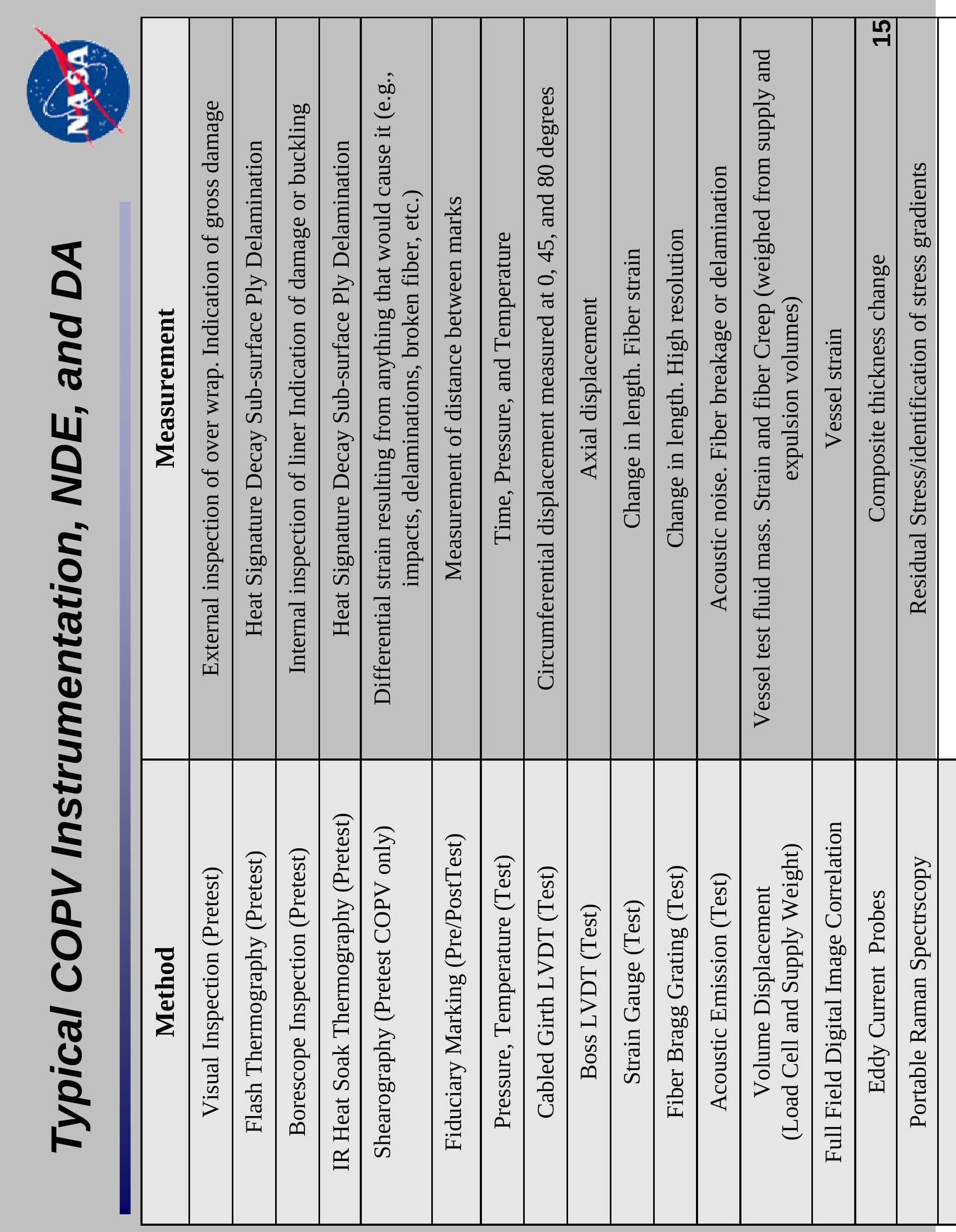




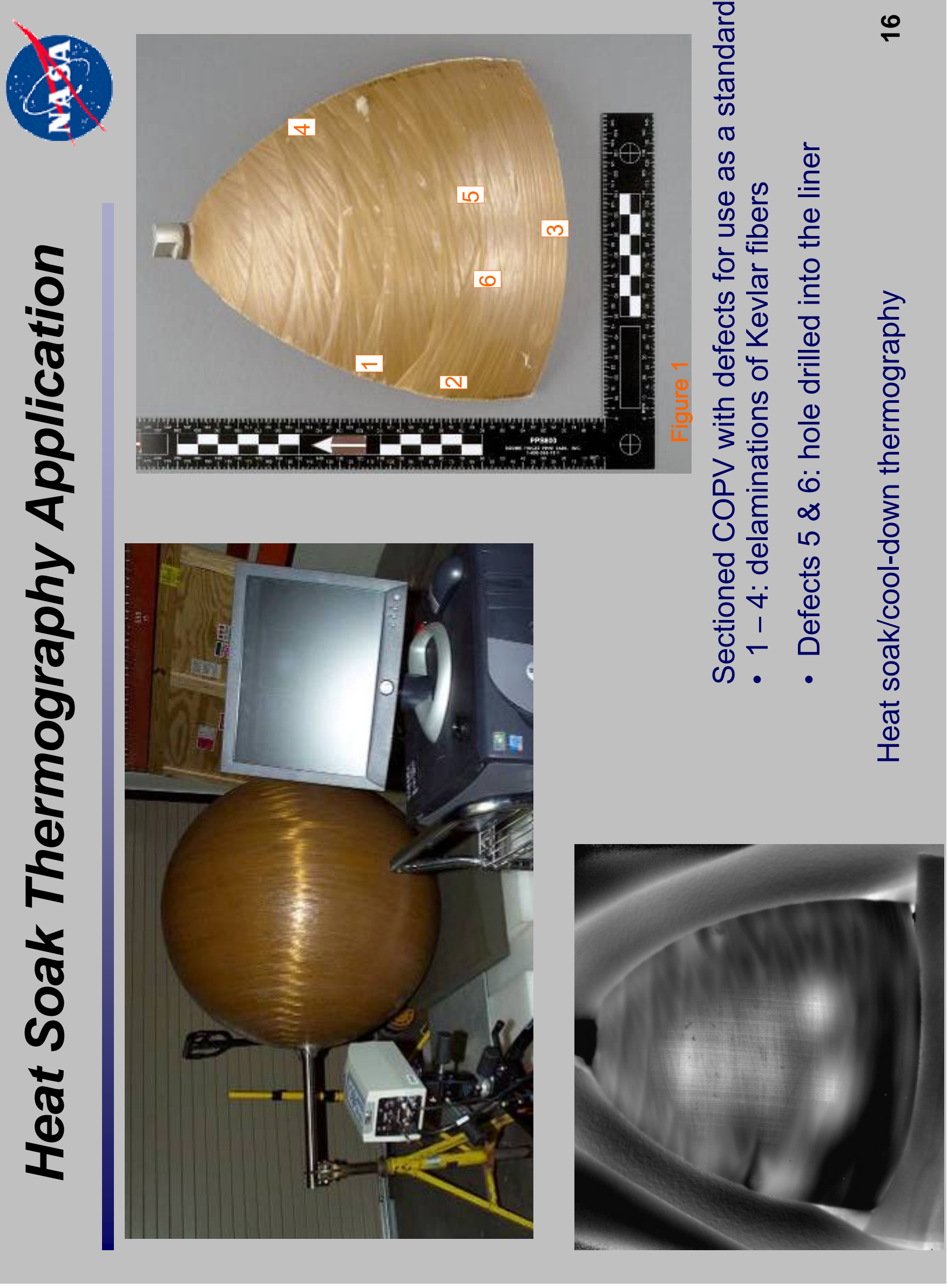




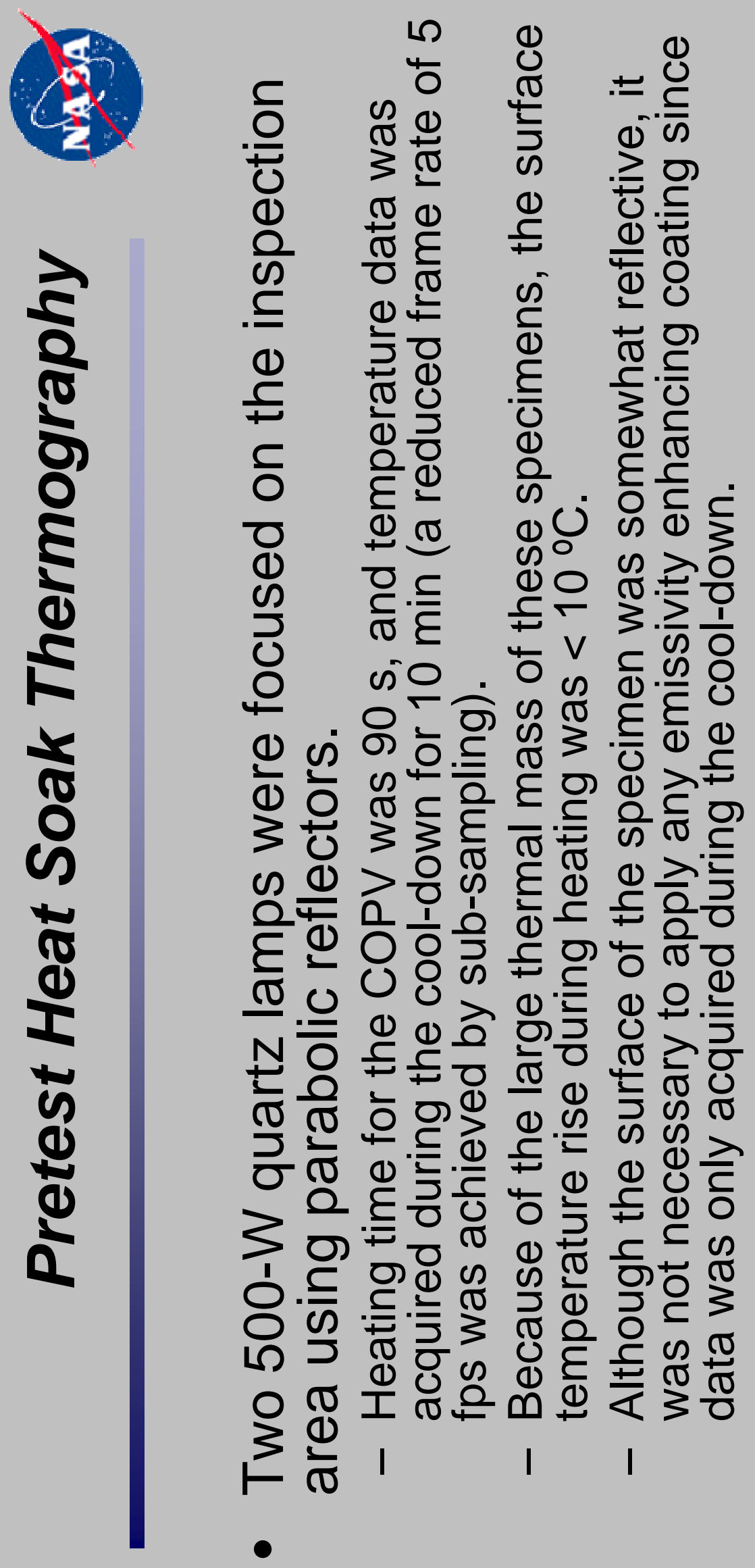



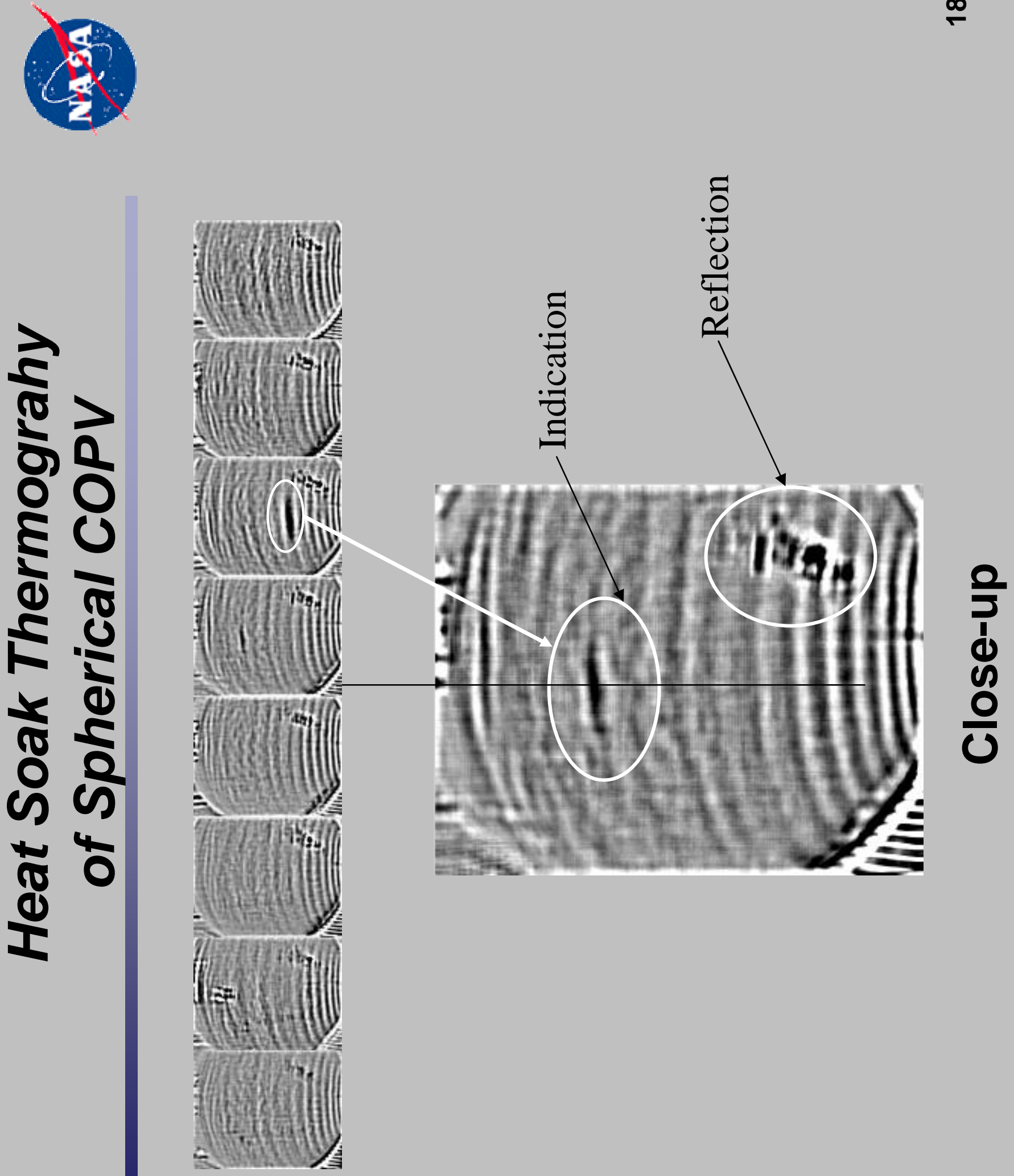

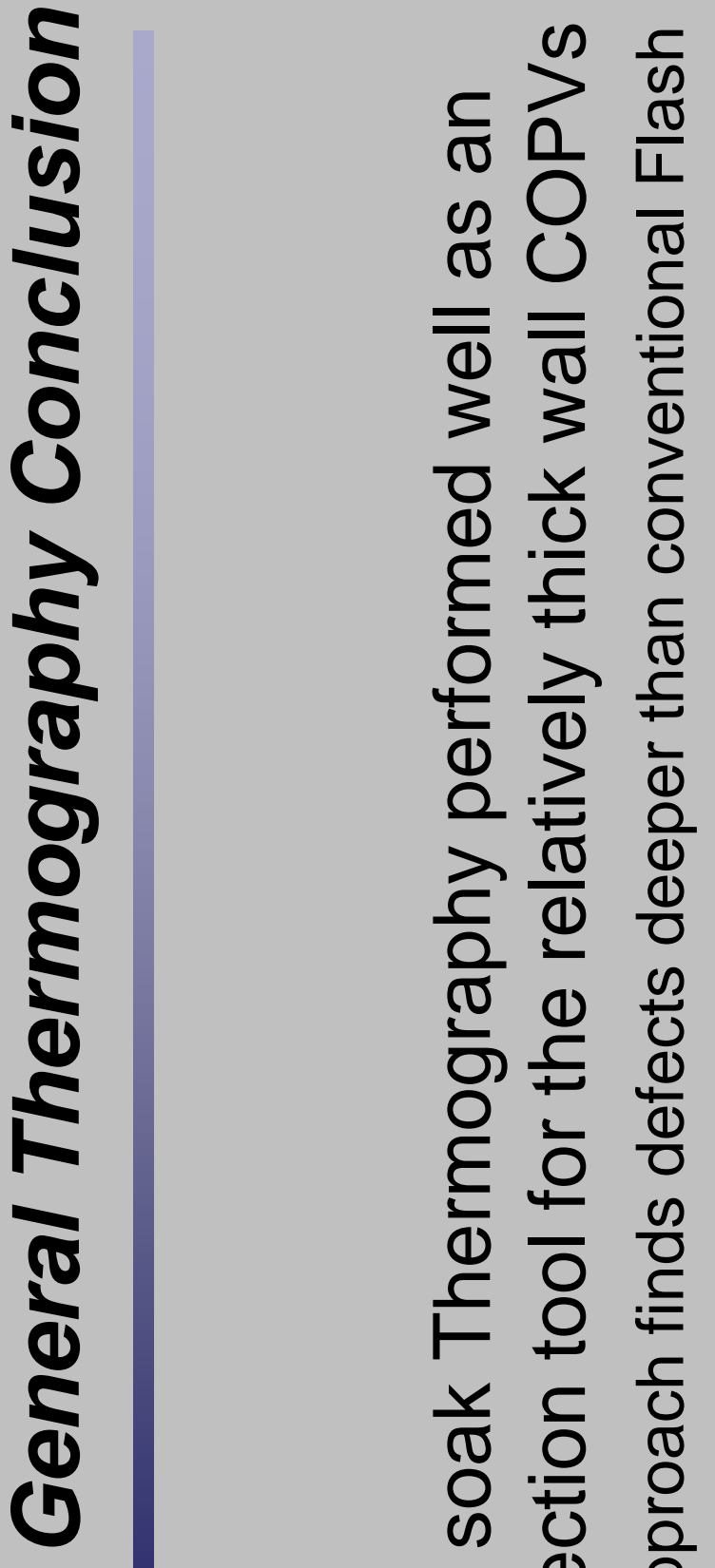

ऐ) $\overline{\frac{\sigma}{3}}$

원

过

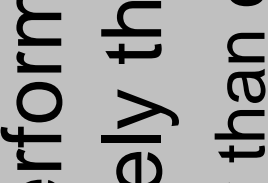

ब(ํ)

르잉

중 ब

음

(1)

ర뒁

$0 \div \frac{4}{0}$

हें 음

高

흥

สิ

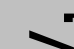

ह

잉

진

응

สั ป

ज $\frac{1}{0}$

○ 증 ठ

인 $\stackrel{\frac{0}{\sigma}}{\text { जी }}$

$\forall$ 등ㅎㅇ

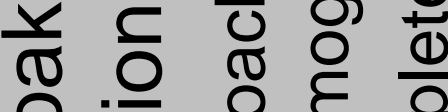

융 응 है

떠응

б

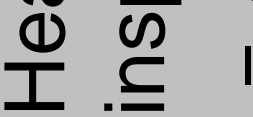

ठ

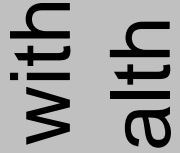

들

$\subseteq \frac{ᄃ}{\sigma}$

이

药 充

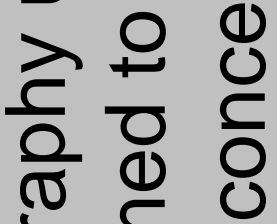

잉 $\frac{1}{0}$

든 方

(1)

$\vDash \sum_{3}$ 
$\frac{2}{2}$
$\frac{\pi}{0}$
$\frac{0}{\sigma}$
$\frac{0}{5}$
$\frac{8}{0}$
0

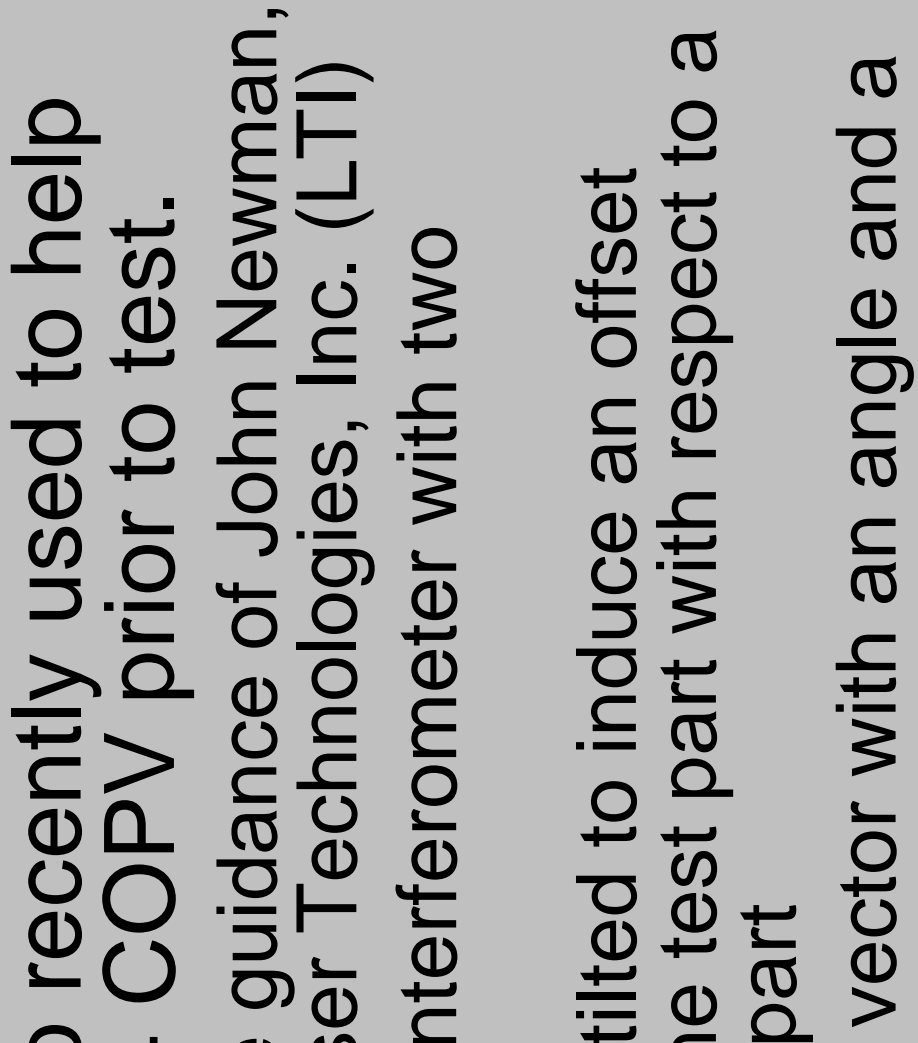

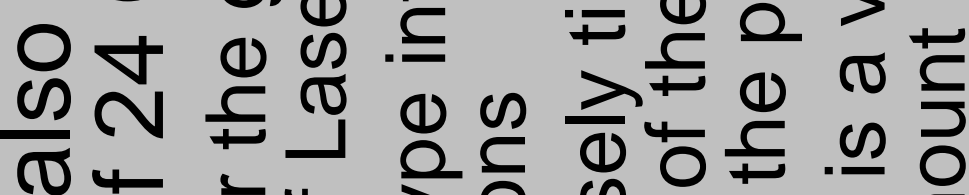
бั

元

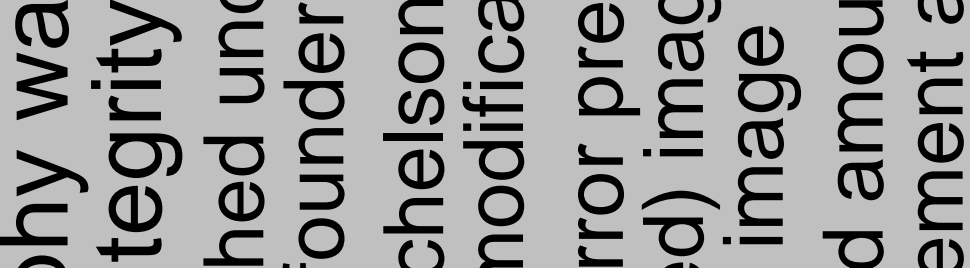

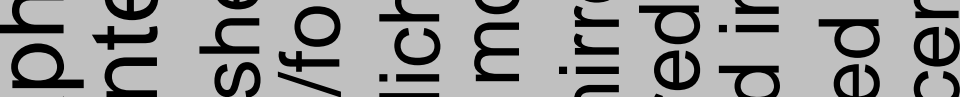

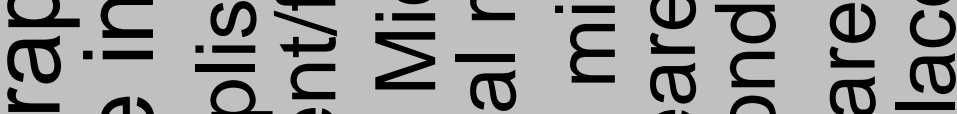

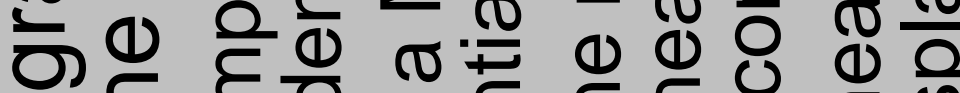

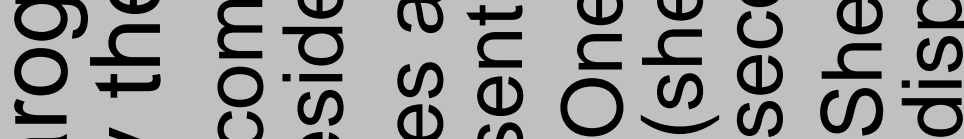

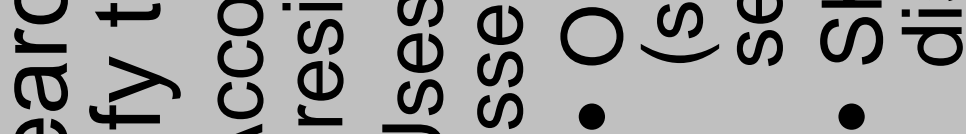
(1) 는

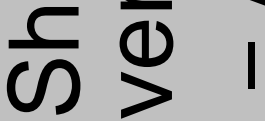




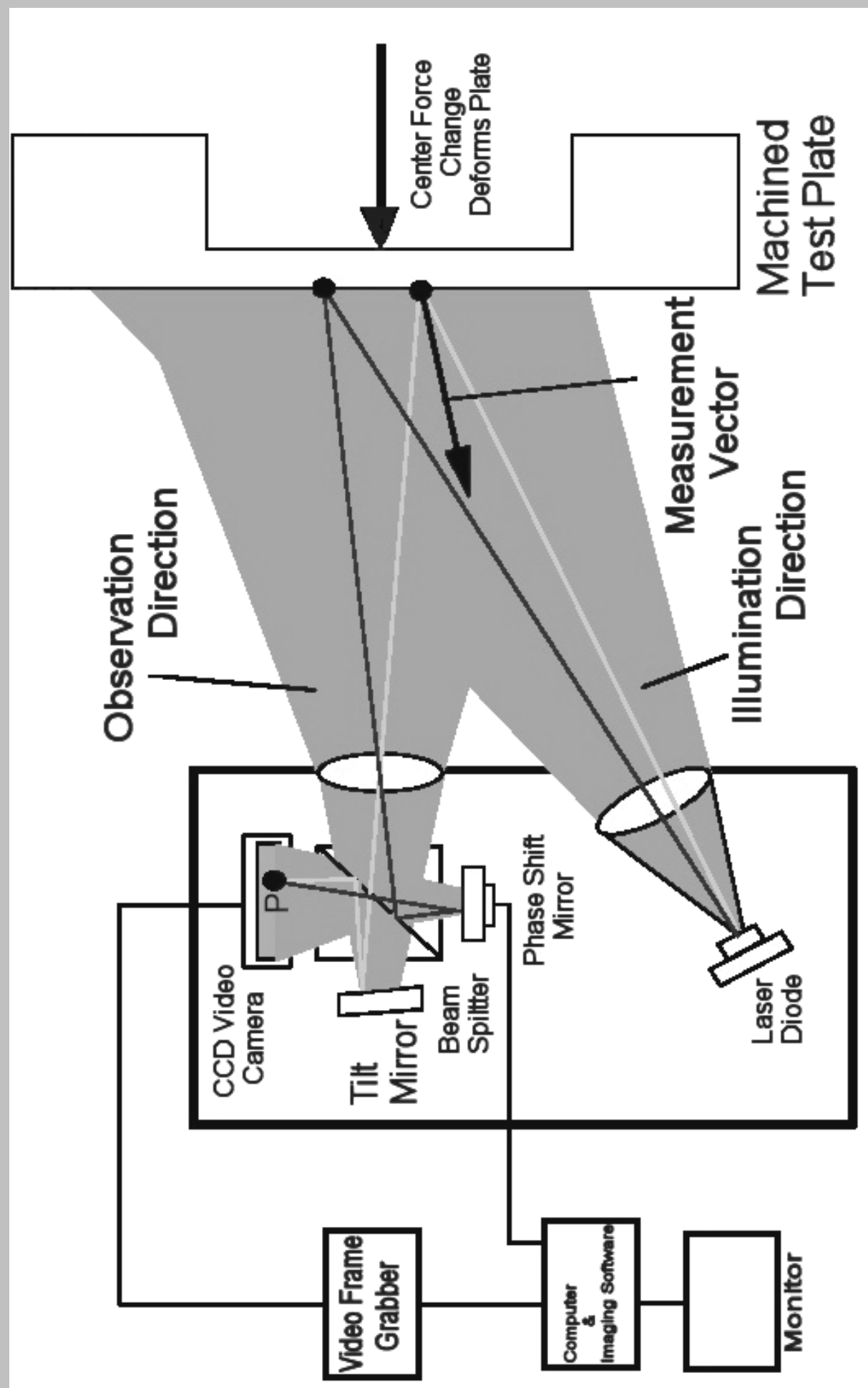



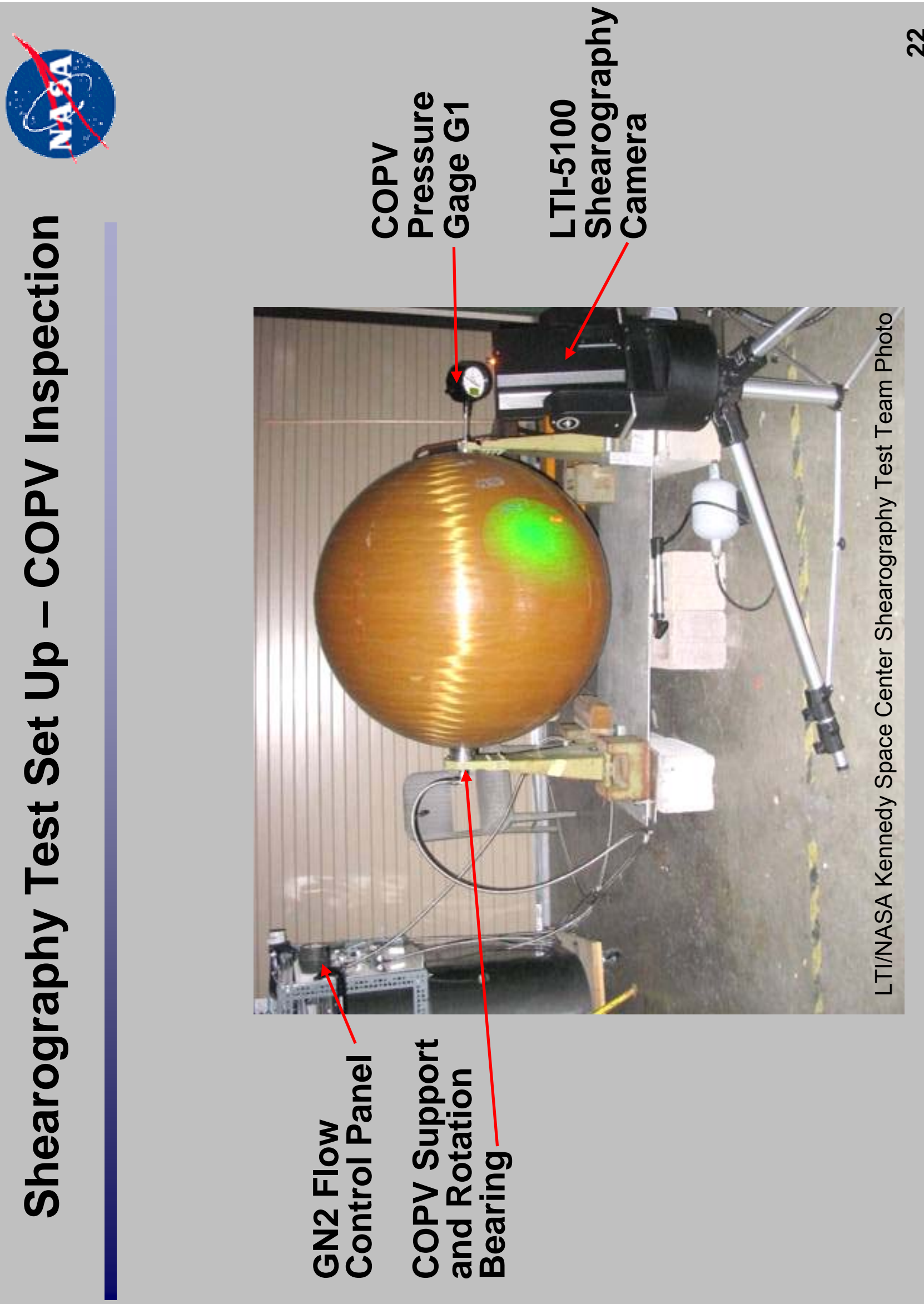


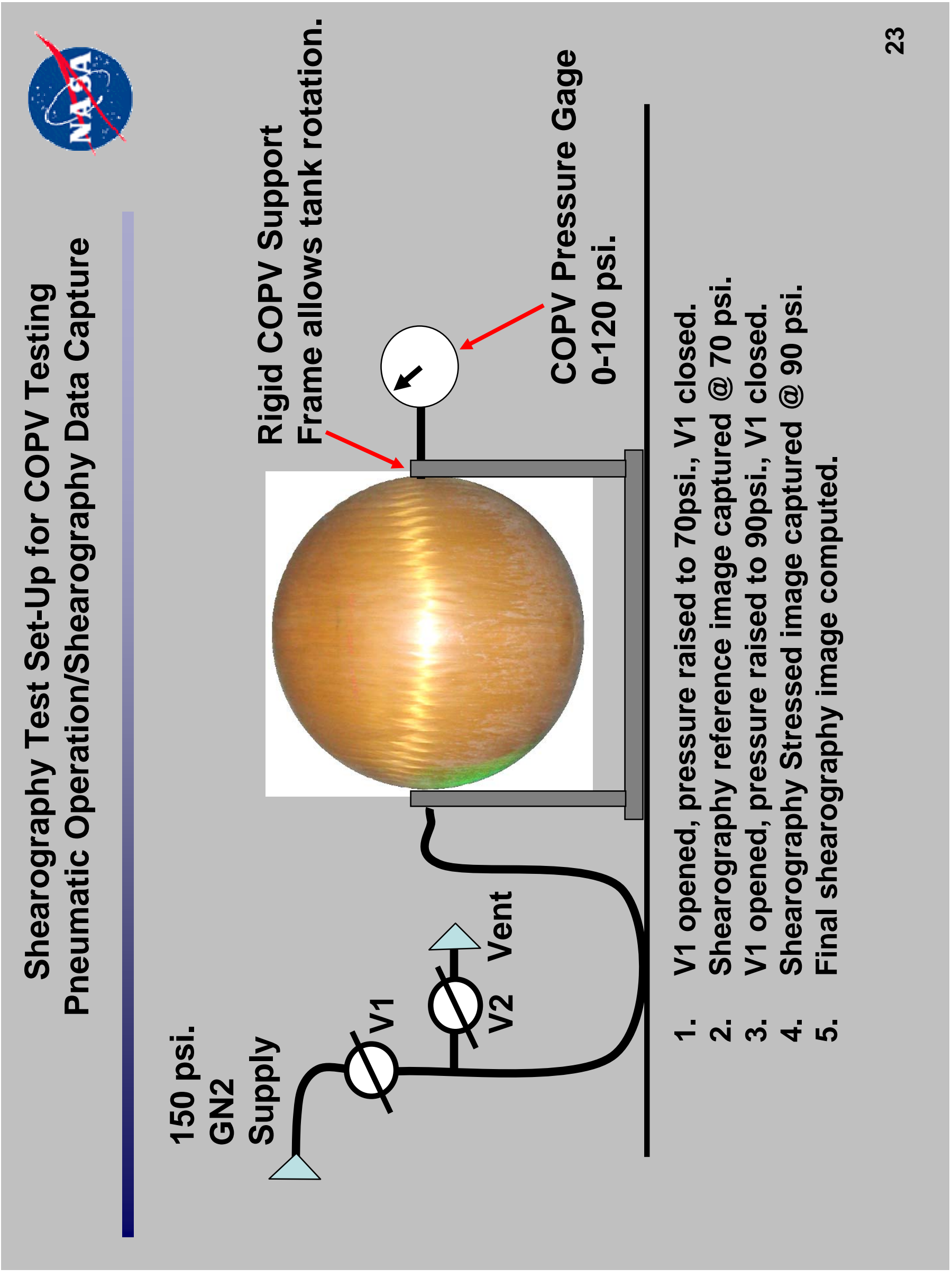




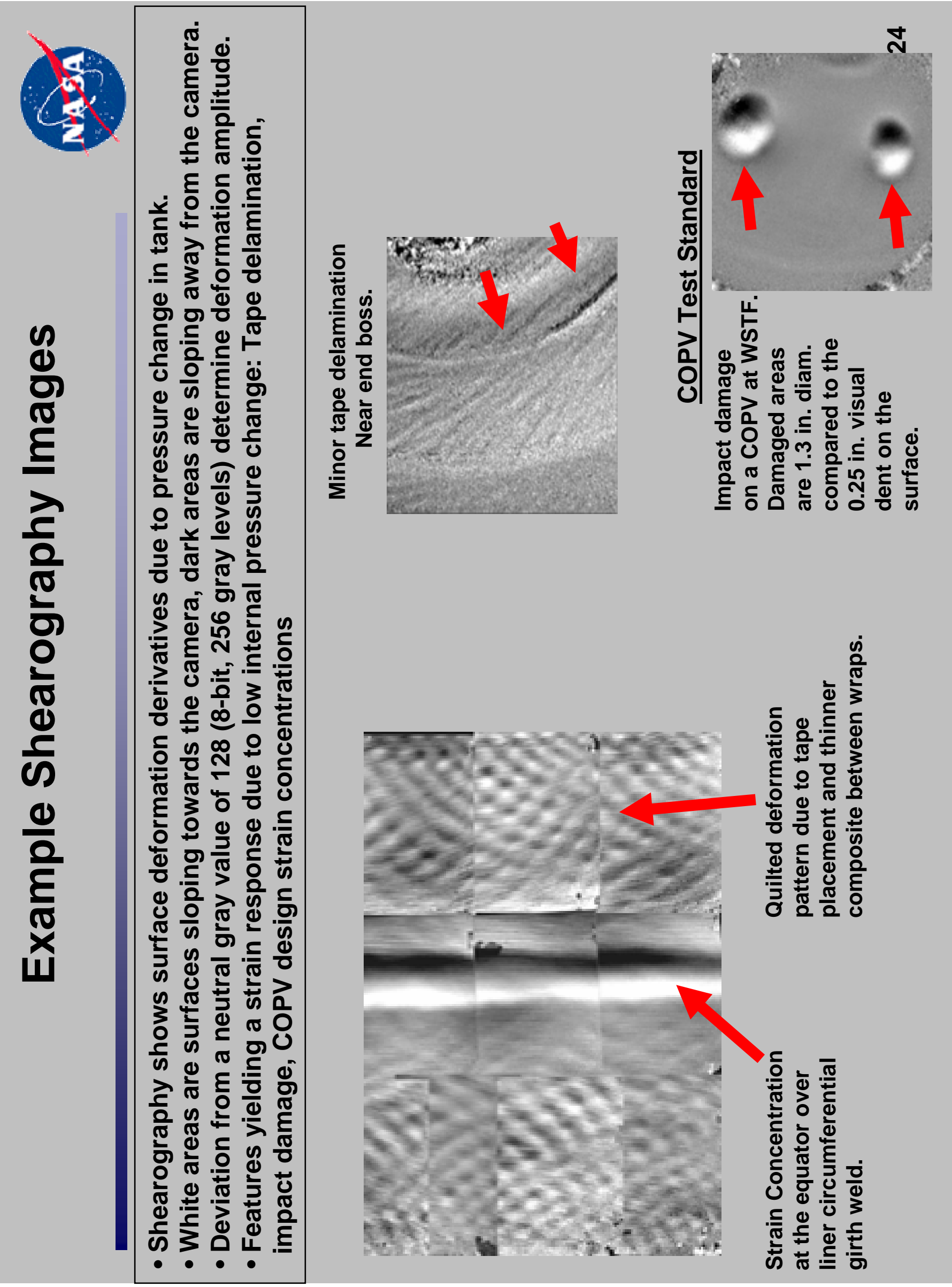




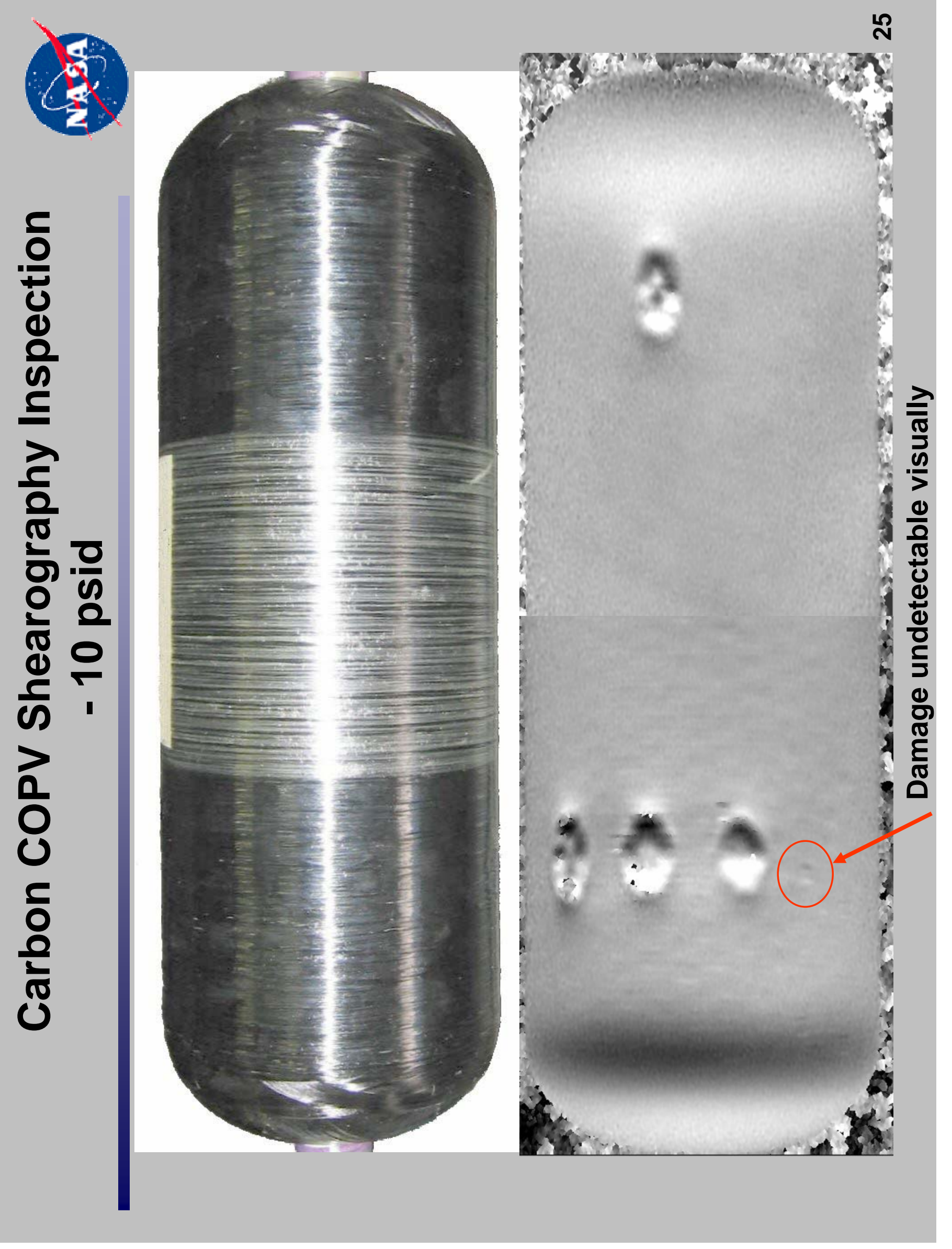




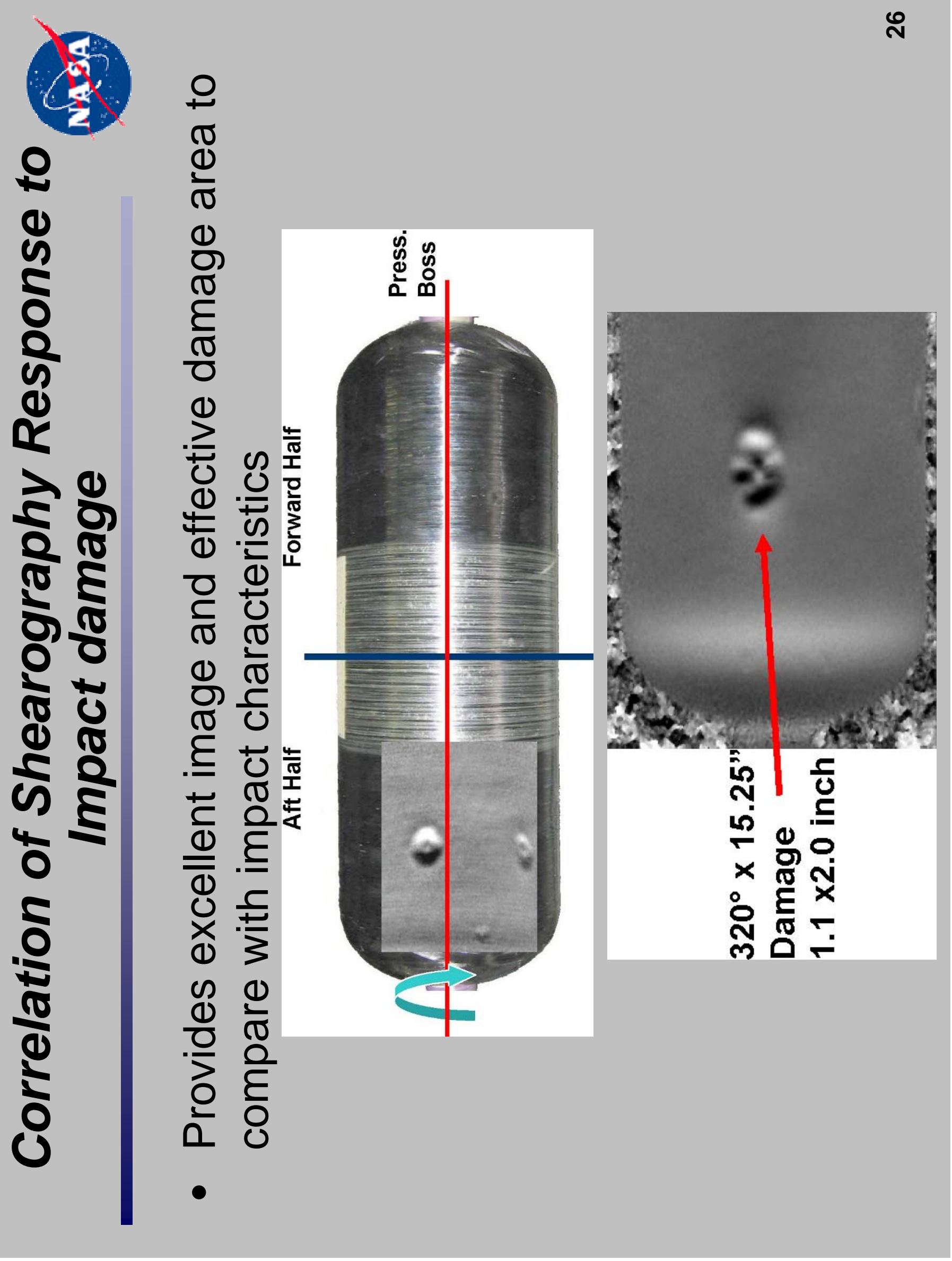



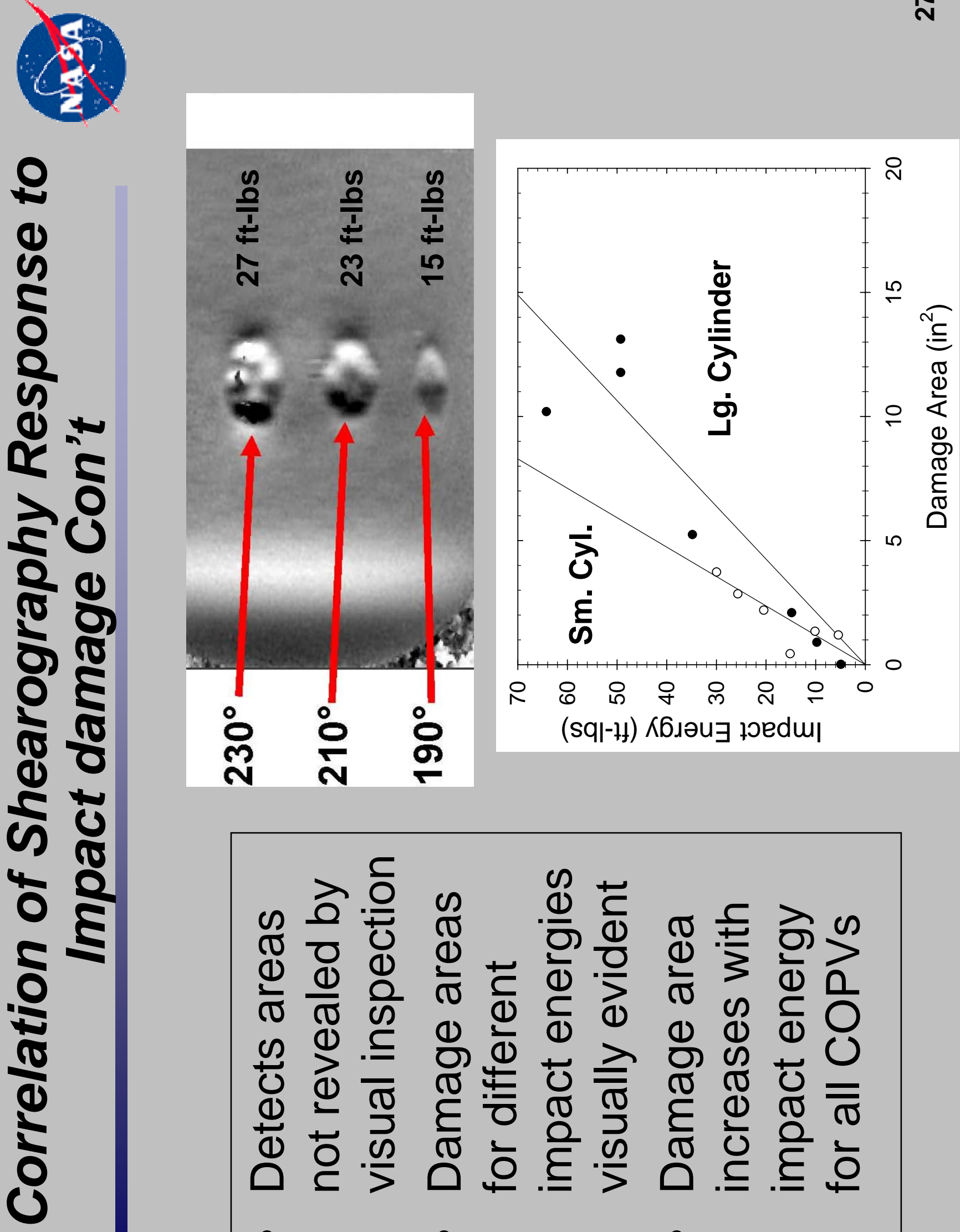

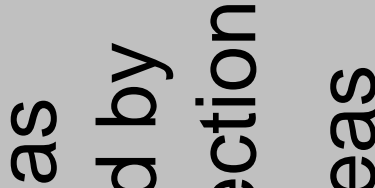
$\stackrel{\mathscr{D}}{\frac{1}{0}} \frac{1}{0}$

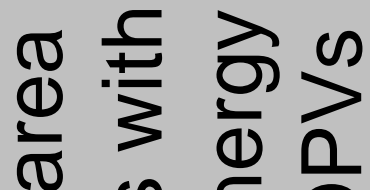

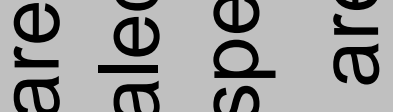
के के बे व

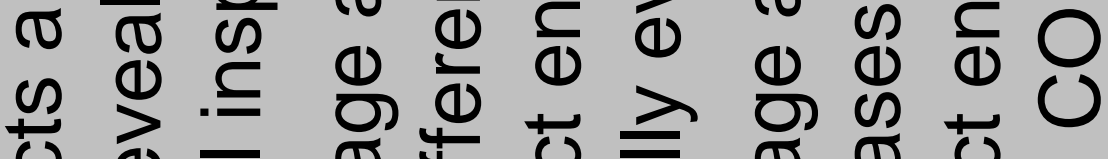
U 凹
㫕 ¿ 


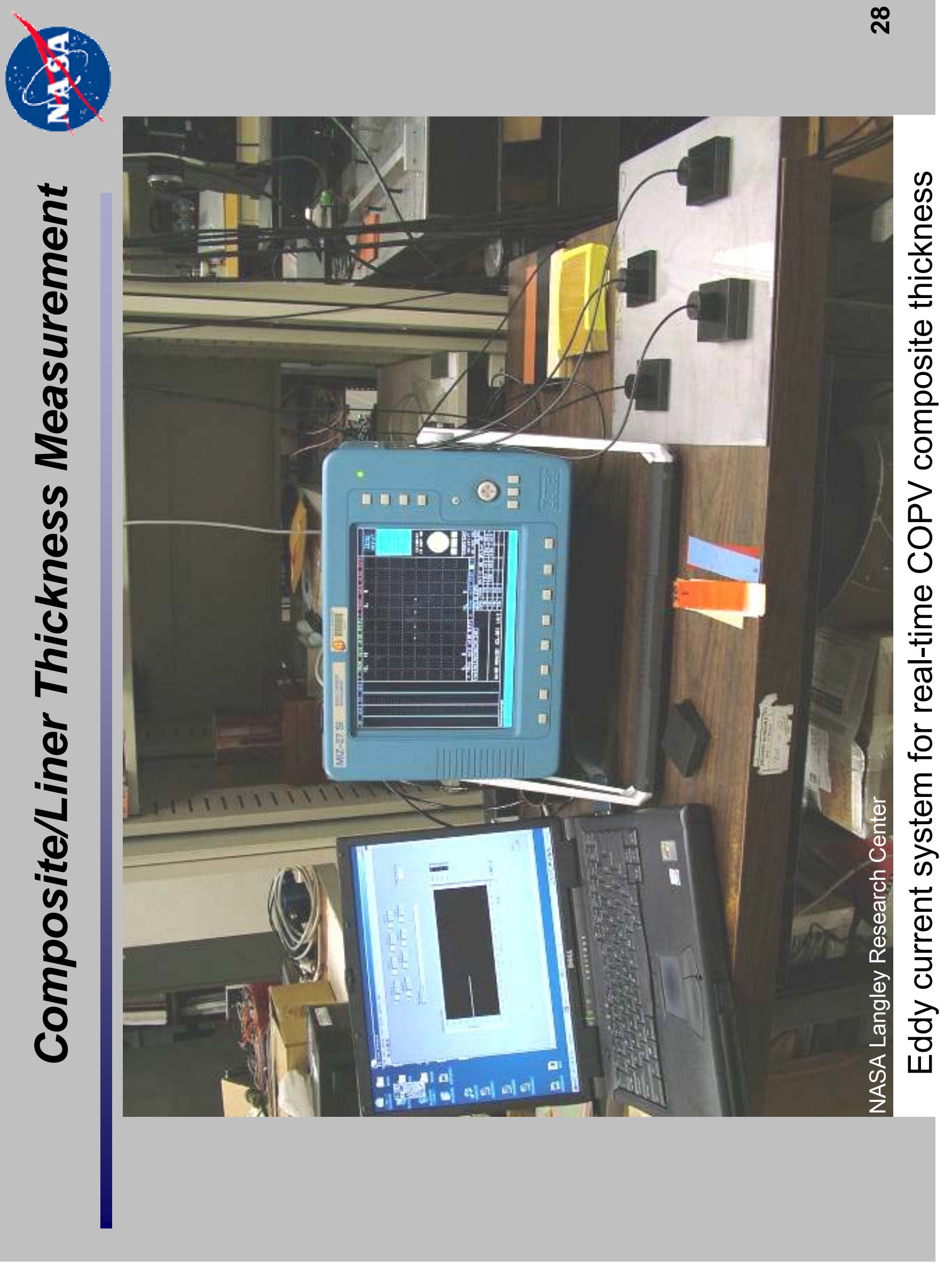




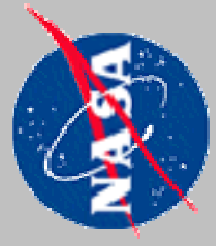

10

0

15

15

(1)

$\square$

$\geq$

10

1

1

$\checkmark$

$E$

(a)

$+$

0

$\rightarrow$

(1)

1

5

(a)

5

2

0

11 

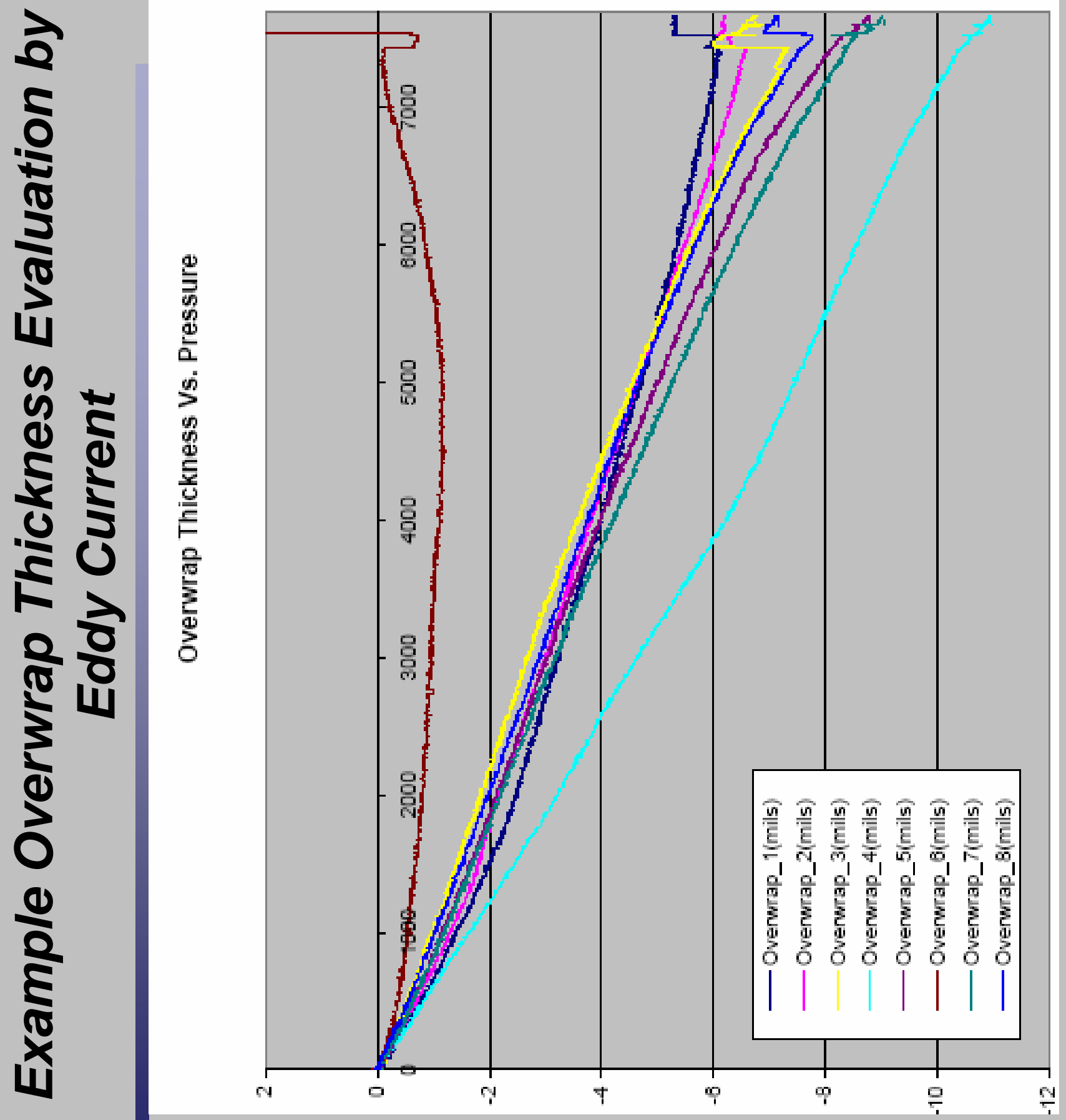

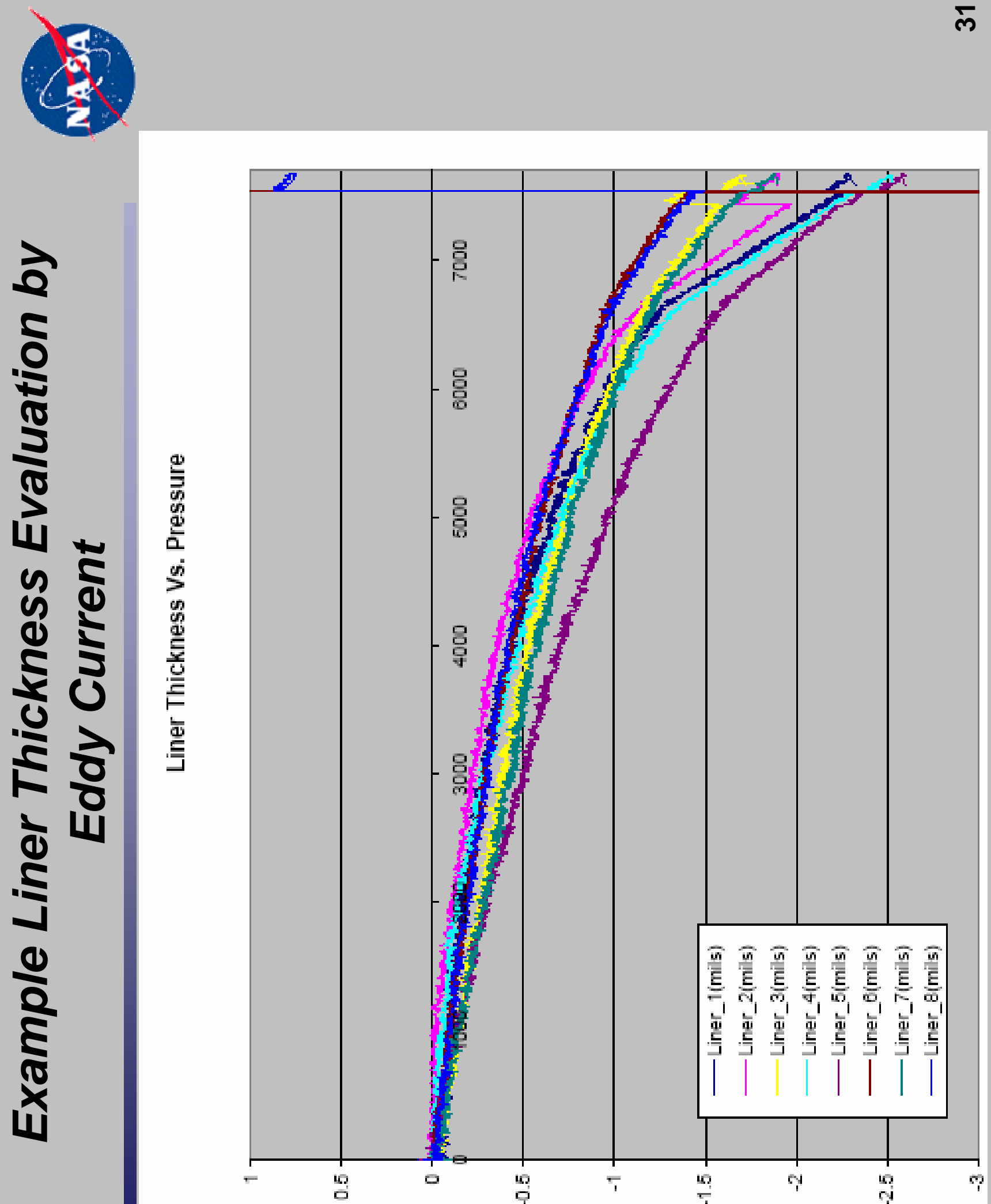


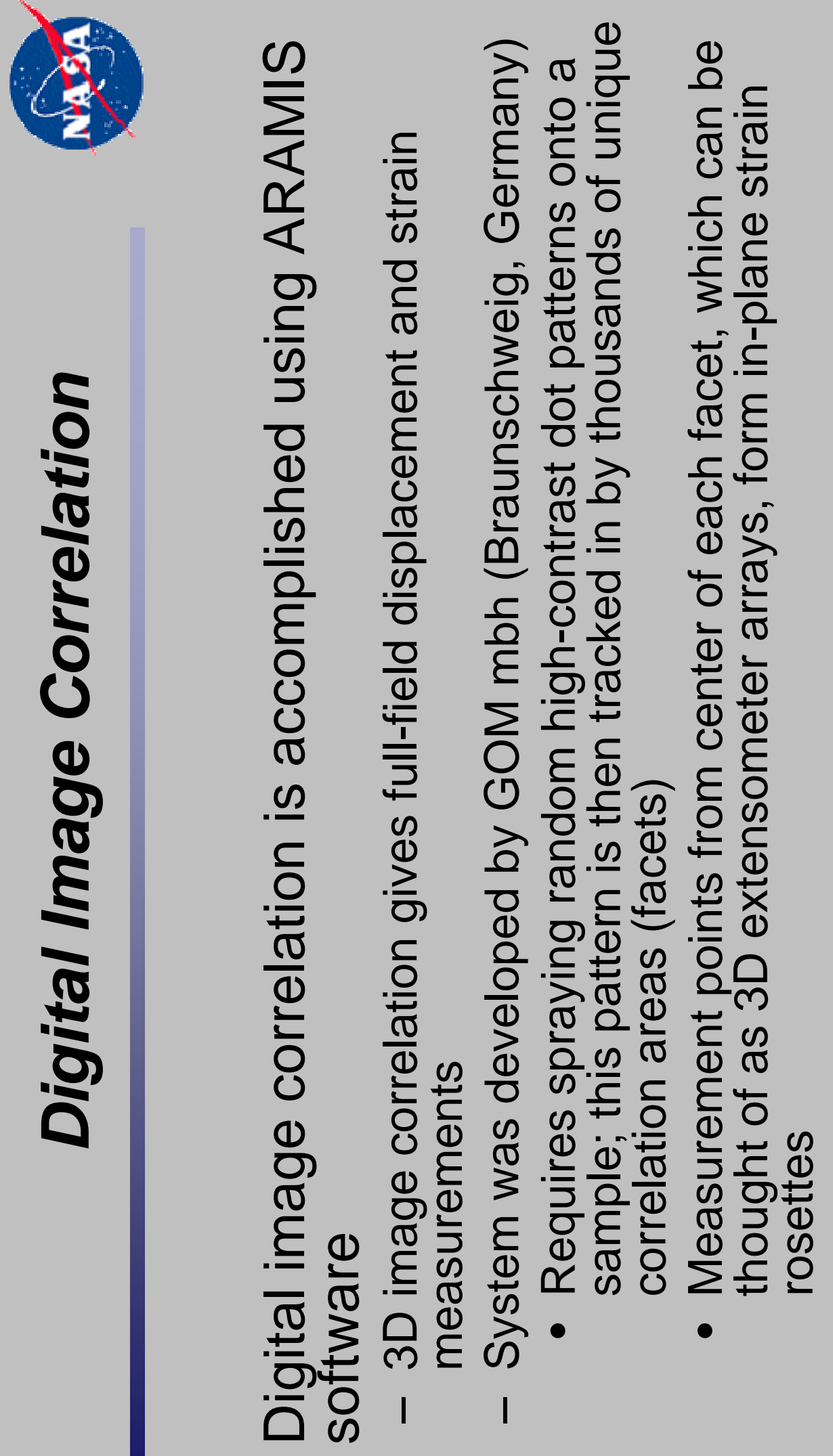




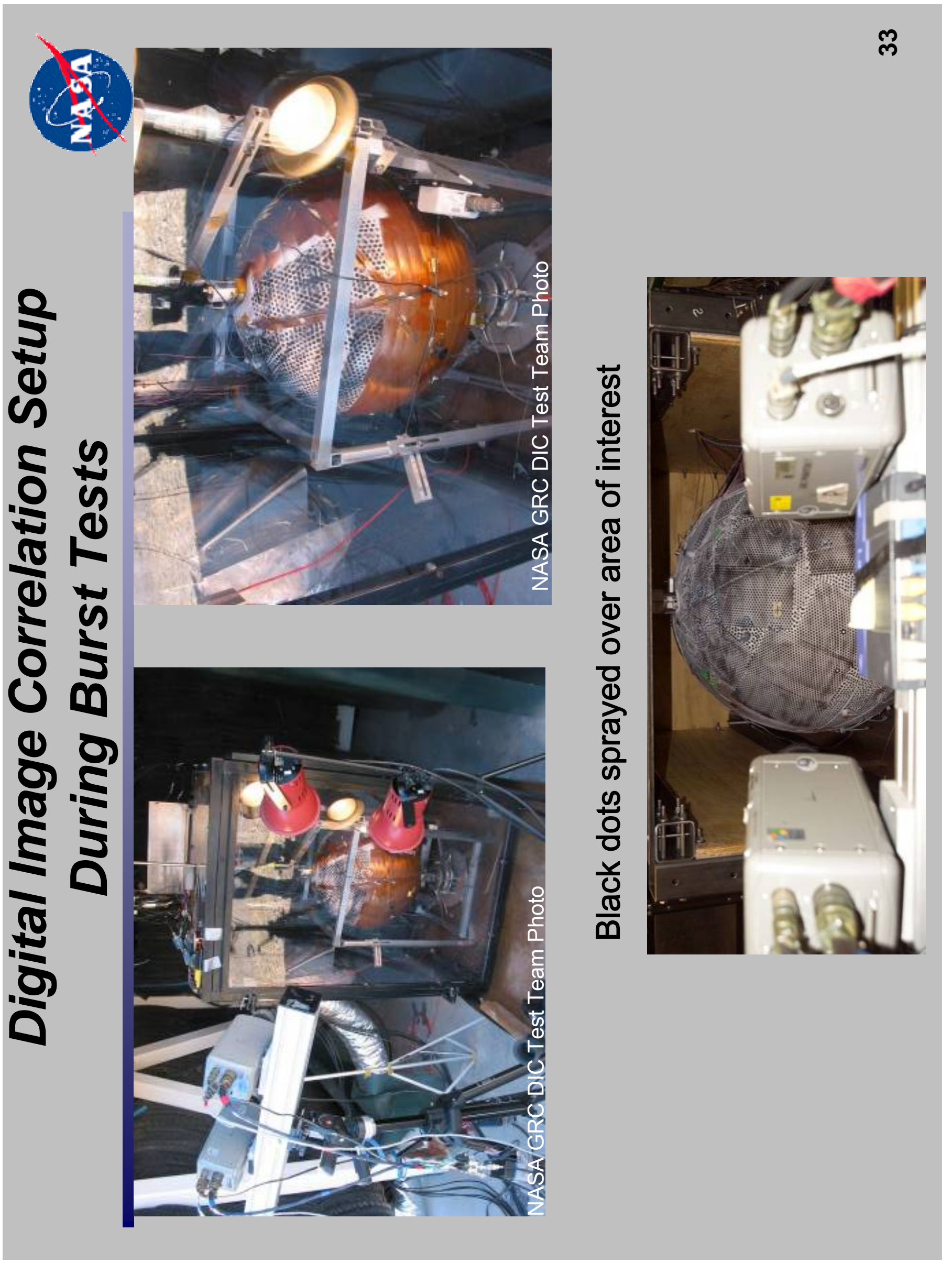




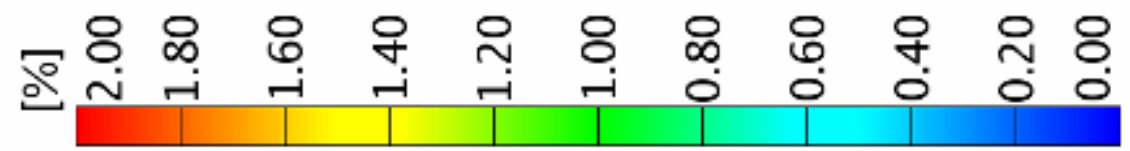
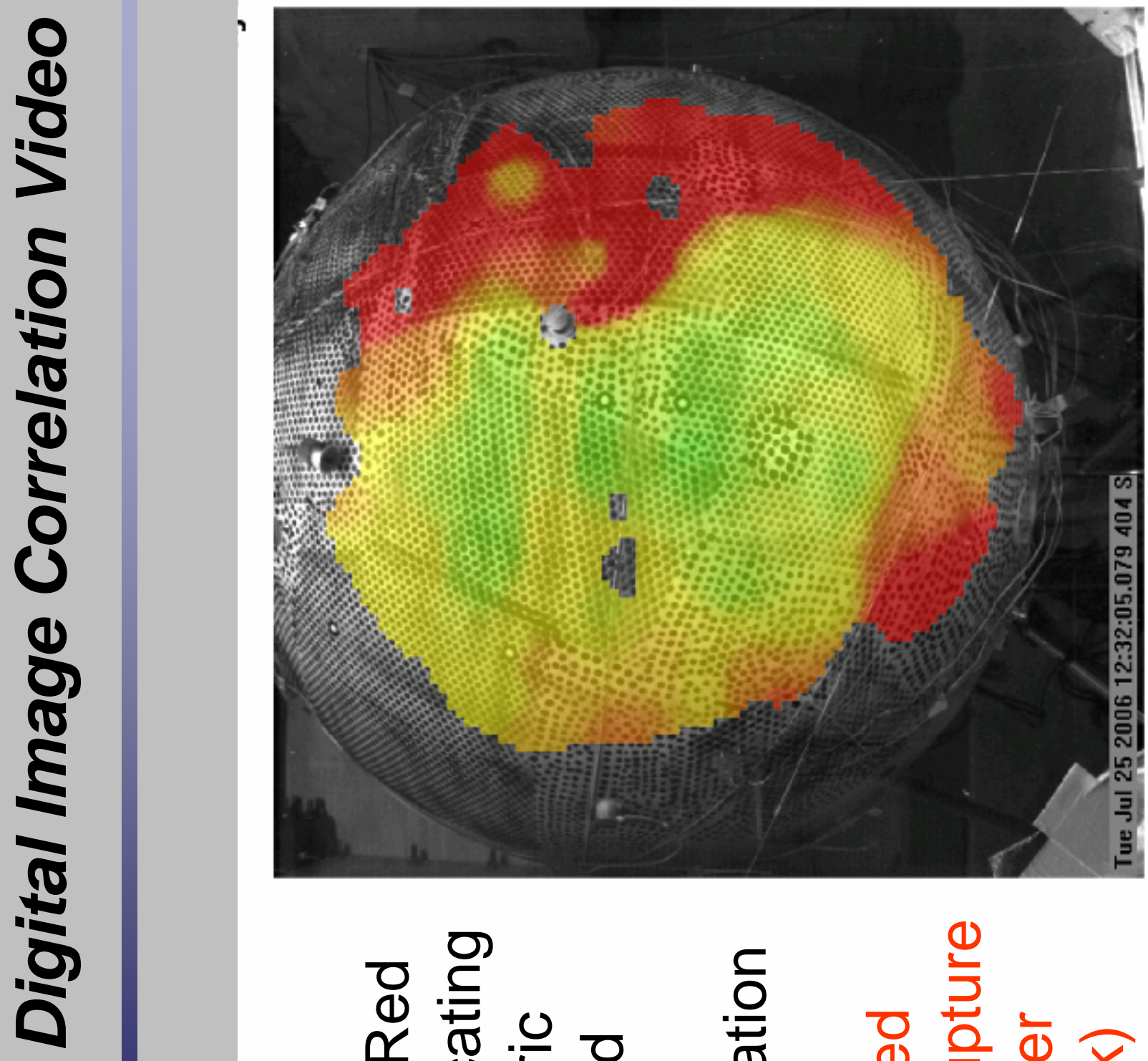

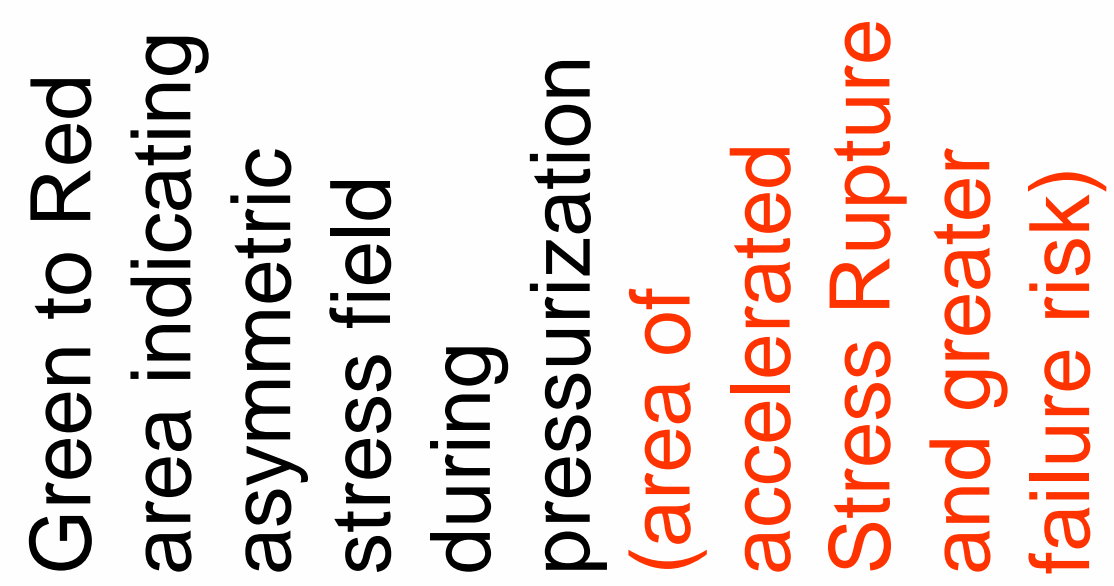



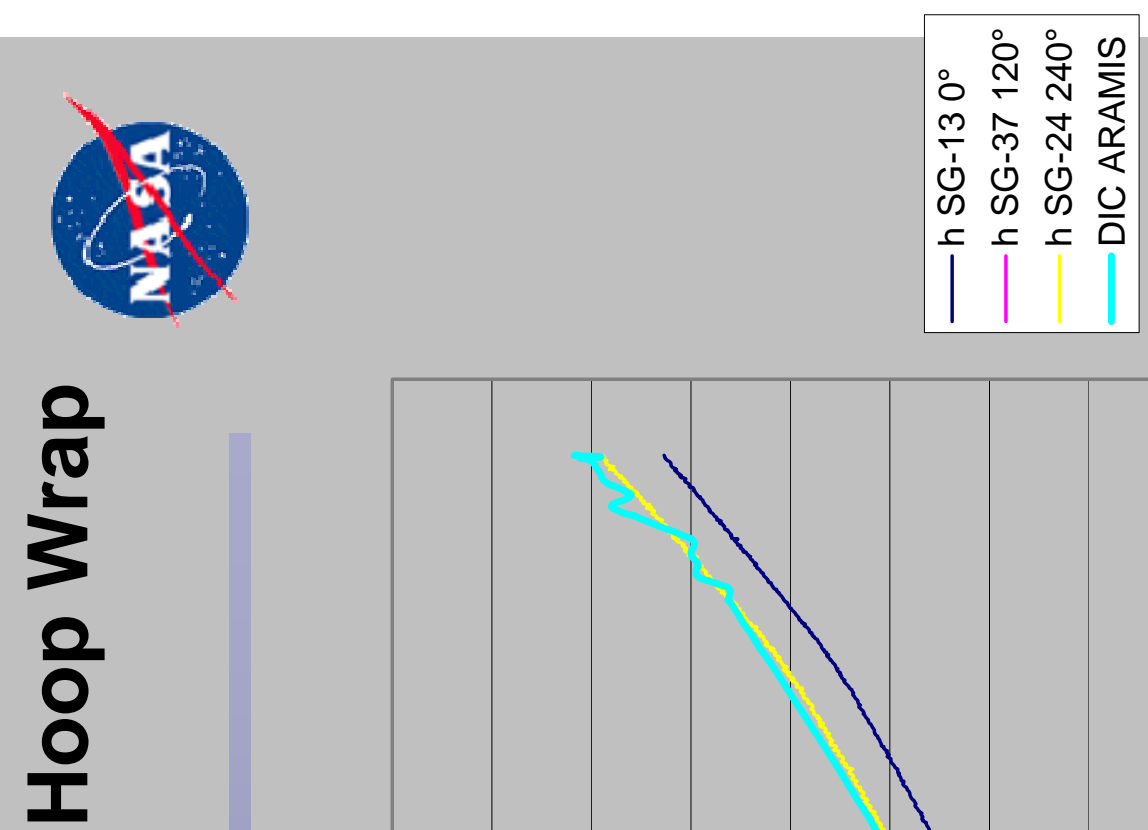

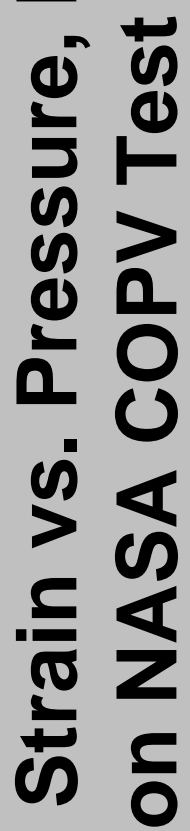

일

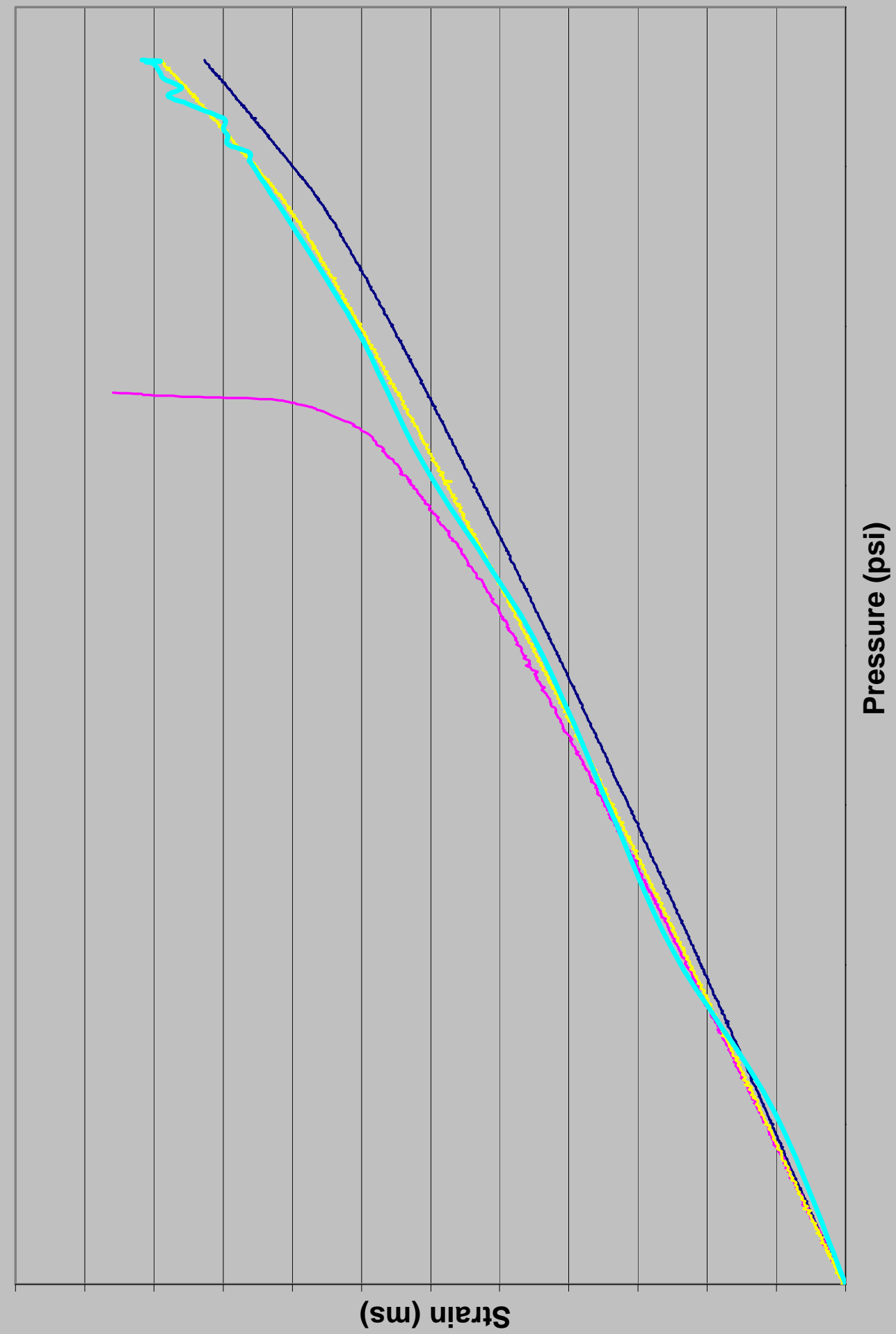



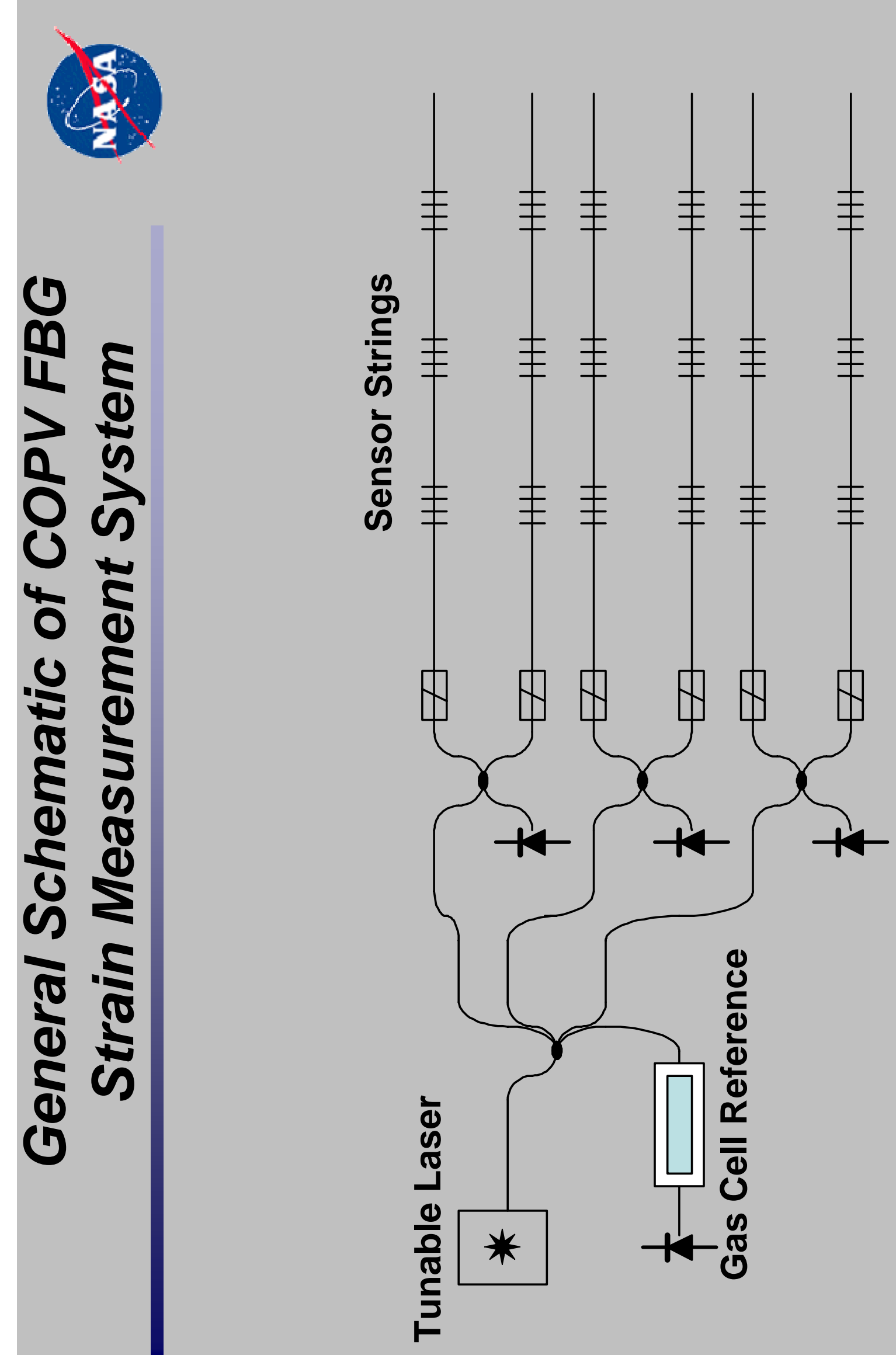


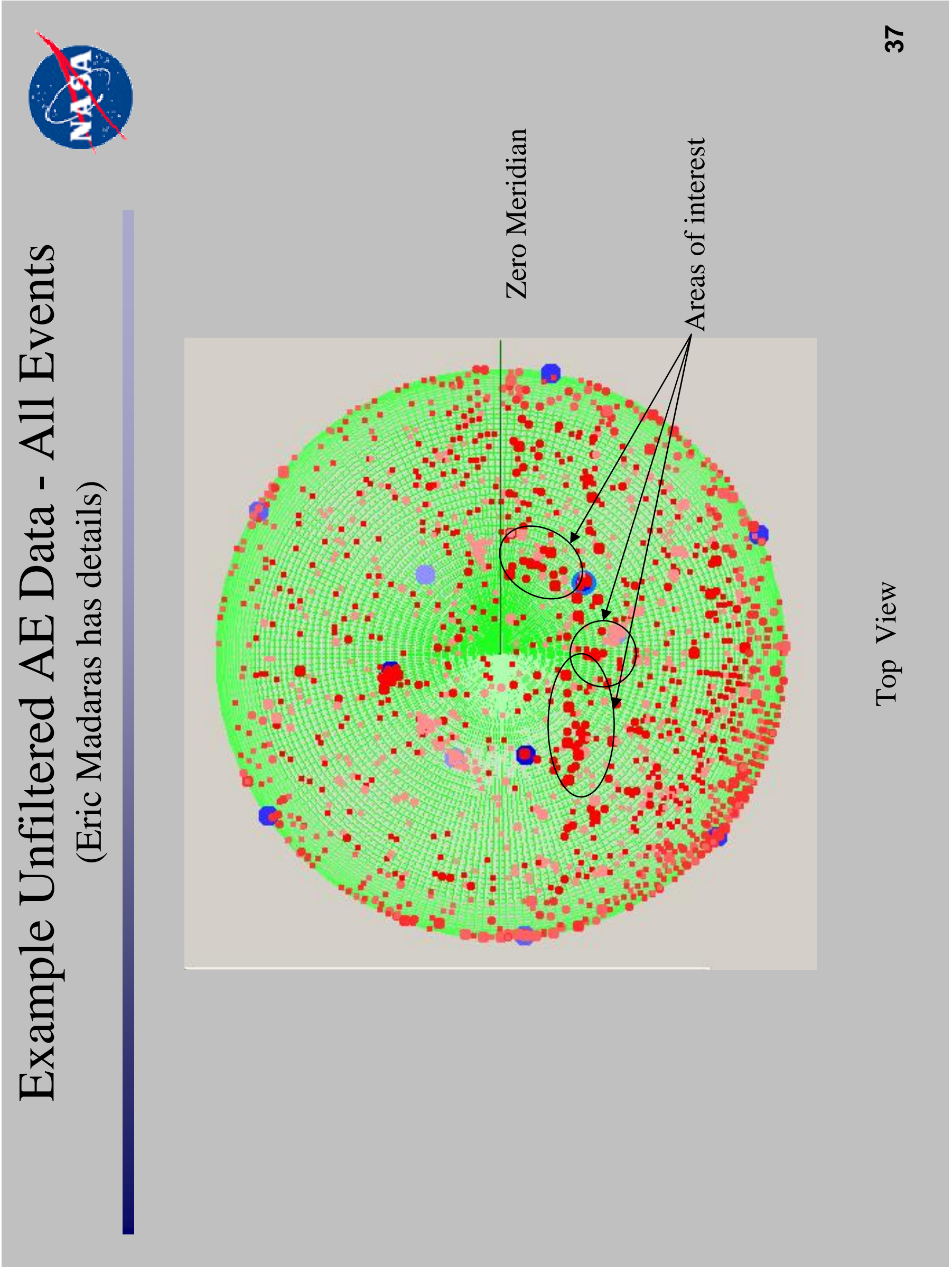



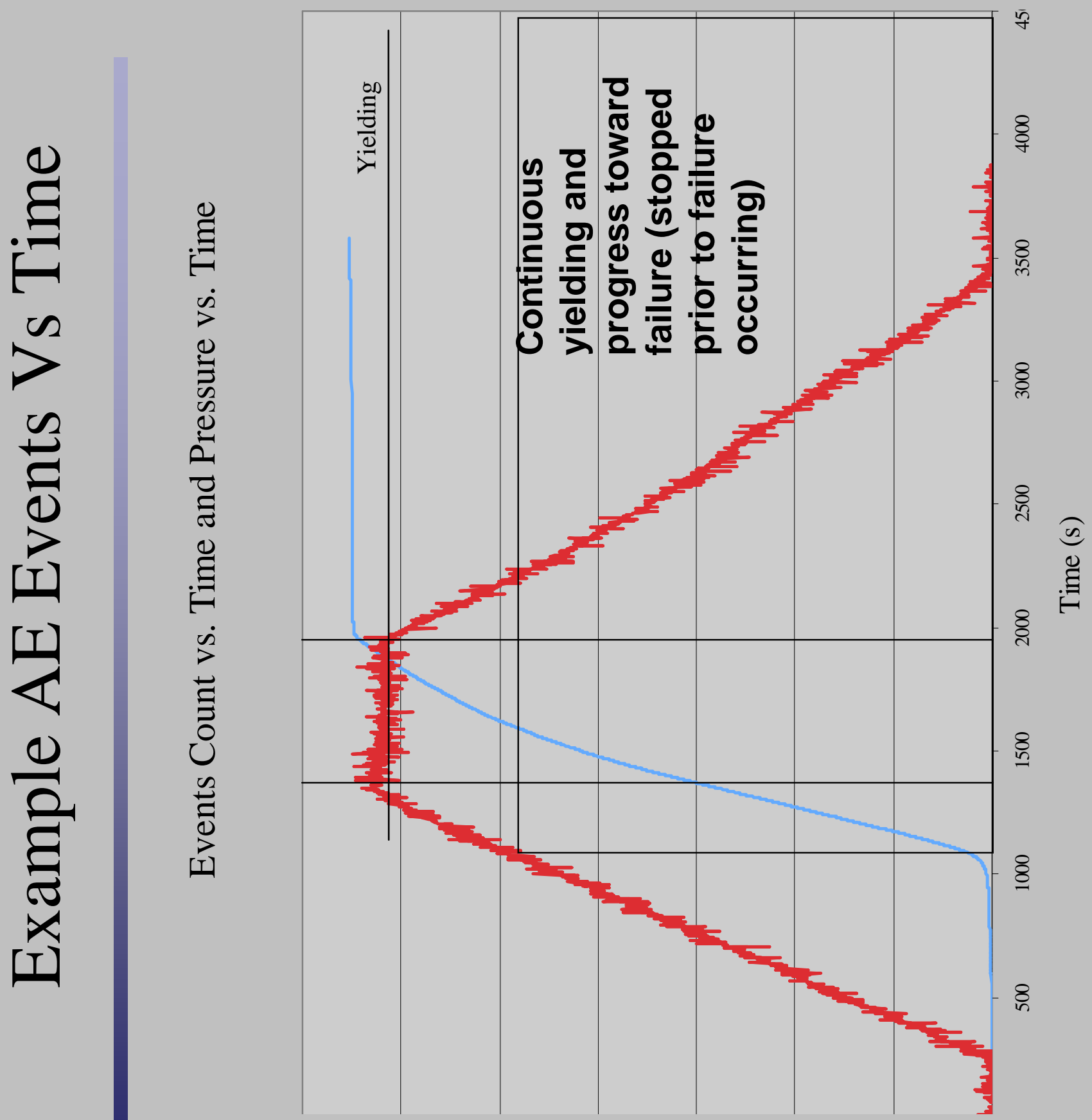


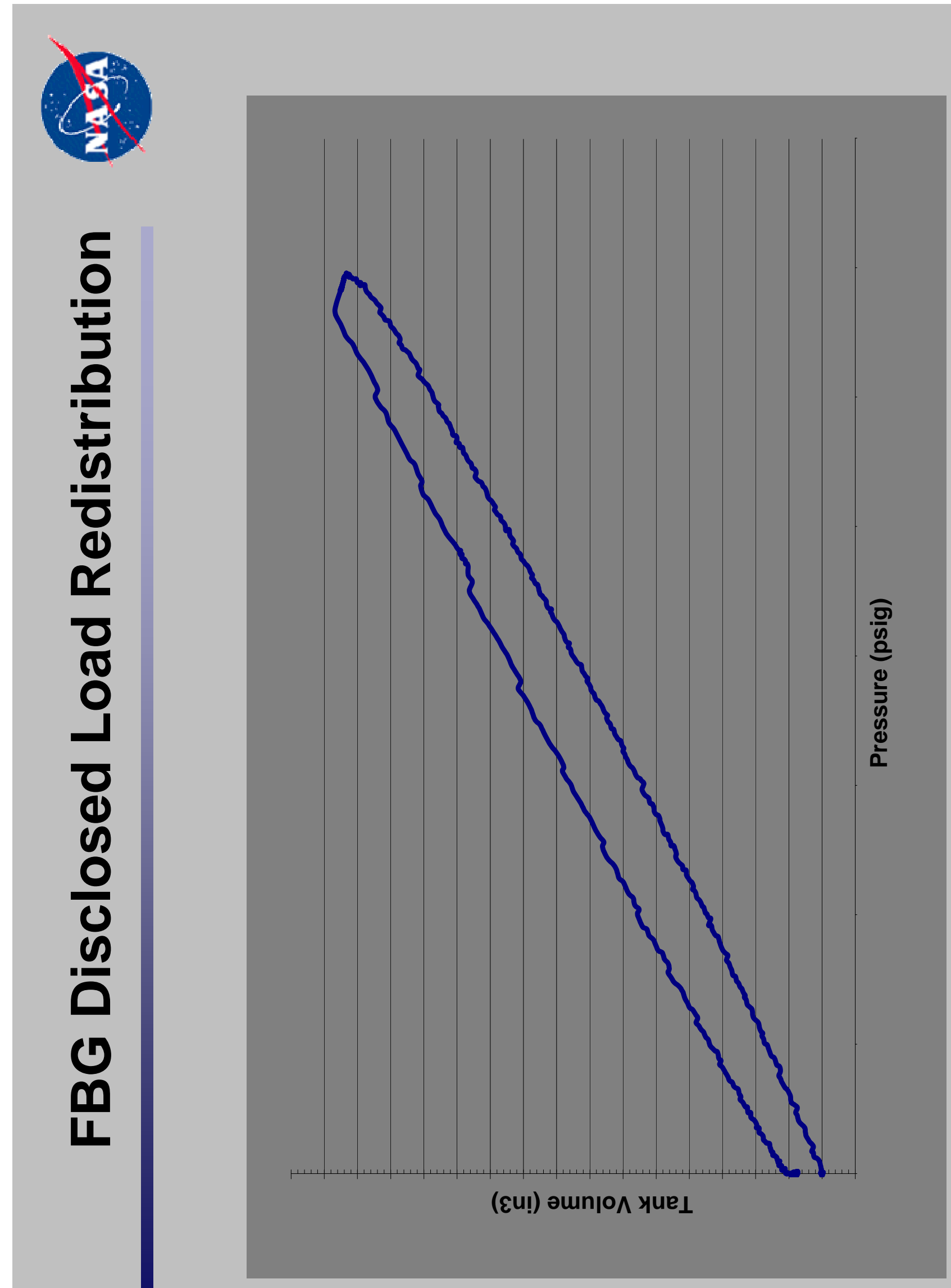



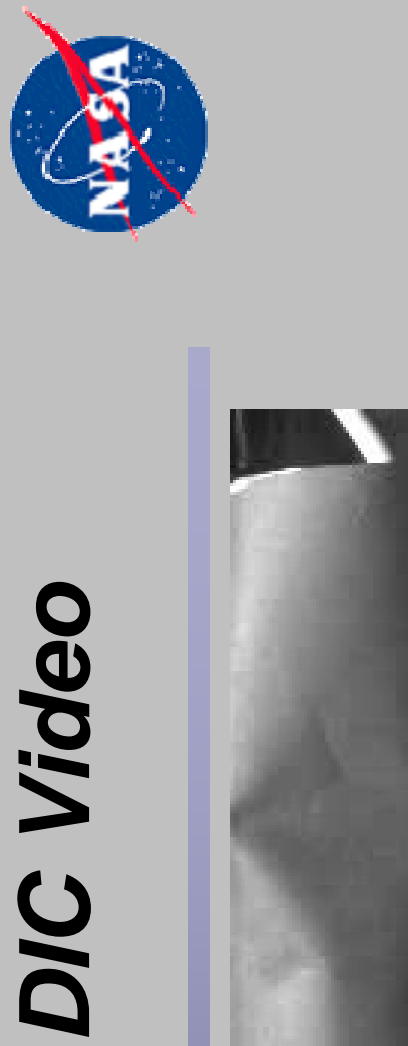

$\frac{\mathfrak{2}}{\mathfrak{2}}$

$\sum^{n}$

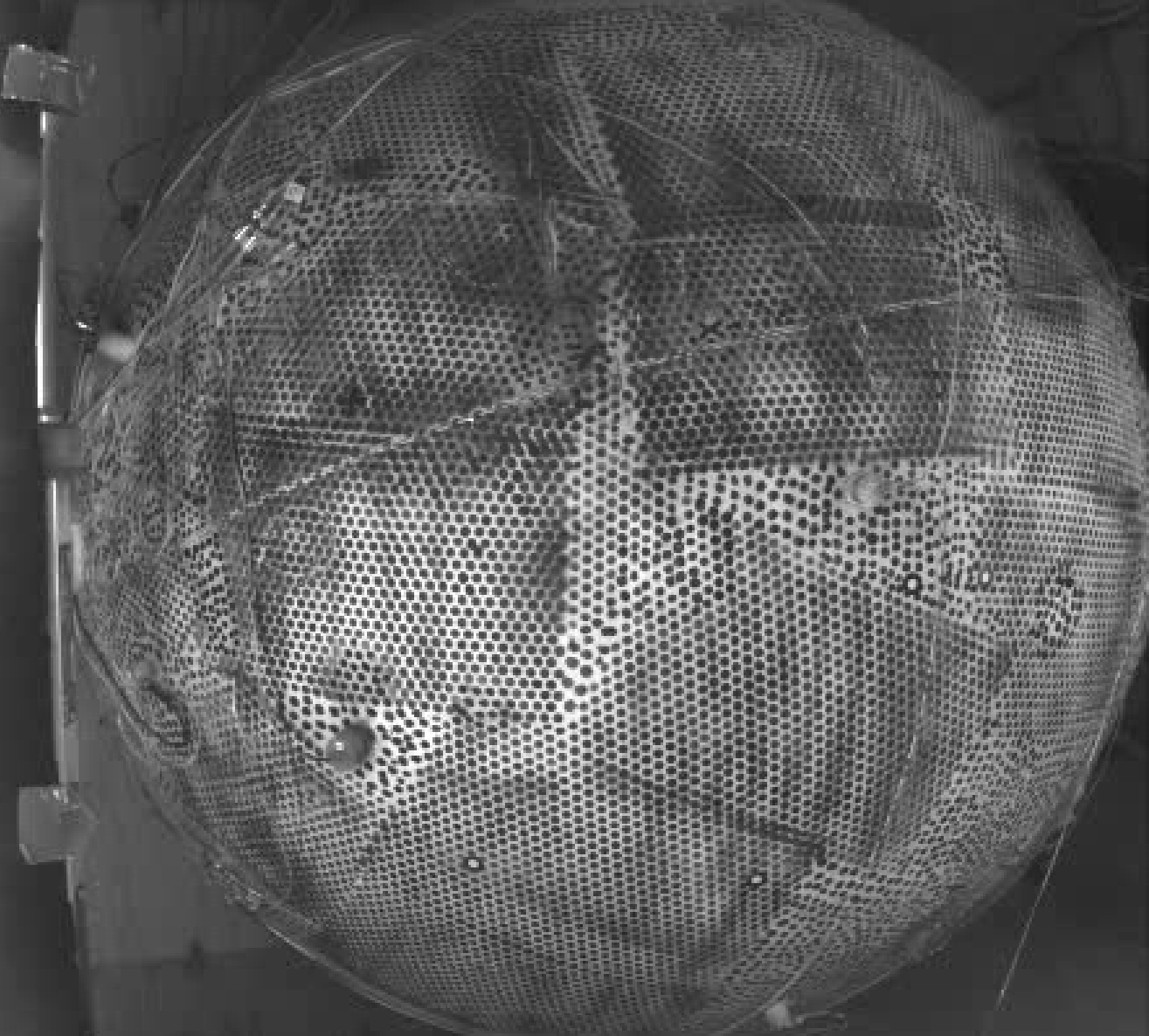



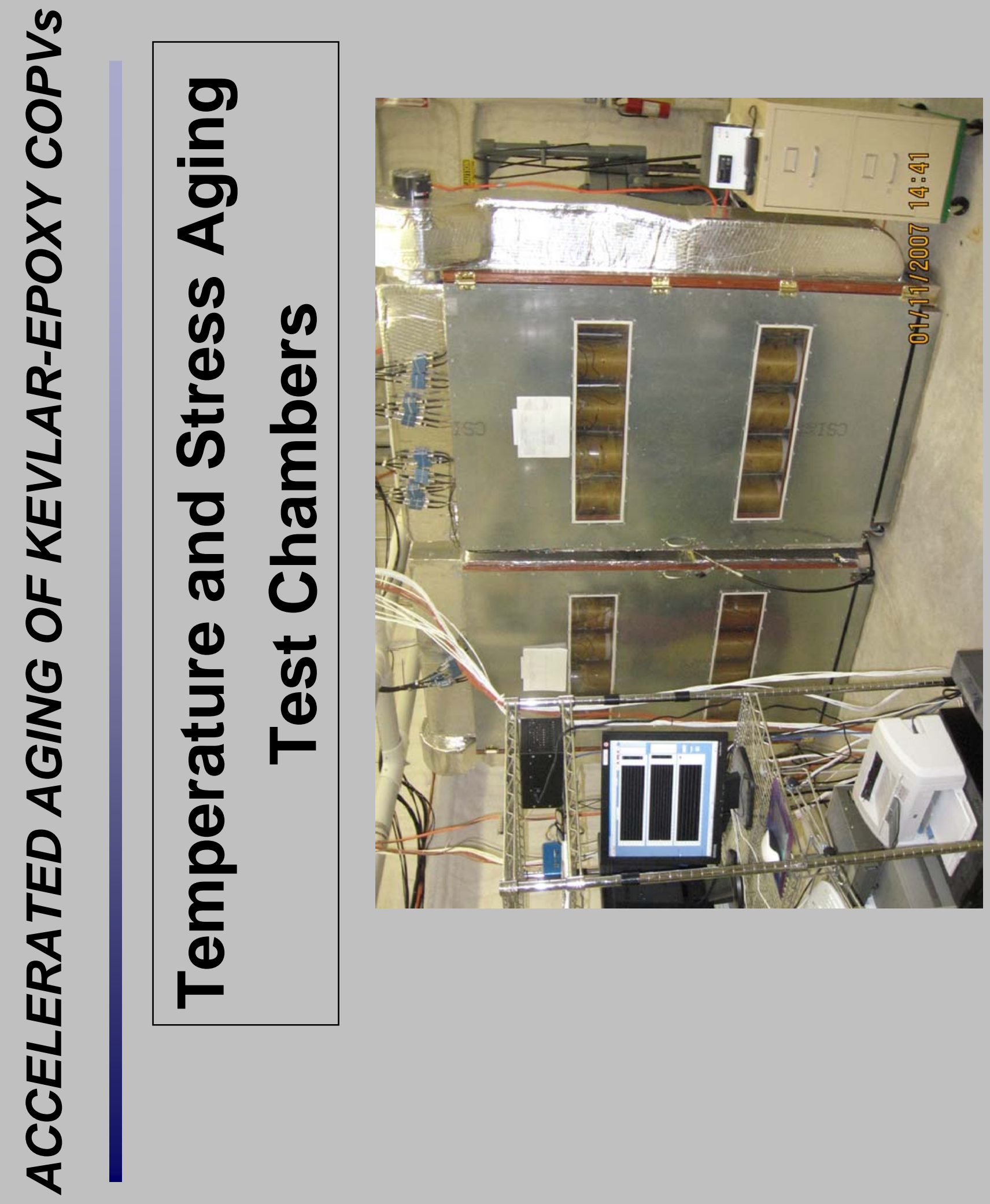


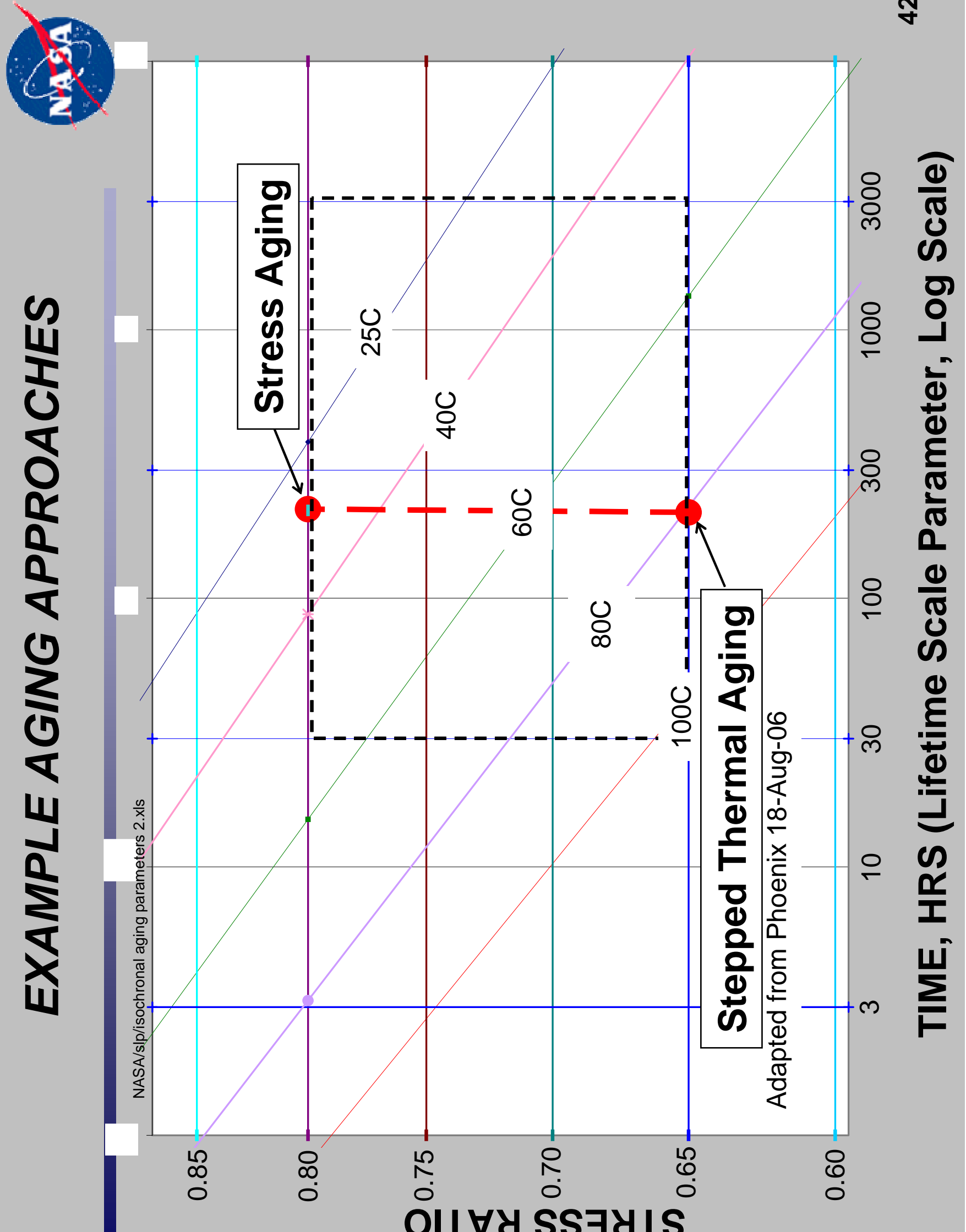


¿

ֻับ

(1)

ธุ

o

Sn

c

ఖ

잉

के क

ज

के

क

\&

(1) ะ

ร ธ

U

₹.

$\lambda$

S

ธ

(1)

도 종

일

ब

ह

สิ

d

닐

0

름ㄴㅇ

(1)

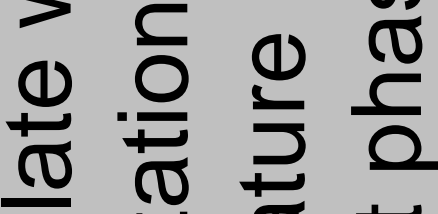

$\bar{\Xi}$ 을

ह 둬 ब

을 읃

U ट ह थ

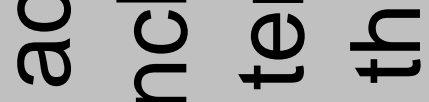

이 के 으

으

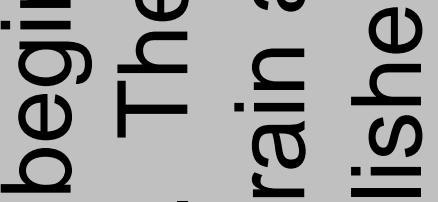

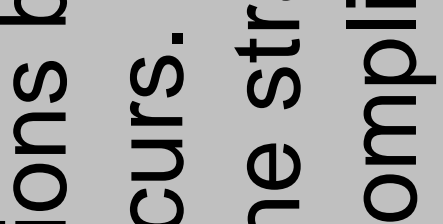

శ

তु 0 ○

으 (1)

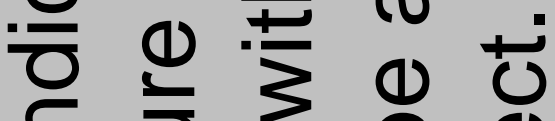

.$\equiv$ శ。

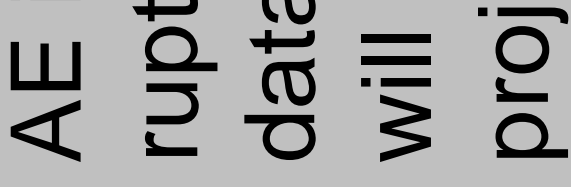




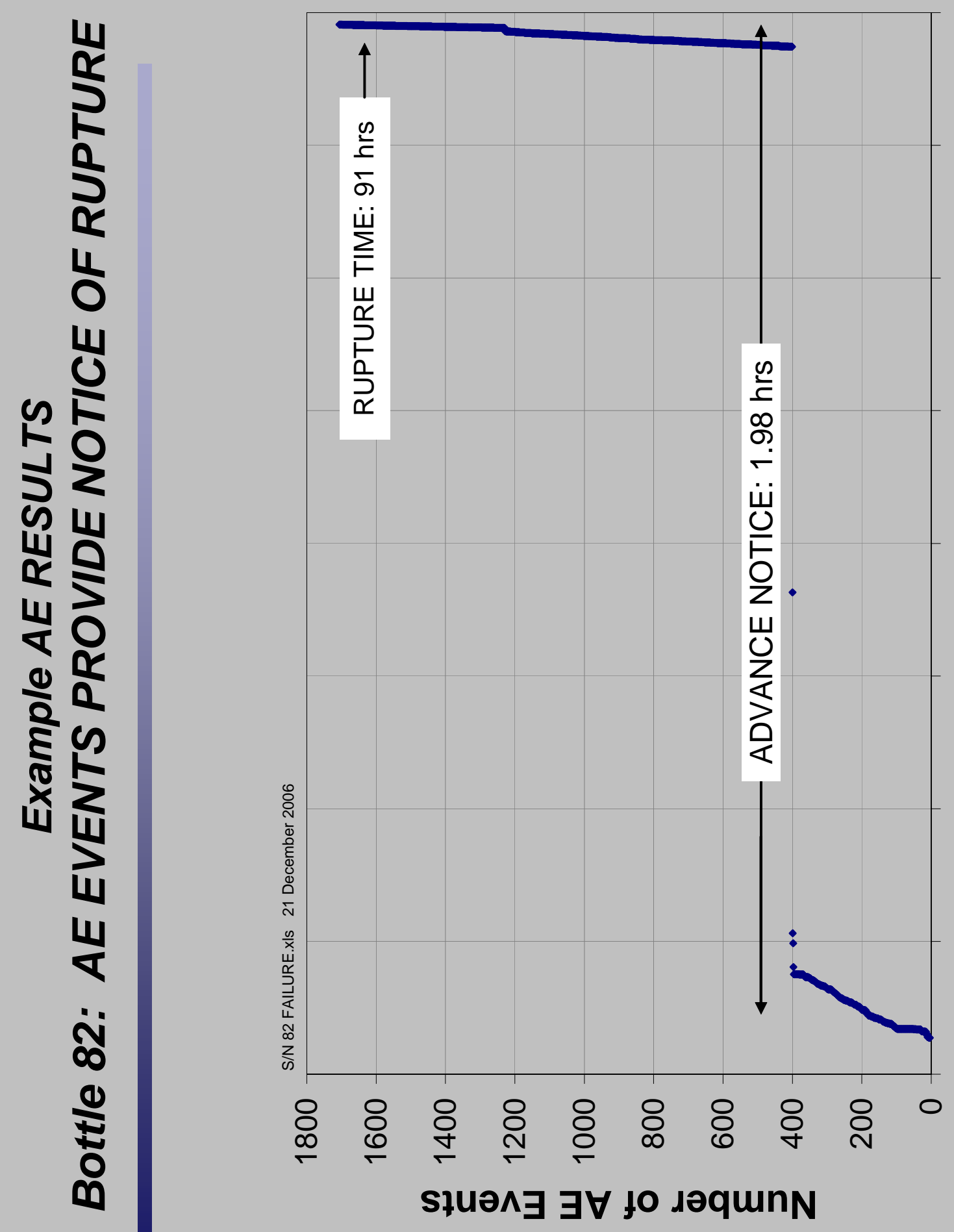




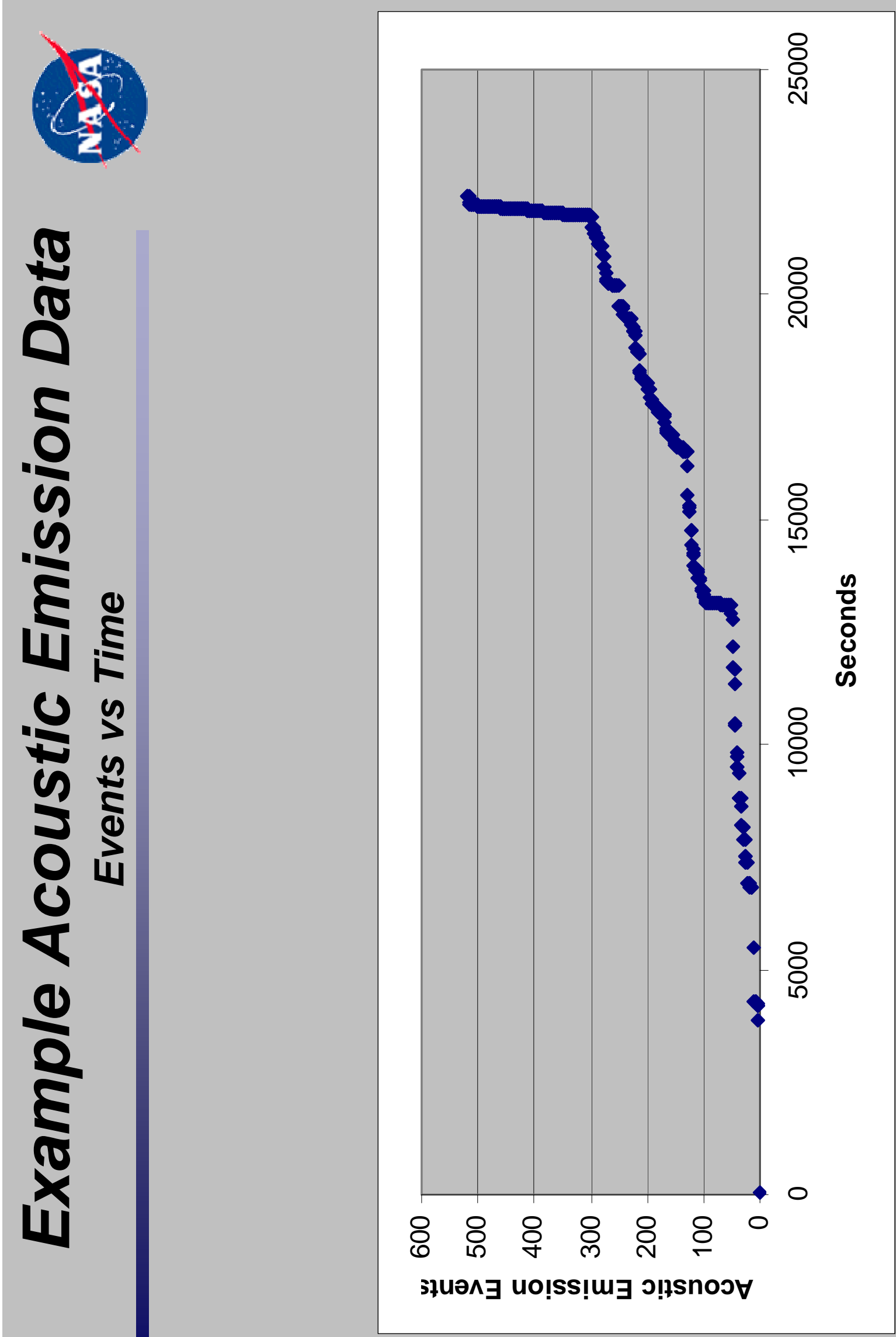


$\frac{1}{\frac{\pi}{0}}$

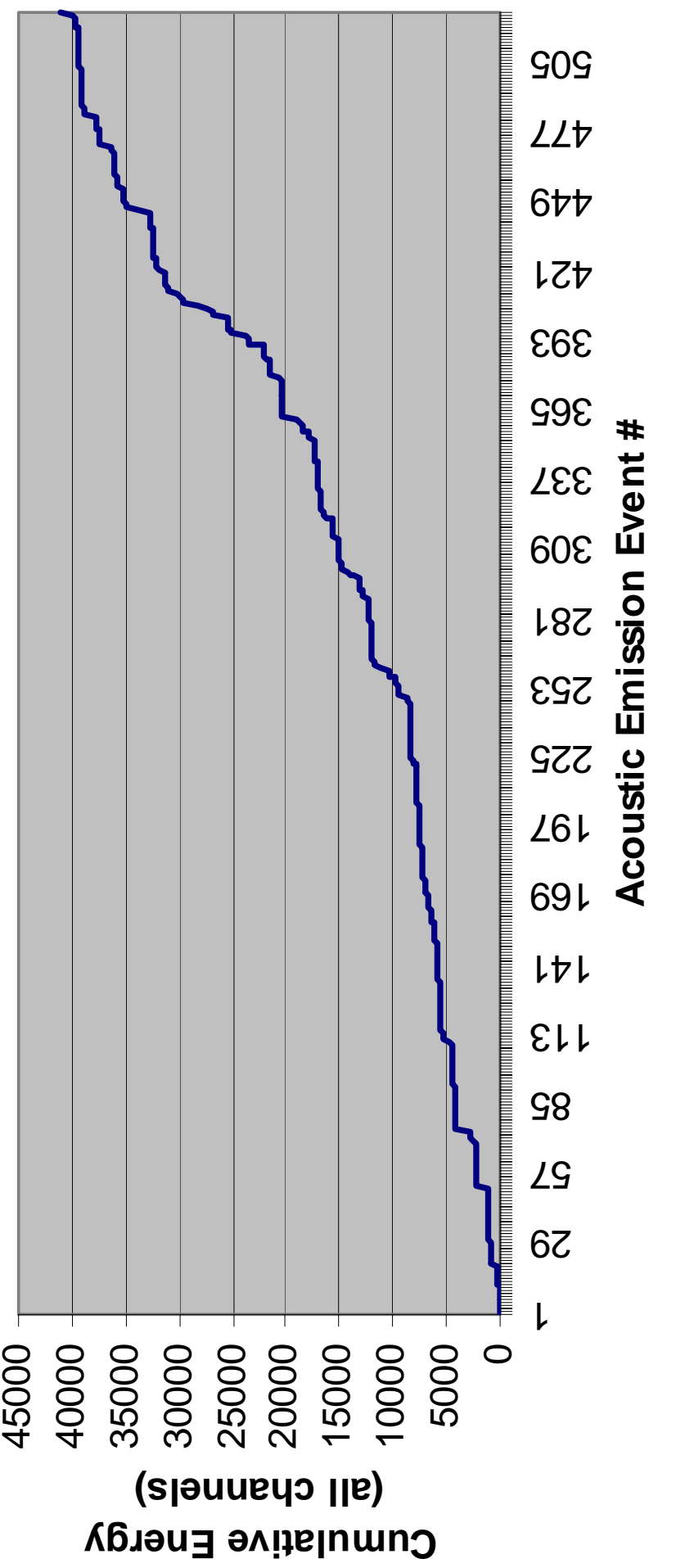




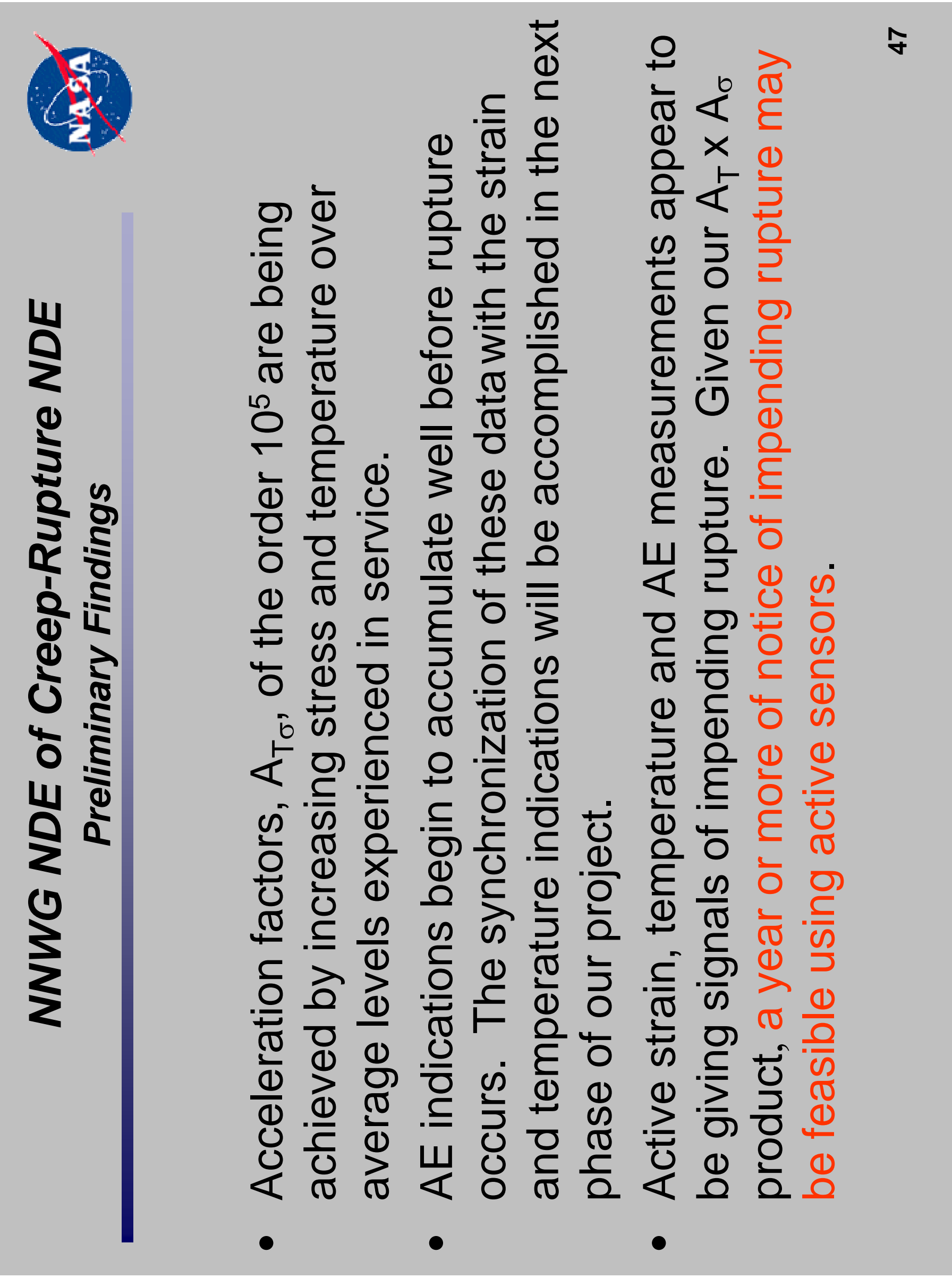




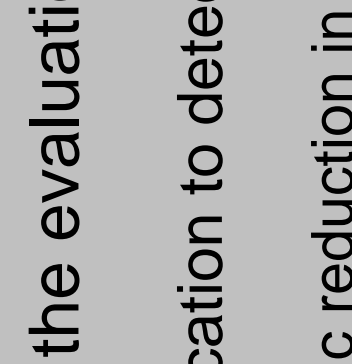

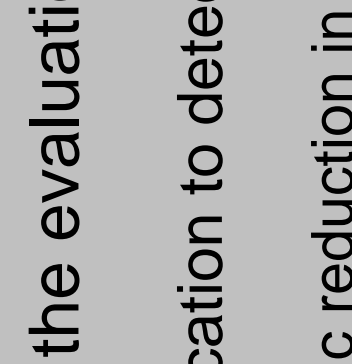

응 $\frac{.0}{\circ}$

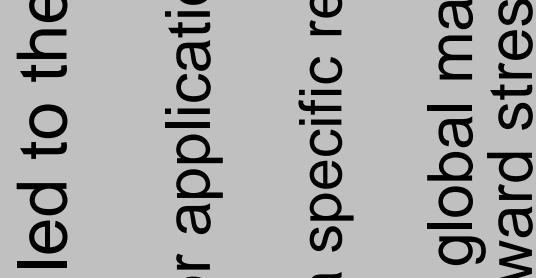

ఫे

8 용

n

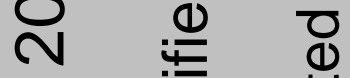

.$\equiv \quad \frac{\pi}{0} \frac{\pi}{0}$

음 $\frac{0}{2}$

$\stackrel{0}{ \pm}$

즐 $\frac{\mathrm{\sigma}}{\mathrm{c}}$

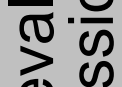

व)

¿

흐웡

(1) ब

$\div 0$ (1) ฮै

(1)

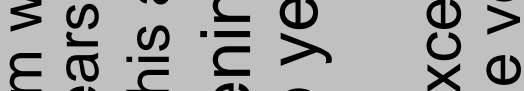

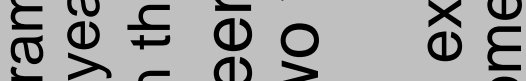

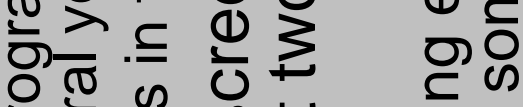

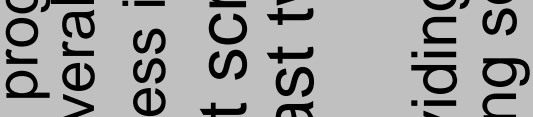

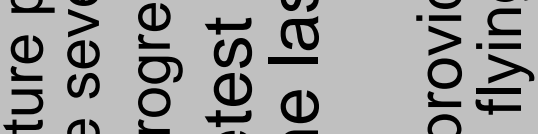
을 을 늘 을

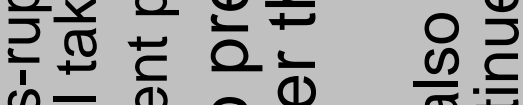

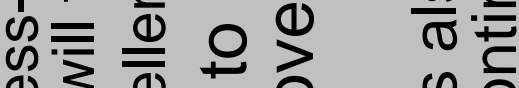

(1)

ज光

б

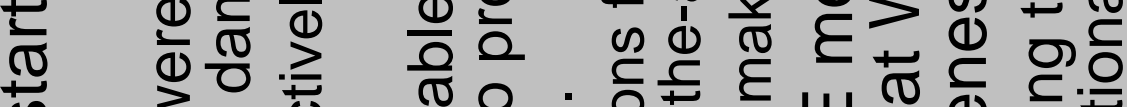

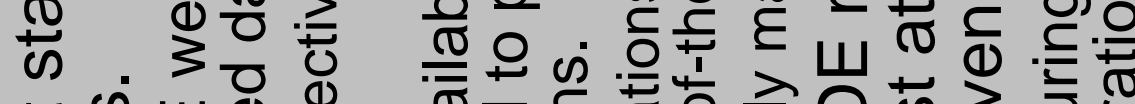
๘ (1) $Z$ Z

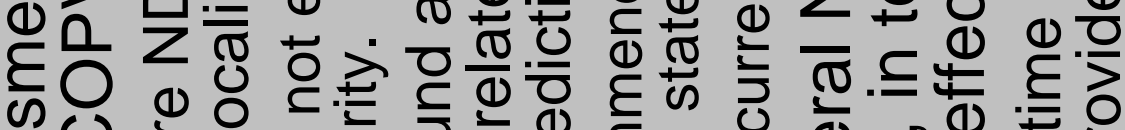
ตU

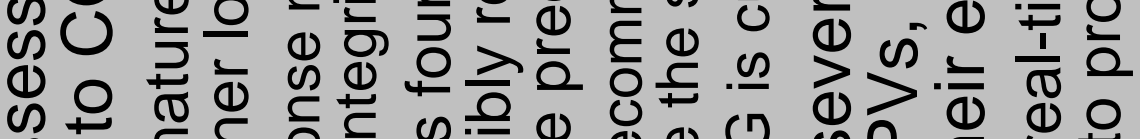

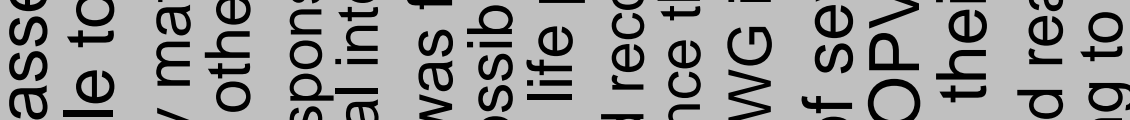

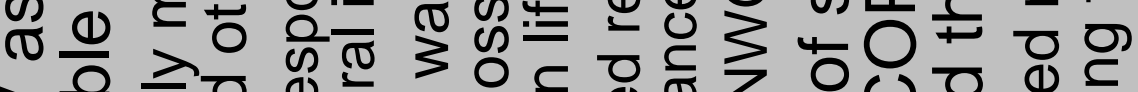

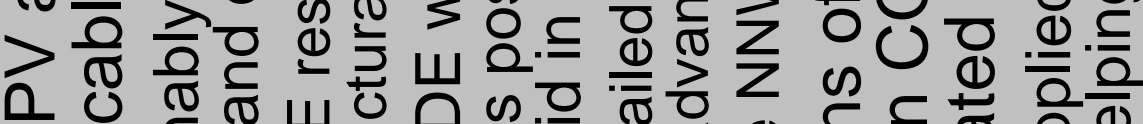

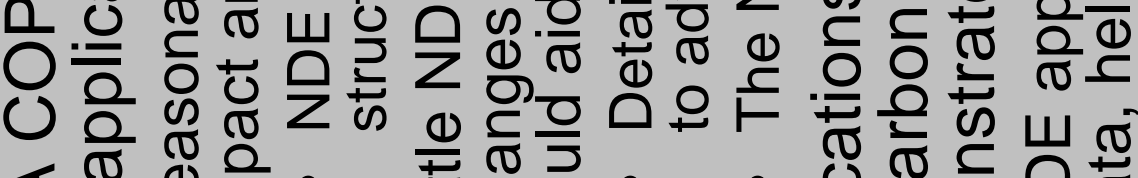

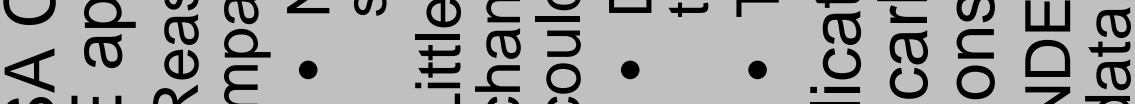

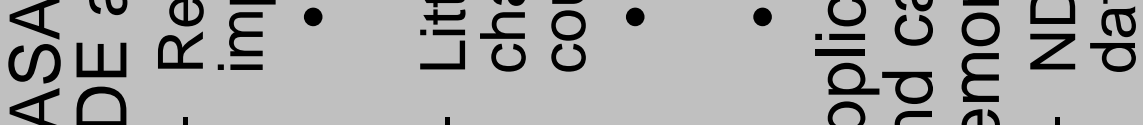
和। 这完 
(1)

ज़

(1) ह

$\stackrel{0}{0}$

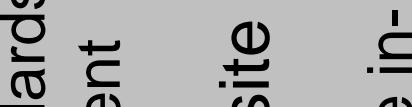

ᄃ

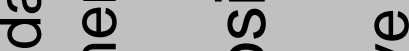

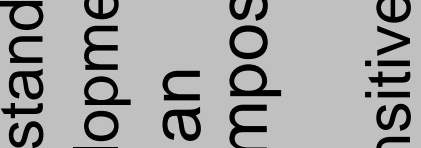

ज $\frac{0}{0}$ б。

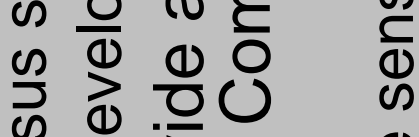

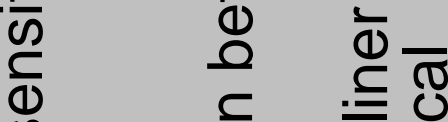

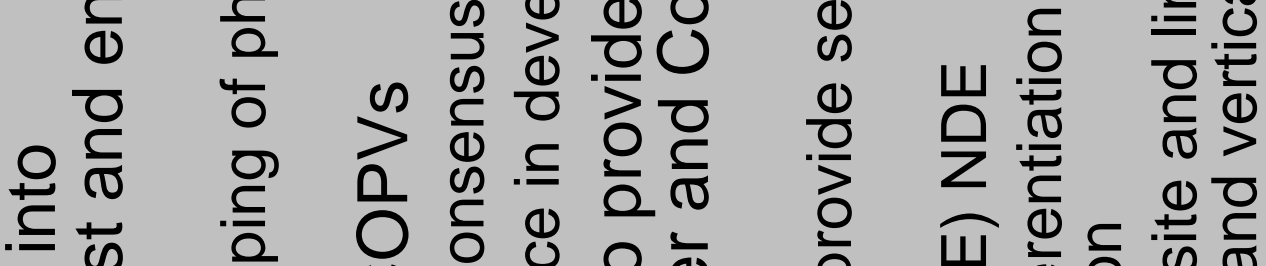

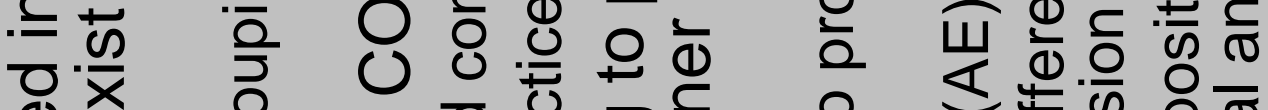

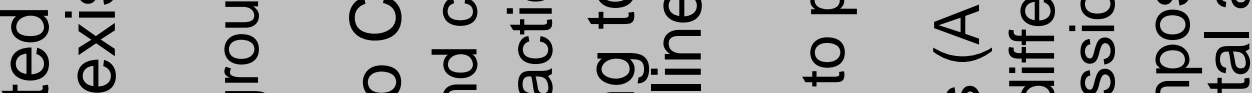

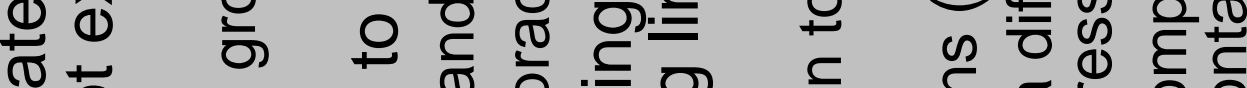

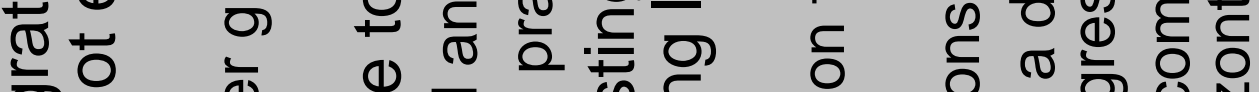

흥 ब ब

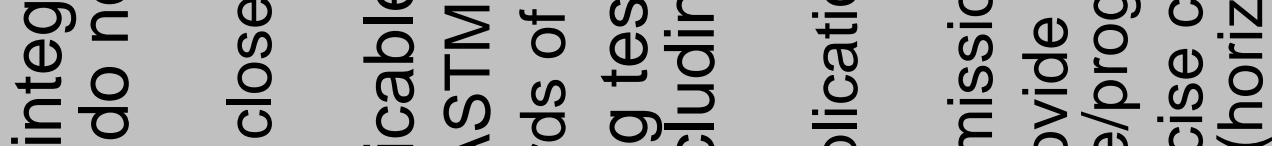

Q

()

(4) (

อุ

응

으 은 응 을

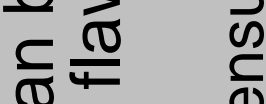

U

$+\frac{1}{\sigma}$

ชู ชู

3

트

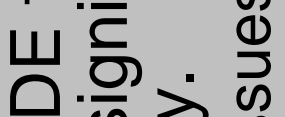

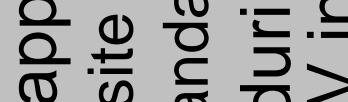

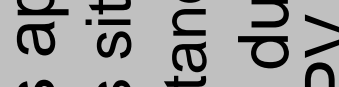

ง

ㅎํํ 윽 는

응 ฮㄷ

(1)

ซேత్ర

$\pi$

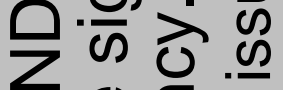

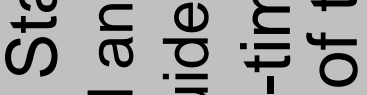

응

응 틍ํㅇ 잉

ㄱ. 는 을 은

드 흘

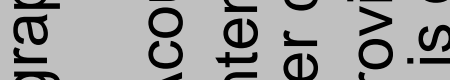

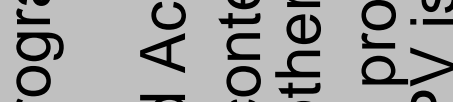

임 0 잉

ฮে ฐ

ज

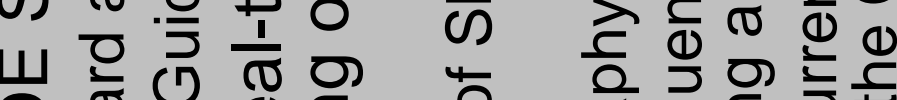

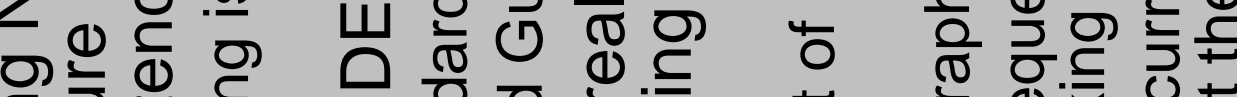

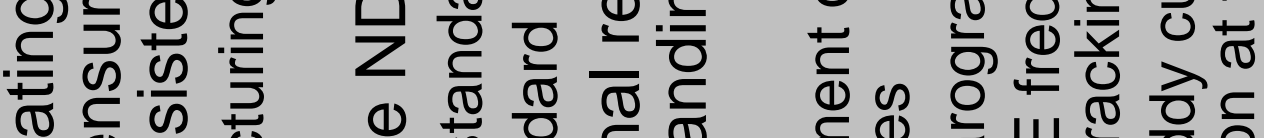

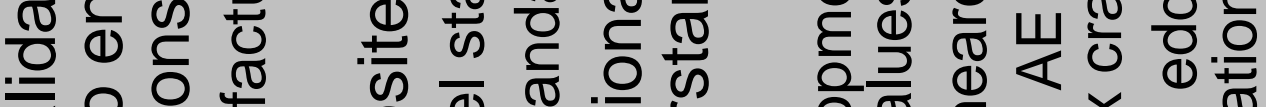

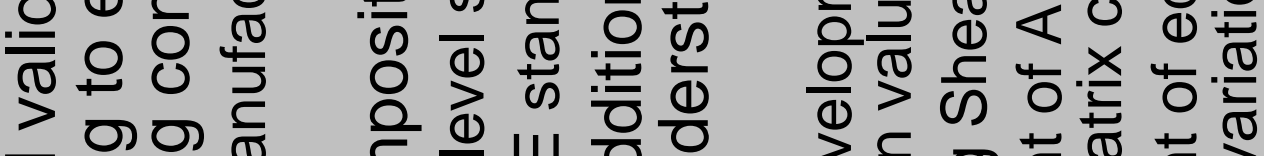

드르

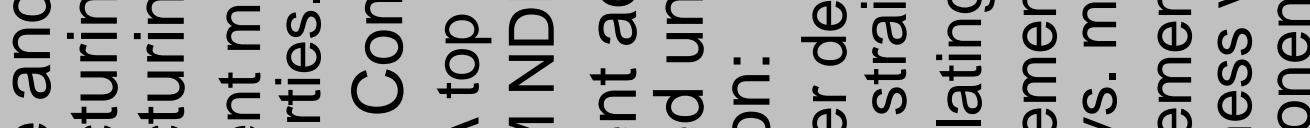

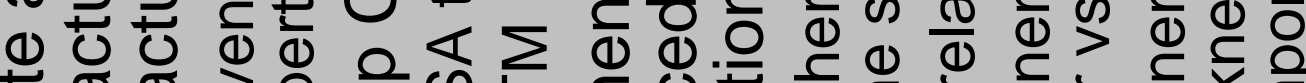

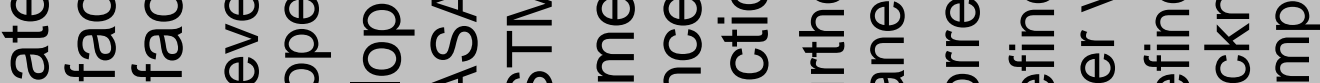

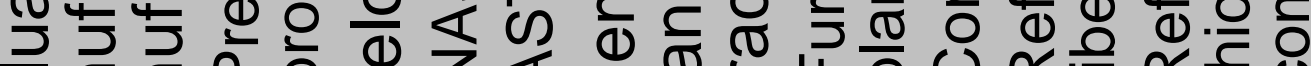

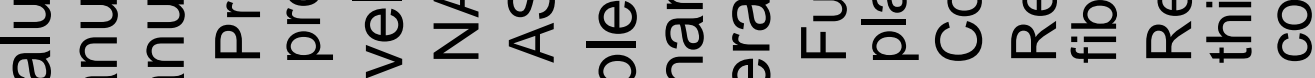

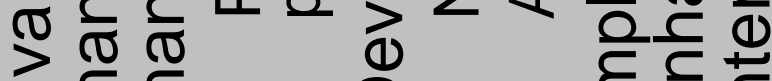

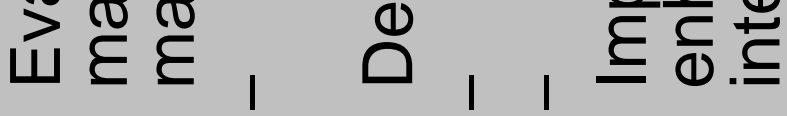


$\frac{0}{\frac{\sigma}{U}}$

으

강

U

శర

๓ 


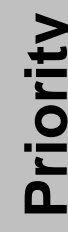

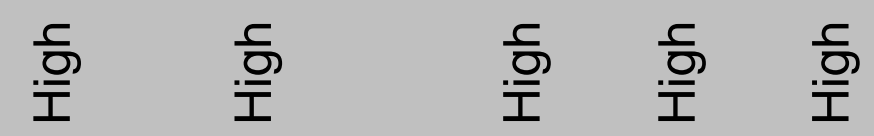

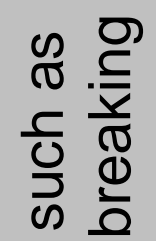

윻

山

으 흐

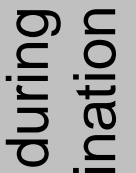

힣ำ

(s)

जु

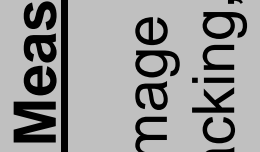

只

ह 흠

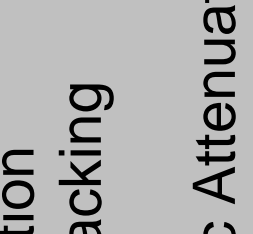

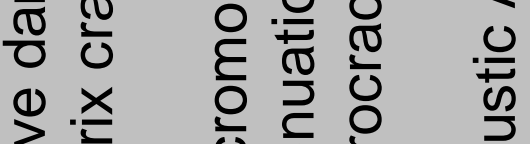

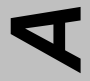

त्ञ

당

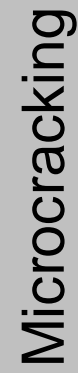

창

。

竞竞

의

눈

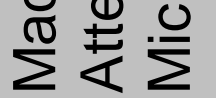

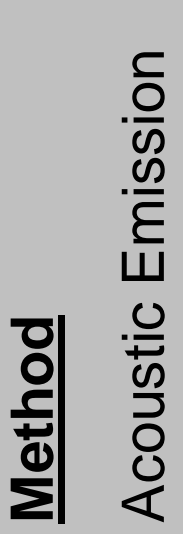

(1)

$\frac{\omega}{2}$

믐ำ

으 음

。

0

d

등 은

U

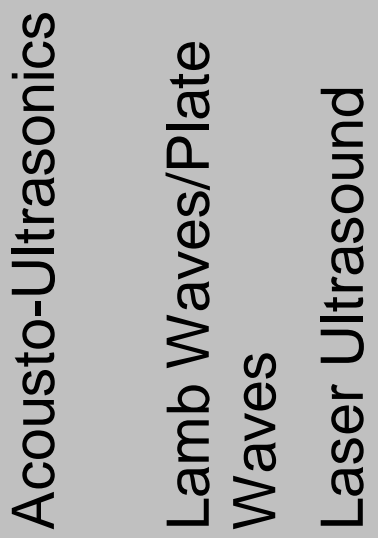




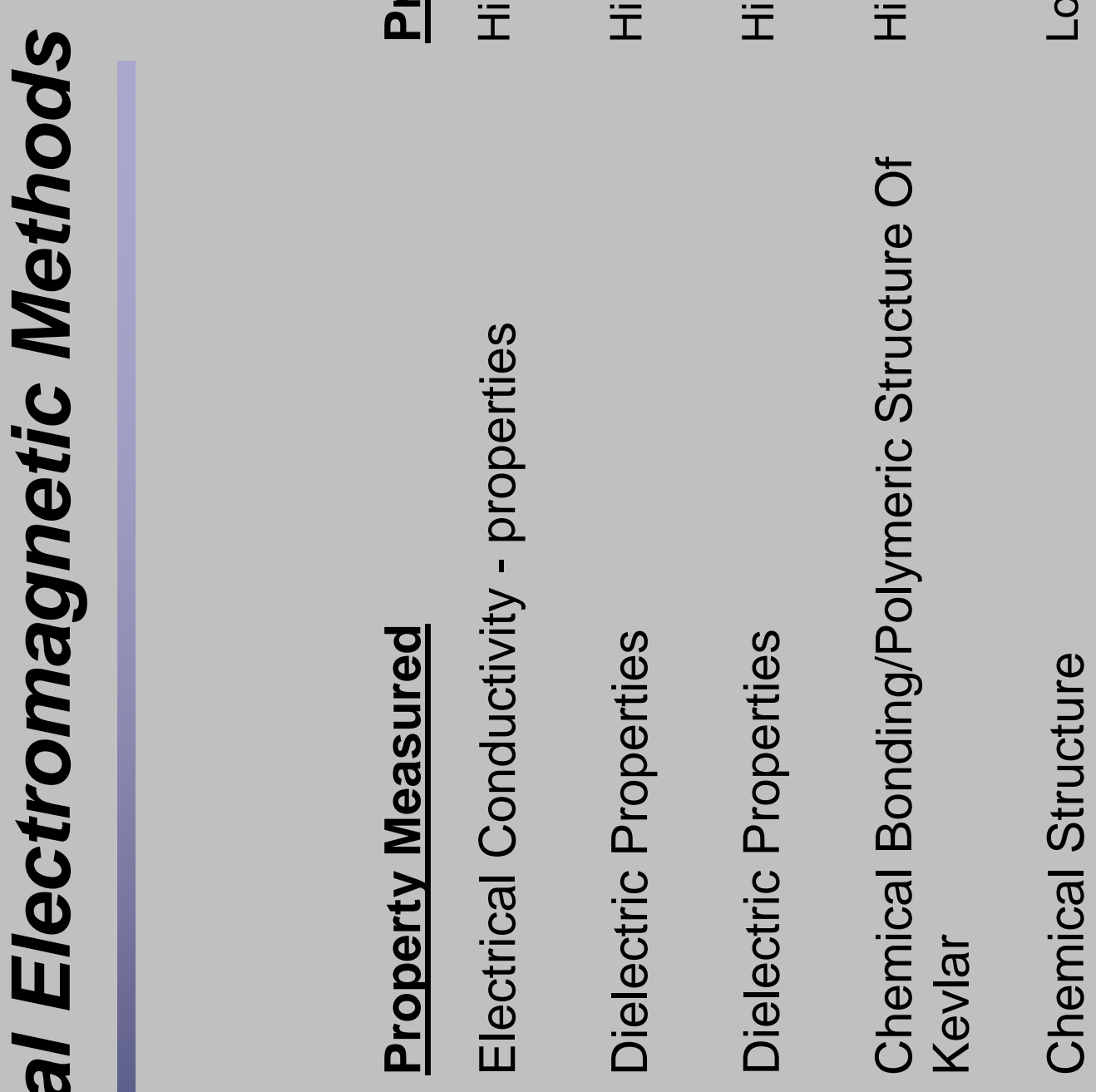

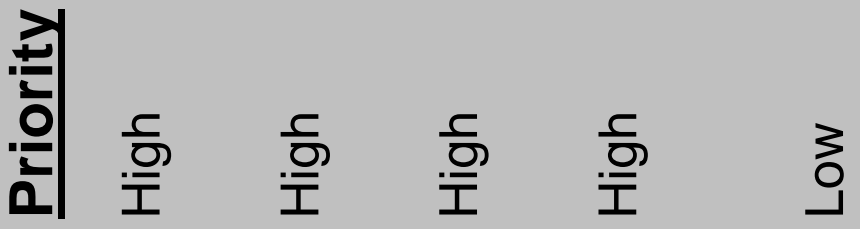




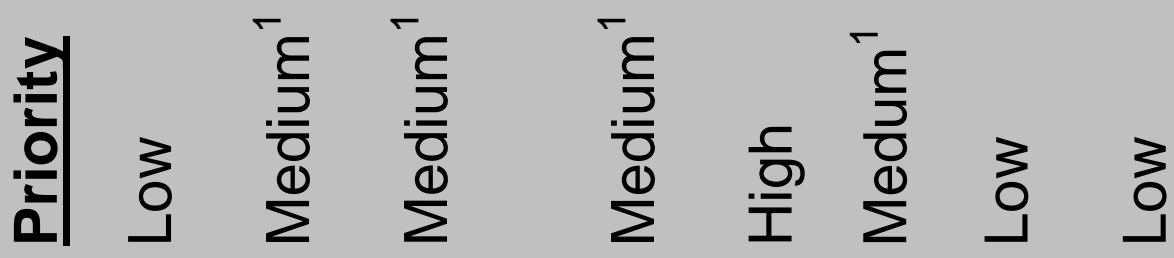

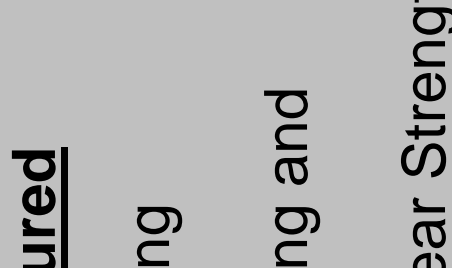

⿹气़े

đั ठ ठ 仓

$\sum_{\square}^{\infty} \bigcirc \bar{c}$

규 তర $\overline{0}$

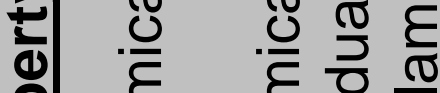

잉 ब $\frac{0}{0}$

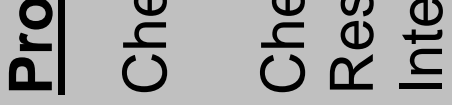

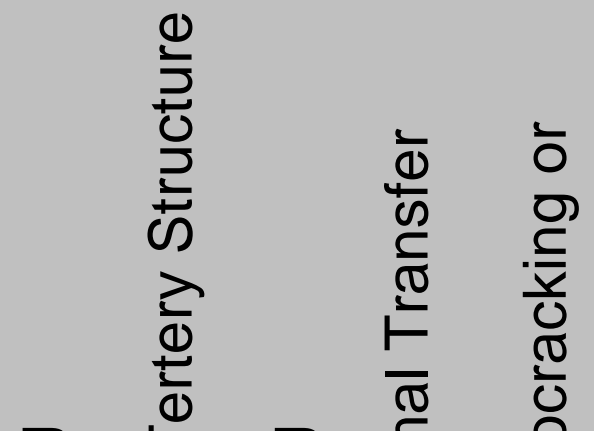

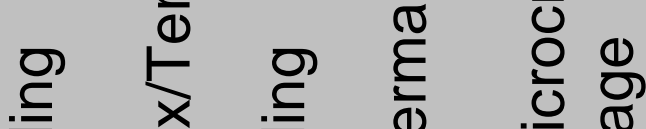

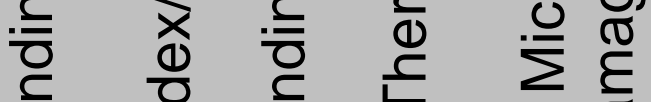

ठ 하

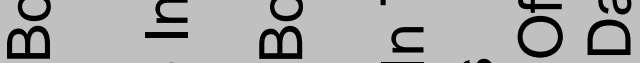

$\bar{D} \quad \overline{0}$

ర)

O는 근

㐫

六

들

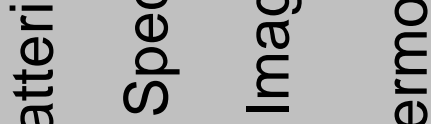

议 


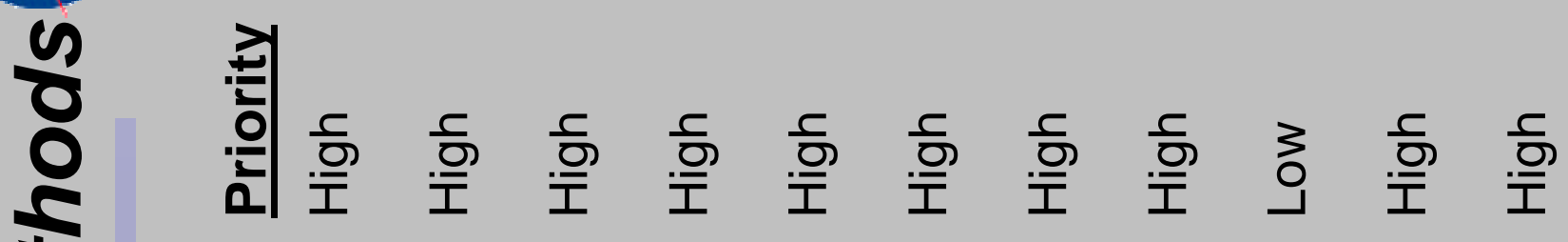

()

$\sum$

엄

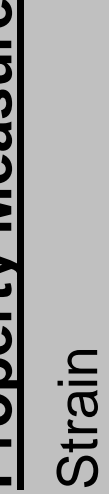

ต

(ช

(1)

(1)

$$
\begin{aligned}
& \text { 은 } \\
& \text { 苛 }
\end{aligned}
$$

$\frac{5}{\pi}$

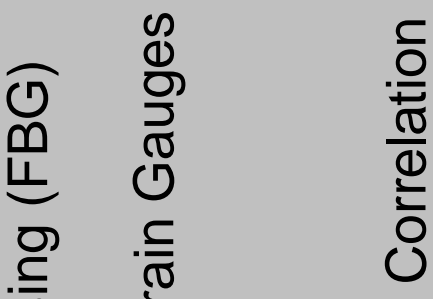

$\widetilde{T}$

$\pi$

$\underset{2}{2}$

8

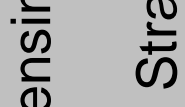

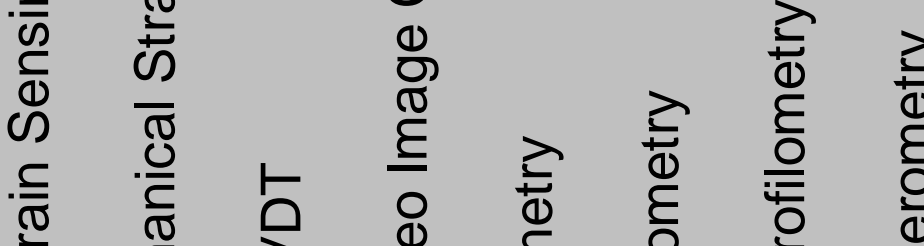

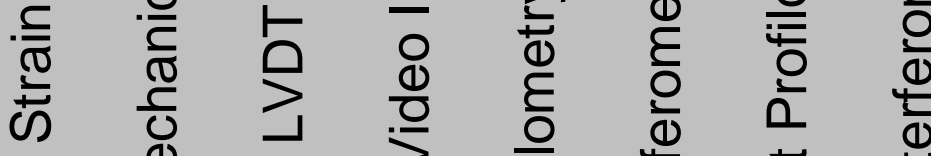

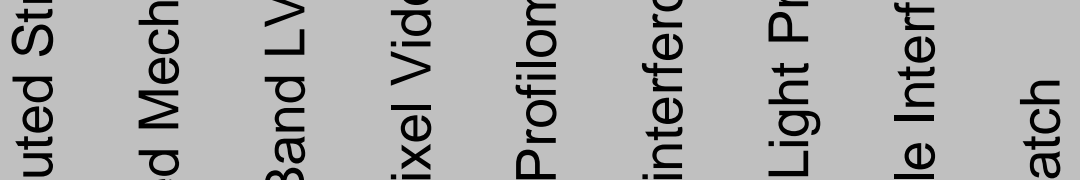

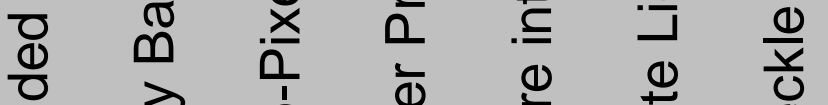

$\frac{\pi}{2} \frac{\pi}{0}$ $\sum$ 


\section{山}

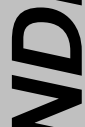

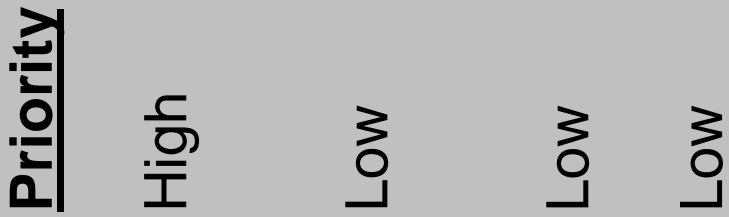

$\frac{\pi}{2}$

岕

-

히뉴

ㅇ)

$\leqslant n$

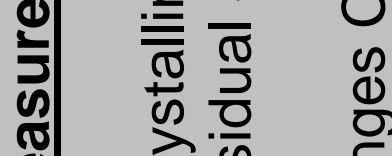

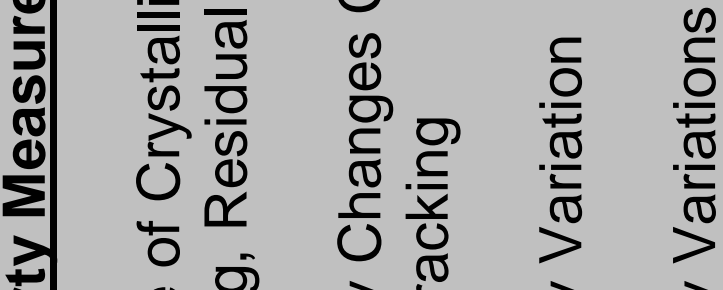

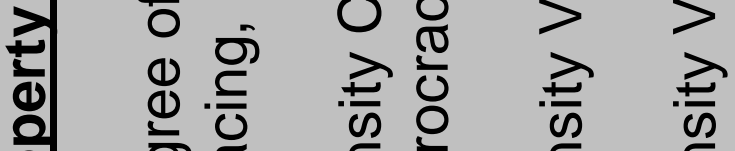

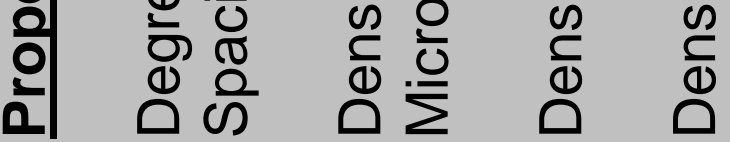

a

$\frac{\pi}{2}$

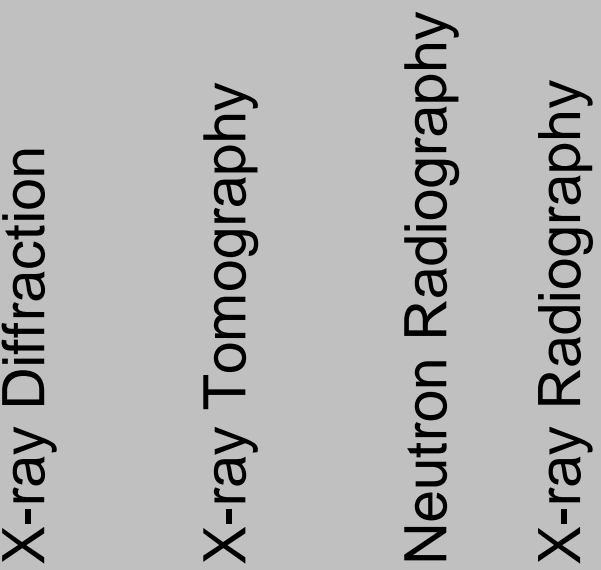


$\frac{0}{8}$

은 은 $\frac{1}{\square}$

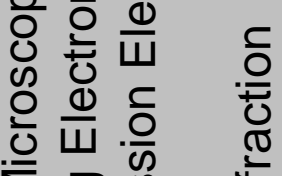

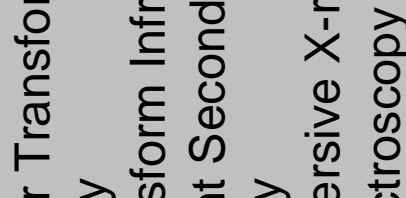

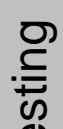

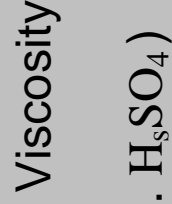

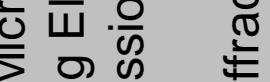

के

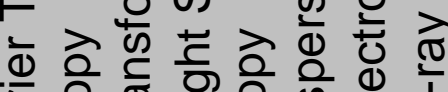

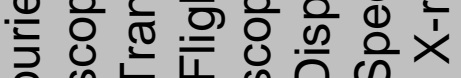

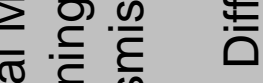

ठํํ유

ठ

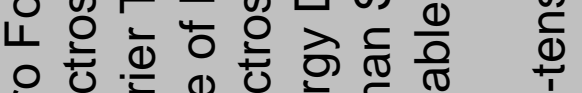

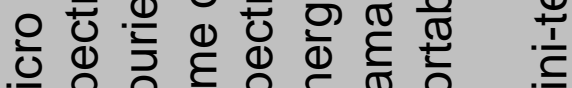

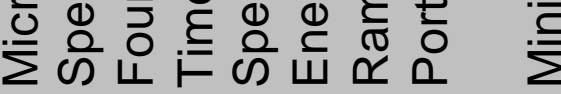

สั

$\frac{1}{c}$

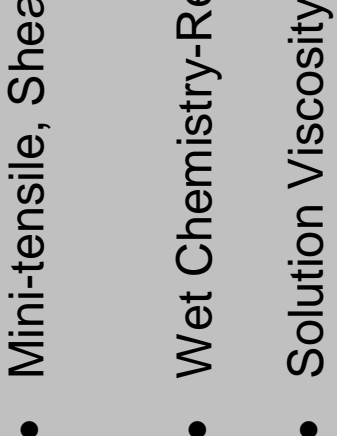

0

(1)

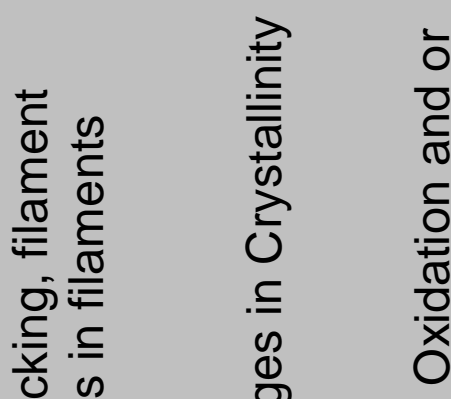

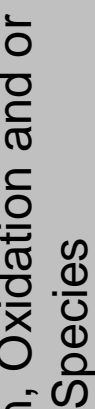

ฮ

윰

0

$>$ 무

0

过

突

ज 읃

ข

प्ठ

ชᄄ

亡ั ప

니 윰

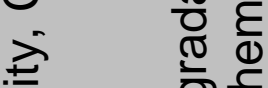

ठ্ঠ

离

믐

ส

Z

थ

응 응

(1)

$\subseteq \tau$

ज)

(1)

닐

㐫

品

吾 O

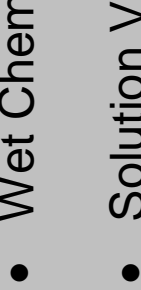

$+\sum^{\frac{1}{4}}$

응흐 흐 흔

늘 ग

त ह

U స

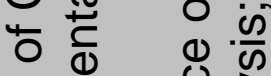

을 은 흐 을

ญ

ฮั

훙으 응 홍

ป ত্য $\frac{0}{0}$

ดั 它

这旁 

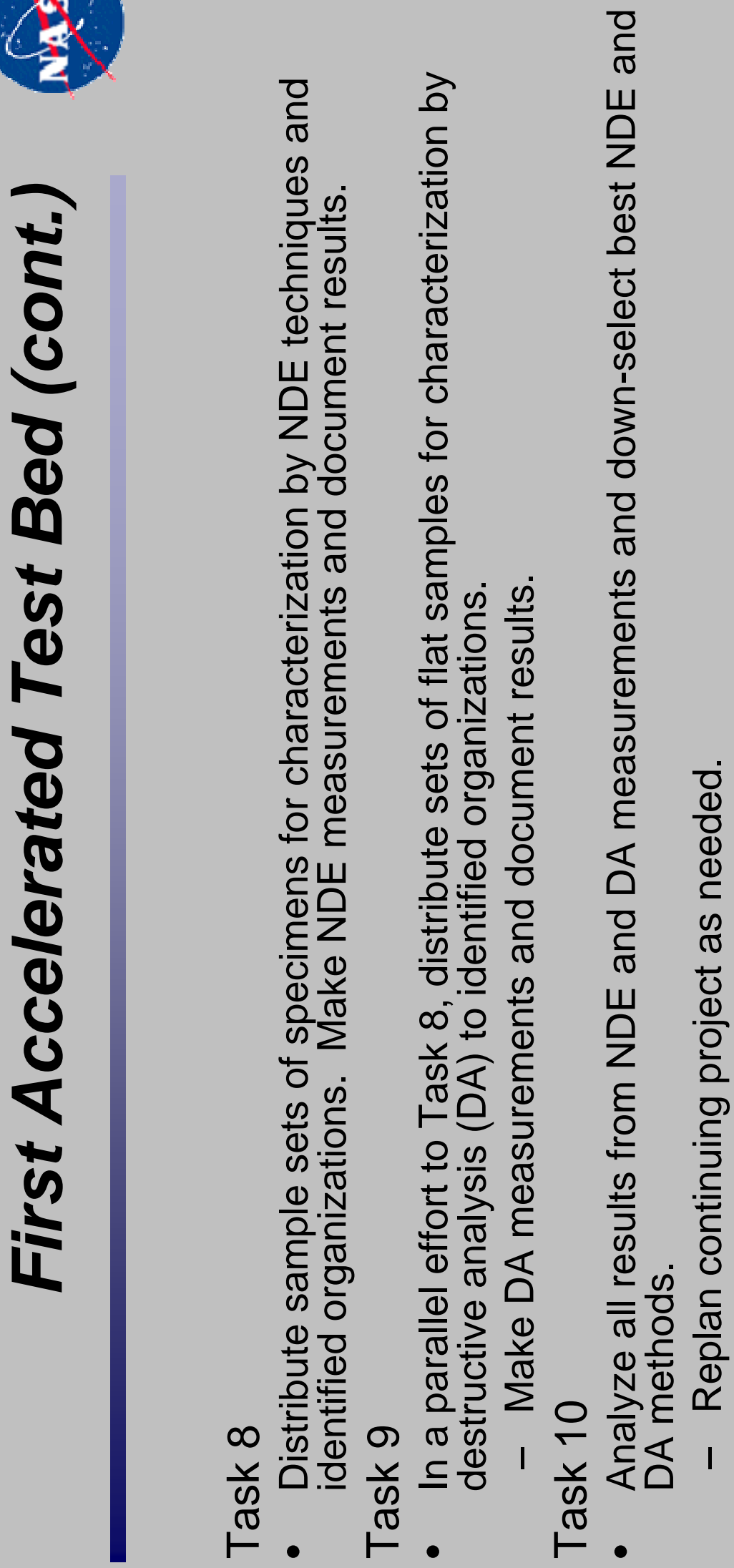


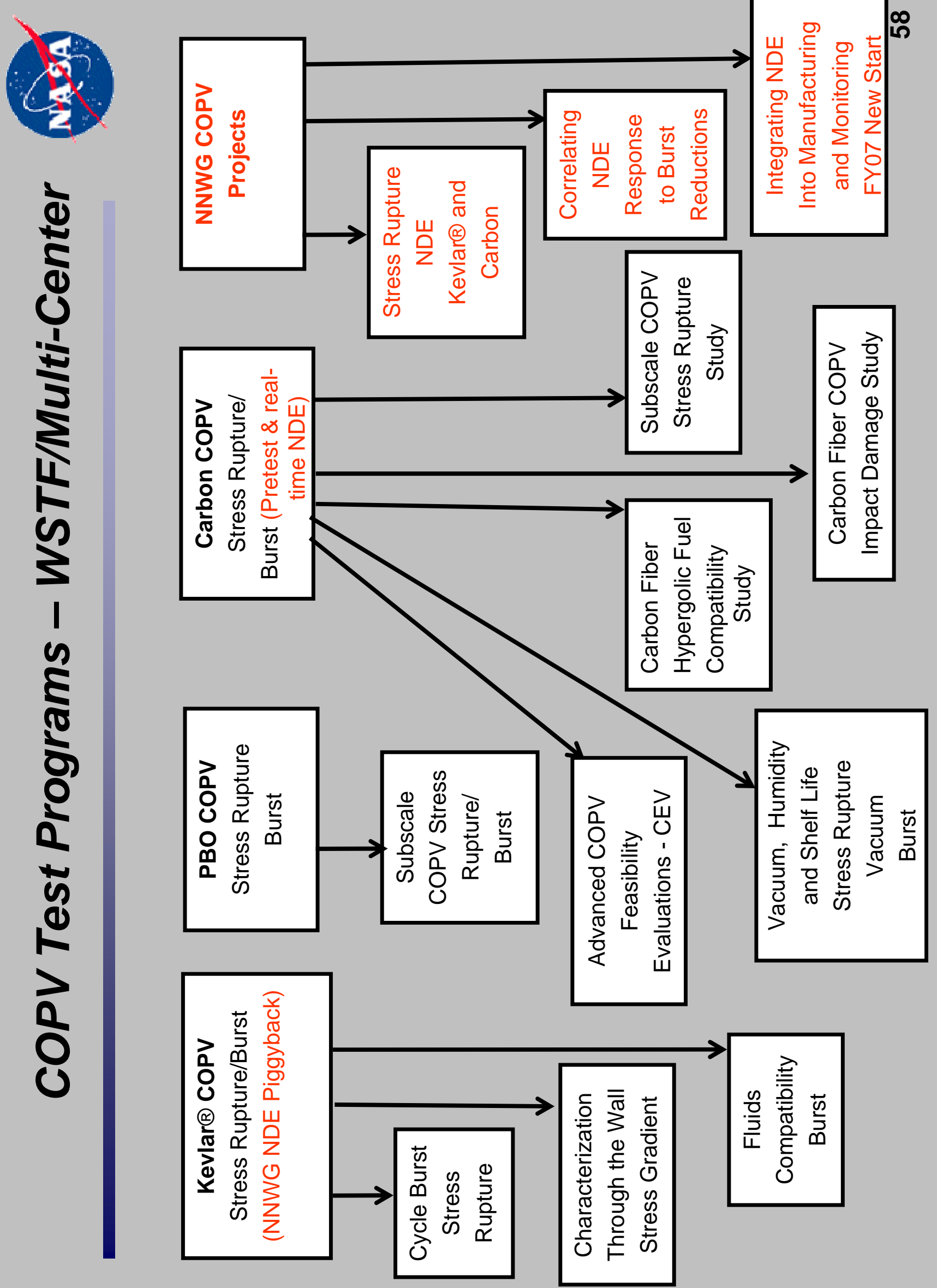

